2015

\title{
APPLICATION OF A HAZARD RATING SYSTEM FOR ROCK SLOPES ALONG A TRANSPORTATION CORRIDOR USING REMOTE SENSING
}

Samantha M. Justice

Michigan Technological University

Follow this and additional works at: https://digitalcommons.mtu.edu/etds

Part of the Geology Commons

Copyright 2015 Samantha M. Justice

Recommended Citation

Justice, Samantha M., "APPLICATION OF A HAZARD RATING SYSTEM FOR ROCK SLOPES ALONG A TRANSPORTATION CORRIDOR USING REMOTE SENSING", Master's report, Michigan Technological University, 2015.

https://doi.org/10.37099/mtu.dc.etds/979

Follow this and additional works at: https://digitalcommons.mtu.edu/etds

Part of the Geology Commons 
APPLICATION OF A HAZARD RATING SYSTEM FOR ROCK SLOPES ALONG A TRANSPORTATION CORRIDOR USING REMOTE SENSING

By

Samantha M Justice

\begin{abstract}
A REPORT
Submitted in partial fulfillment of the requirements for a degree of MASTER OF SCIENCE

In Geological Engineering
\end{abstract}

MICHIGAN TECHNOLOGICAL UNIVERSITY

2015

(C) 2015 Samantha M Justice 

This report has been approved in partial fulfillment of the requirements for the Degree of MASTER OF SCIENCE in Geological Engineering.

Department of Geological and Mining Engineering and Sciences

$\begin{array}{cc}\text { Report Co-Advisor: } & \text { Thomas Oommen } \\ \text { Report Co-Advisor: } & \text { Stanley Vitton } \\ \text { Committee Member: } & \text { Rüdiger Escobar Wolf } \\ \text { Committee Member: } & \text { Alessandro Tibaldi }\end{array}$

Department Chair: John S Gierke 



\section{Table of Contents}

List of Figures ....................................................................................................................... vii

List of Tables............................................................................................................ ix

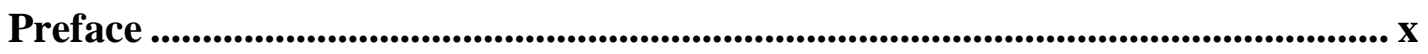

List of Abbreviations ........................................................................................

Acknowledgements .................................................................................................................. xii

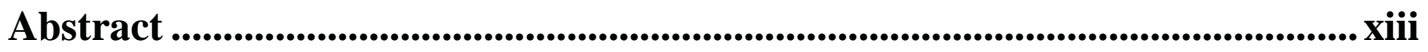

1 Introduction .......................................................................................................... 1

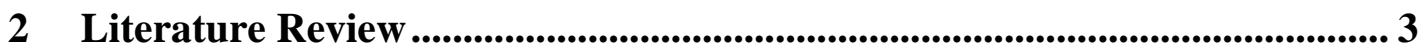

2.1 Geotechnical Asset Management .............................................................. 3

$2.2 \quad$ Hazard Rating System............................................................................... 5

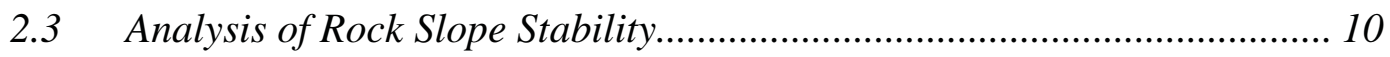

2.3.1 Rock Slope Properties ...................................................................... 10

2.3.2 Remote Sensing................................................................................... 15

3 Study Site - Southern Nevada rock slope............................................................ 20

3.1 Location ............................................................................................ 20

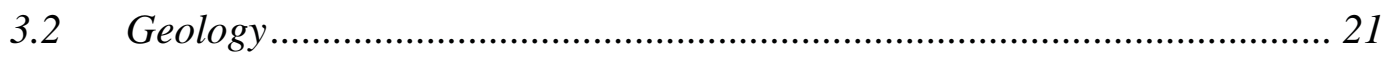

3.3 Rock Structure......................................................................................... 24

3.4 Slope Excavation Effects..................................................................... 28

4 Methodology Applied to the Transportation Corridor..................................... 29

$4.1 \quad$ Initial Conditions Assessment................................................................. 29

4.2 Assessment of Rock Slope Hazard ............................................................ 32

4.3 Application of SMR to the Transportation Corridor ................................... 36

$4.4 \quad$ Remote Sensing Analysis .......................................................................... 37 
5 Application to a Transportation Corridor ....................................................40

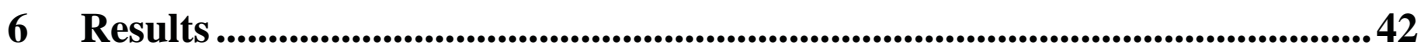

6.1 Assessment of Initial Conditions ................................................................ 43

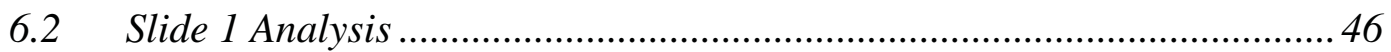

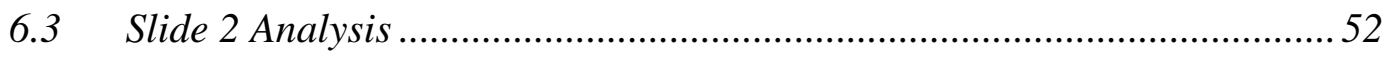

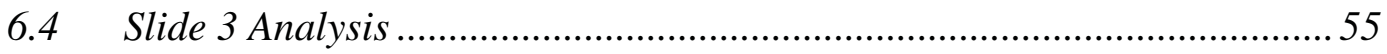

$7 \quad$ Discussion and future work...........................................................................5

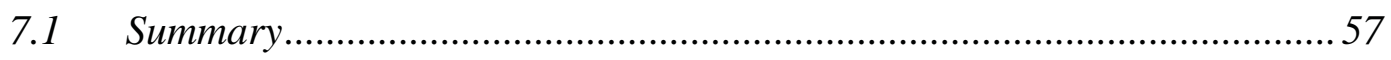

7.2 Assumptions and Limitations of the method...............................................58

8 Conclusions and Recommendations ..................................................................59

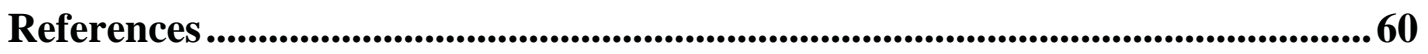

Appendix A: Permissions ...............................................................................................6 


\section{List of Figures}

Figure 2-1: Schematic of geotechnical assets as defined by the Federal Highway Administration (10).

Figure 2-2: A generic flow diagram of a landslide asset management program (14)..

Figure 2-3: A flowchart describing how to use LiDAR to determine the hazard rating of a rock slope (5).

Figure 2-4: The modified GSI chart using visual estimates of the surface condition and the structure of the rock mass (23).

Figure 2-5: There is a strong correlation between GSI and RMR values (21).

Figure 2-6: Terrestrial LiDAR scanner used at the study location in Southern

Nevada. 15

Figure 2-7: Optical photogrammetry set-up use at the study site location in Southern Nevada. 16

Figure 2-8: The Federal Highway Administration's use of LiDAR to determine structural discontinuities in outcrops (48)..................................................... 18

Figure 3-1: Location of the transportation corridor and study sites. ....................... 20 Figure 3-2: Nevada Bureau of Mines geology map of the transportation corridor and

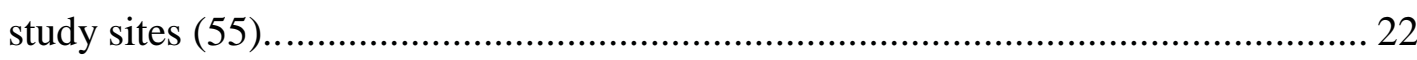

Figure 3-3: Relevant geology map of the study sites Slide 1 and Slide 2............... 23

Figure 3-4: Location of major rock structures for Slide 1, including the area that

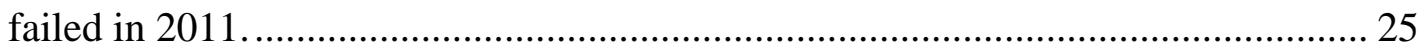

Figure 3-5: Slide 1 structures plotted, with the planar failure area highlighted....... 26

Figure 3-6: Slide 2 structures plotted, with wedge failure area highlighted. ........... 27

Figure 3-7: Rock structures at Slide 2 can be seen in this photograph.................... 28

Figure 4-1: Methodology Flowchart for determining the hazard score and stability of a rock slope along a transportation corridor. 30

Figure 4-2: A relative exposure risk map for a transportation corridor for rock falls and slides, based on user-chosen initial conditions.

Figure 4-3: A 1 meter resolution ortho-photo of the study corridor in Southern

Nevada. 33

Figure 4-4: Zoomed in ortho-photo of Slide 3. 35

Figure 4-5: Zoomed in ortho-photo of Slide 3 for geological condition. 35 
Figure 4-6: Terrestrial LiDAR point cloud of study site Slide 1........................... 38

Figure 4-7: Optical Photogrammetry point cloud of study site Slide 1................... 38

Figure 4-8: HRDEM of the study site, slide 1, in southern Nevada. ....................... 39

Figure 4-9: High resolution slope profile measured from the remote sensing HRDEM, modeled in RocScience RocFall......................................................... 40

Figure 6-1: Location of the three study sites along the transportation corridor.........42

Figure 6-2: One mile bounding area on both sides of the railroad track along the transportation corridor.

Figure 6-3: Slopes with an angle greater than 30 degrees, within the bounding area of the transportation corridor. 44

Figure 6-4: Areas with an H/L ratio of greater than 1/4, based on the locations identified by the previous two criteria. 45

Figure 6-5: Final risk exposure for the railroad tracks along the corridor. 45

Figure 6-6: Lidar and optical photogrammetry point clouds for Slide 1 are combined into a single image. 48

Figure 6-7: Rockfall propagation paths for Slide 1, modeled using RocScience

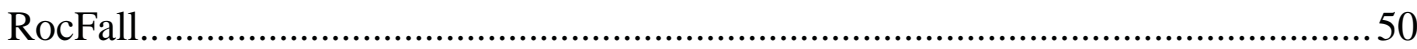

Figure 6-8: Wedge failure for Slide 1 modeled in RocScience Swedge................... 51

Figure 6-9: Planar failure modeled for Slide 1, using RocScience RocPlane. ..........52

Figure 6-10: LiDAR point cloud generated for Slide 2. ....................................... 54

Figure A-1: Permission to reproduce table seen in Table 2-3. ................................66

Figure A-2: Permission to reproduce table seen in table 3-2............................... 67

Figure A-3: Permission to reproduce table seen in Figure 2-4 ............................... 68

Figure A-4: Permission to reproduce image seen in Figure 2-2.............................69

Figure A-5: Emails with author of the $\mathrm{Ph}$. D dissertation (2) giving permission to reproduces images seen in Figure 2-3 and Table 2-2.

Figure A-6: Emails with author of the $\mathrm{Ph}$. D dissertation (2) giving permission to reproduces images seen in Figure 2-3 and Table 2-2. 


\section{List of Tables}

Table 2-1: The RHRS rating criteria and score sheet from the Oregon Department of Transportation (1)...

Table 2-2: Hazard rating system categories that can be determined using only

LiDAR information (5).

Table 2-3: Parameters for Beiniawski (1989) Rock Mass Rating (RMR) system (2).

Table 2-4: The chart used to determine the four adjustment factors applied in the Slope Mass Rating Method (34).

Table 4-1: RHRS scoring sheet for rock slopes along a transportation corridor, based on 1 meter resolution photograph data..................................................... 34

Table 4-2: GSI score sheet, used to determine an RMR value.............................. 37

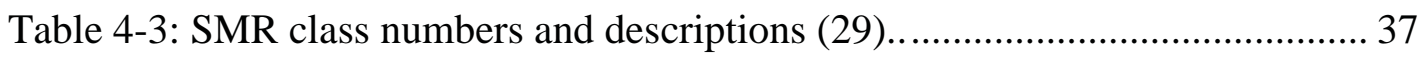

Table 6-1: RHRS score sheet for Slide 1 using the 1 meter ortho-photos. Geologic

Case 1 was used, so Geologic Case 2 is ignored...................................................4 47

Table 6-2: Tabulation of the GSI, RMR, and SMR values, as well as the SMR class

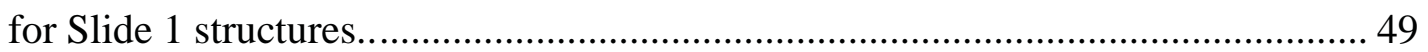

Table 6-3: RHRS score sheet for Slide 2 using the 1 meter ortho-photos. .............. 53

Table 6-4: Tabulation of the GSI, RMR, and SMR values, as well as the SMR class

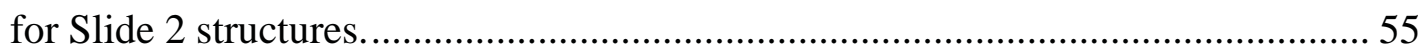

Table 6-5: RHRS score sheet for Slide 3 using the 1 meter ortho-photos. .............. 56

Table 7-1: Final results for all slides analyzed................................................. 57 


\section{Preface}

The work presented in this report is original, and was completed by myself. The field work was performed by Dr. Stanley Vitton, Dr. Rüdiger Escobar Wolf, and El Hachemi Bouali. The core paper was written by myself with guidance from my committee members. 


\section{List of Abbreviations}

\begin{tabular}{|c|c|}
\hline DEM & Digital Elevation Model \\
\hline DOT & Department of Transportation \\
\hline GIS & Geographic Information System \\
\hline GSI & Geological Strength Index \\
\hline $\mathrm{H} / \mathrm{L}$ & Height-to-Length Ratio \\
\hline HRDEM & High Resolution Digital Elevation Model \\
\hline InSAR & Interferometric Synthetic Aperture Radar \\
\hline JRC & Joint Roughness Coefficient \\
\hline LiDAR & Light Detection and Ranging \\
\hline NDOT & Nevada Department of Transportation \\
\hline NOAA & National Oceanic and Atmospheric Administration \\
\hline RGB & Red, Green, Blue color spectrum \\
\hline RHRS & Rockfall Hazard Rating System \\
\hline RMR & Rock Mass Rating \\
\hline RSRM & Remote Sensing Rock Mechanics \\
\hline RQD & Rock Quality Designation Index \\
\hline SCR & Surface Condition Rating \\
\hline SR & Structural Rating \\
\hline SMR & Slope Mass Rating \\
\hline Q & Rock Tunneling Quality Index Method \\
\hline
\end{tabular}




\section{Acknowledgements}

This research was partially funded by the INVOGE Program through Michigan Technological University, Houghton, MI USA, and the University of Milan - Bicocca, Lombardy, Italy. The field work for this study was supported by the US Department of Transportation, through the Office of the Assistant Secretary for Research and Technology (USDOT-OST-R). The views, opinions, findings, and conclusions reflected in this paper are the responsibility of the authors only and do not represent the official policy or position of the USDOT-OST-R, or any state or other entity. Additional information regarding this project can be found at www.mtri.org/geoasset.

This report would have been possible without the support and contributions from my advisors, Dr. Thomas Oommen, Dr. Stanley Vitton, and my committee members, Dr. Alessandro Tibaldi, and Rüdiger Escobar Wolf.

Also, the efforts of my fellow research members, El Hachemi Bouali and Zachary Champion were vital to the completion of this project.

Finally, I would like to express my gratitude to Paul C Hagadone II, for his unconditional support through all of this. And to my family, always. 


\section{Abstract}

Rockfall hazards are a significant and ongoing threat to infrastructure located within steep terrain. Assessing the relative hazard along a transportation corridor is important in determining the likely location and mode of rock slope failure. Understanding where to focus attention and funds is vital for the infrastructure agencies because of the high cost of implementing preventative measures for long lengths of infrastructure. Hazard analysis has historically relied upon experienced field engineers assessing each site, which is not time or cost effective. This study focuses on using remote sensing techniques to analyze rock slopes along transportation corridors. A case study from Southern Nevada is presented with several failing rock slopes along a railroad line. The analysis uses Digital Elevation Models (DEMs), ortho-photos, and high resolution remote sensing data to analyze individual rock slopes with a risk of failure. The rockfall hazard is measured using the Rockfall Hazard Rating System (RHRS) method, while the rock mass strength is measured using the Slope Mass Rating (SMR) method. A workflow is developed that can be immediately implemented by transportation agencies for use in maintenance programs.

Key Words: LiDAR, Photogrammetry, Hazard Rating, SMR, Geotechnical Asset Management 



\section{Introduction}

Geotechnical assets are an integral aspect of transportation infrastructure but have not been included in traditional asset management systems due to the high cost of collecting and analyzing data needed for a management system. Geotechnical assets would include any structure along a transportation corridor that is composed of soil or rock or integral to the functioning of structures made of traditional engineering materials such as steel and concrete. Common examples of geotechnical assets would be slopes, retaining walls and tunnels. The main limitation of assessing geotechnical assets along transportation corridors is the length of the corridor as well as the method used to assess the asset.

A key geotechnical asset for transportation corridors in mountainous regions are rock slides. While large scale rock slides are fortunately not common, but when they do occur they can shut down a rail line or highway for a significant amount of time and be costly to remediate. Even small rock falls can create serious conditions especially for railroads, which can lead to derailment or the stopping of trains. The focus of this report will be on the geotechnical asset of rock slides also known as rockfalls. Rockfalls are a serious hazard for roads and railways and can cause significant economic loss as well and social costs.

In order to determine where to focus limited financial resources, field engineers would be required to travel to all potentially hazardous locations to assess rock slopes. This is a costly and time-consuming process but would still be based on a visual assessment and engineering judgment. Today, some state departments of transportation use the rockfall hazard rating system (RHRS) (1). This system indicates areas that are relatively more hazardous than others and allows state departments to narrow their area of concern to the rock slopes that are most likely to fail. The RHRS, however, does not address the types of possible failures, or suggest how to best remediate the hazardous condition.

To understand how a rock slope might fail, the slope's geometry and rock mass properties at each individual location must be known. For example, field engineers can perform in-situ tests to determine the strength of the rock, and determine how intact the rock mass is. These are key parameters in determining the Rock Mass Rating (RMR) (2). However, in-situ tests are sometimes prohibitively expensive, and require specialized knowledge and equipment, making it difficult to test all potentially hazardous sites. To help analyze a slope with the aid of rock 
testing, the Geologic Strength Index (GSI) can be used to provide an estimate of the RMR based on surficial visual assessments. In order to better understand the failure mechanisms of rock slopes, engineers can go a step further and use the Slope Mass Rating (SMR). This system takes into account the slope's geometry and most aspects of a rock mass, and provides an estimate of the stability of the rock slope (3). The SMR class system also provides estimates on the potential failure mechanism and possible remediation measures. This method provides a measure of the slopes with the highest need for remediation, so it is possible for state transportation departments to accurately focus the budget on the project with the highest return value.

Though it is helpful to know where the most potentially hazardous geotechnical assets are located, it is still costly to send a field engineer to each site for annual assessments once the initial determinations have been made. Also, it is possible that there might not be an accurate record kept of each location. In some cases only a form with the field engineer's comments might be available(4). This prevents the creation of quantitative estimates of specific site movements based on past records.

In order to improve geotechnical asset management, the use of remote sensing has been applied (5), through the use of technologies such as LiDAR (Light Detection and Ranging) and optical photogrammetry. Using these technologies it is possible to accomplish the required tasks for transportation agencies to assess their geotechnical assets. There has been significant research on how LiDAR and photogrammetry work, and how the technologies can be applied to the geotechnical field (6-8). Each method can be applied separately, and in conjunction with one another. Using both LiDAR and optical photogrammetry to analyze a rock slope can supplement the shortcomings of either technique, and can provide a full color, 3D representation of the slope. Images, created by LiDAR and optical photogrammetry, can be analyzed for geological structural features, which can then be used in the assessment of the rock slope properties. Indeed, remote sensing can act very similarly to the visual assessment made by geological engineers in the field, and thus, can be applied to the GSI and SMR methods for predicting slope stability. Another advantage of the using LiDAR point clouds is in the creation of highresolution digital elevation models (HRDEMs). These HRDEMs can be used to draw extremely accurate 2D and 3D profiles of the slope for failure modeling, and as a base layer for generating hazard maps with a geographic information system (GIS) software package. Both of these are good visual ways to interpret the potential 
rock slope hazards along a transportation corridor. Another advantage in using remote sensing technologies is the virtual record keeping that results in the using these technologies. When using LiDAR and photogrammetry over the course of several years, it is easy to compare the slope profiles year to year, and determine if there has been any change in the profile. This simple deformation monitoring system can be extremely helpful in analyzing how the hazard rating for a specific site changes throughout time.

A first attempt at using the remote sensing techniques of LiDAR and optical photogrammetry to analyze a transportation corridor is outlined in this paper. A study site in southern Nevada is used that has several years of LiDAR and optical photogrammetry point clouds. Other remote sensing technologies, such as Interferometric Synthetic Aperture Radar (InSAR), were also collected at this site, but will not be discussed in this study. The study determined a hazard rating for the site along with an estimate of slope stability and failure mechanisms. The results were verified with physical data for the rockslide performed by a geotechnical consulting firm. Once the current state of geotechnical assets has been determined, a performance model can be created for individual geotechnical assets, which can be used by agencies in a decision support capacity (9). A discussion of applicability and future modifications is provided at the end of this report.

\section{Literature Review}

\subsection{Geotechnical Asset Management}

Asset management is a program that is enacted to ensure physical assets can meet their lifetime performance goals. An asset management program can be applied to any type of infrastructure that requires routine maintenance. For transportation infrastructure, physical assets can range from the road pavement or railway tracks to bridges to traffic signals and signage (10). The criterion that a transportation asset management program uses to monitor includes topics such as asset preservation and sustainability, pollution control, and protection of resources. Geotechnical assets however, have generally not been included in most asset management programs. Geotechnical assets can include embankments, tunnels, and drainage ditches. Geotechnical assets are intrinsically linked to transportation assets, and are sometimes hard to distinguish as a separate component. Figure 2-1 illustrates a number of geotechnical assets along a highway in hilly terrain. 


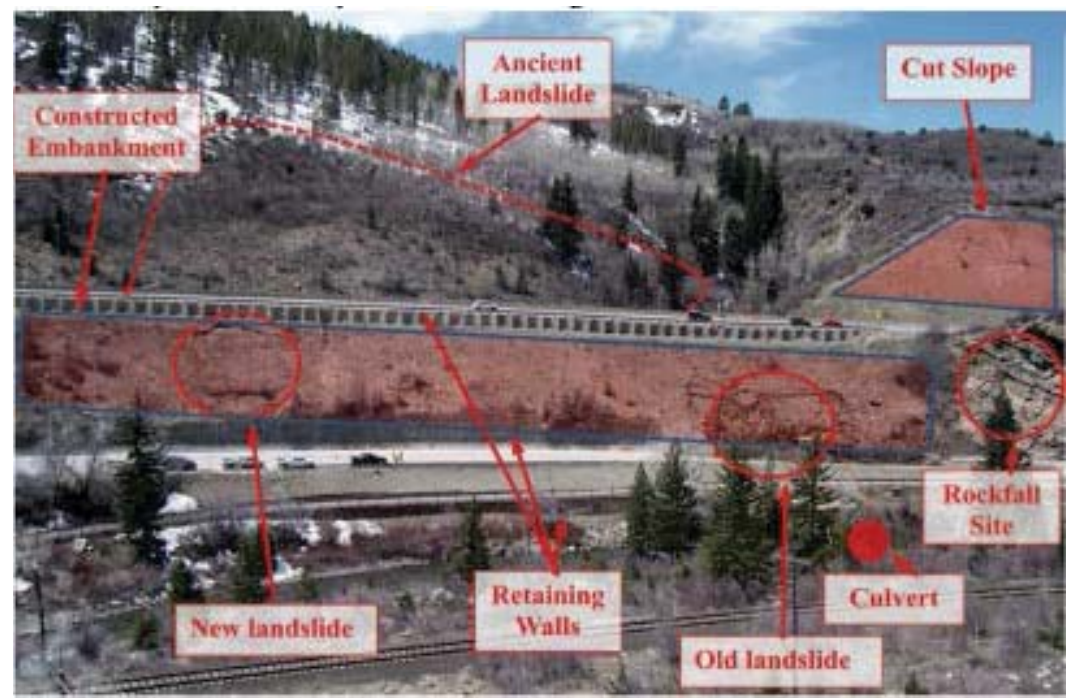

FIGURE 2-1: SCHEMATIC OF GEOTECHNICAL ASSETS AS DEFINED BY THE FEDERAL HIGHWAY AdMINISTRATION (10). THERE ARE MANY GEOTECHNICAL ASSETS PRESENT ALONG TRANSPORTATION AREAS. THIS DIAGRAM SHOWS THE INFRASTRUCTURE ASSETS ARE INSEPARABLE FROM THE GEOTECHNICAL ASSETS THEY ARE BUILT UPON.

One of the main objectives of an asset management program is to maintain the physical assets in a cost-effective manner. Geotechnical assets, however, can be difficult to identify, and prohibitively costly to support. Even though, it has been found that the economic cost of repairing a failure geotechnical feature is less than the cost of the mitigation options to prevent failure (10). In order to minimize the impact of failures on geotechnical assets, the Federal Highway Administration (FHWA) has strongly supported that geotechnical asset management be incorporated in the established transportation asset management programs (10).

There have been multiple papers describing how to create a geotechnical asset management framework (10-13). The main components of a management framework include assessing the current state of the asset, defining the required level of service, identification of critical assets, and investment strategies (9). Implementation is also a key factor is designing a geotechnical asset management program. For example, the program should be based on already existing systems, so that it can fit into the known management program. If the current system overlaps into the geotechnical assets, it can be used without creating additional workload. 
Finally, the asset program should support the objectives and goals of the agency implementing it. In terms of transportation asset management, adding geotechnical assets would most likely fall under lifetime maintenance goals that the transportation agencies already have in place (11). As an example, Figure 2-2 is a landslide management program that shows the different elements that make up a geotechnical asset management program, and how it can be integrated into existing maintenance programs.

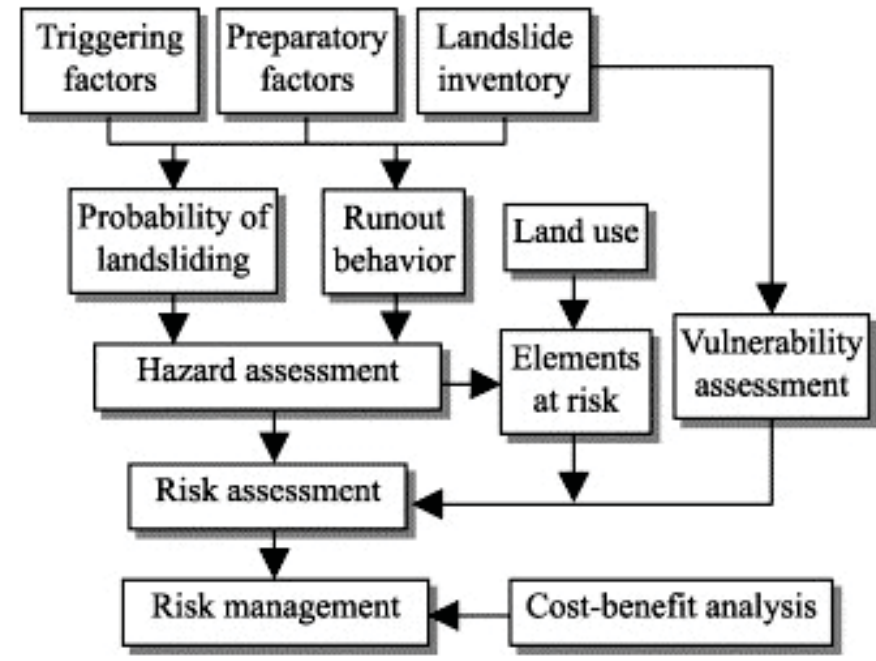

FIGURE 2-2: A GENERIC FLOW DIAGRAM OF A LANDSLIDE ASSET MANAGEMENT PROGRAM (14). THIS IS A SCHEME THAT MANY STATE DOTS USE TO MANAGE INDIVIDUAL GEOTECHNICAL ASSETS.

\subsection{Hazard Rating System}

Hazards due to rockfall failures are a major concern for transportation infrastructure. Rockfalls and rock slides have a high potential to damage roads and railway tracks. There have been several different systems available to assess the hazard along transportation corridors. One of the most widely used, especially by transportation agencies, is the "Rockfall Hazard Rating System" (RHRS) (4). This system was created by the Oregon DOT to be a proactive approach to monitor rockfall hazards. The RHRS is a subjective model, and requires proper training and extensive use of engineering judgment.

The RHRS is meant to be a process by which transportation agencies can monitor and maintain highway systems for rockfall hazards. It provides a rational way to make economic decisions, and focus construction costs on the areas that are 
at the highest risk for hazards. It is comprised of the following six key elements; (1) a uniform method for inventory, (2) preliminary rating of slopes, (3) detailed rating of hazardous slopes, (4) preliminary cost estimate for hazardous slopes, (5) project identification, and (6) annual review (1). While the entire system is for a long-term management program, it can be used on an individual slope basis to determine risk. The categories for the RHRS are identified in Table 2-1.

TABLE 2-1: THE RHRS RATING CRITERIA AND SCORE SHEET FROM THE OREGON DEPARTMENT OF TRANSPORTATION (1). THIS TABLE IS MEANT TO BE USED WITH FULL KNOWLEDGE OF ALL CATEGORIES AND TECHNICAL EXPERIENCE.

\begin{tabular}{|c|c|c|c|c|c|c|}
\hline & \multirow{2}{*}{\multicolumn{2}{|c|}{ CATEGORY }} & \multicolumn{4}{|c|}{ PATING CAITERIA AND SCORE } \\
\hline & & & 3 POINTS & 9 POINTS & 27 POINTS & 81 POINTS \\
\hline \multicolumn{3}{|c|}{ SLOPE HEIGHT } & 25 FEET & 50 FEET & 75 FEET & $100 \mathrm{FEET}$ \\
\hline \multicolumn{3}{|c|}{$\begin{array}{l}\text { DITCH } \\
\text { EFFECTIVENESS }\end{array}$} & $\begin{array}{c}\text { Good } \\
\text { catchment }\end{array}$ & $\begin{array}{l}\text { Moderate } \\
\text { catchment }\end{array}$ & $\begin{array}{l}\text { Limited } \\
\text { catchment }\end{array}$ & $\begin{array}{c}\text { No } \\
\text { catchment } \\
\end{array}$ \\
\hline \multicolumn{3}{|c|}{$\begin{array}{l}\text { AVERAGE VEHICLE } \\
\text { AISK }\end{array}$} & $\begin{array}{l}25 \% \\
\text { of the } \\
\text { time }\end{array}$ & $\begin{array}{l}50 \% \\
\text { of the } \\
\text { time }\end{array}$ & $\begin{array}{l}75 \% \\
\text { of the } \\
\text { time }\end{array}$ & $\begin{array}{l}100 \% \\
\text { of the } \\
\text { time }\end{array}$ \\
\hline \multicolumn{3}{|c|}{$\begin{array}{l}\text { PERCENT OF } \\
\text { DECISION } \\
\text { SIGHT } \\
\text { DISTANCE }\end{array}$} & $\begin{array}{c}\text { Adequate sight } \\
\text { distance, } 100 \% \\
\text { of low design } \\
\text { value }\end{array}$ & $\begin{array}{c}\text { Moderate } \\
\text { sight } \\
\text { distance, } 80 \% \\
\text { of low design } \\
\text { value } \\
\end{array}$ & $\begin{array}{l}\text { Limited sight } \\
\text { distance, } 60 \% \\
\text { of low design } \\
\text { value }\end{array}$ & $\begin{array}{c}\text { Very limited } \\
\text { sight } \\
\text { distance } 40 \% \\
\text { of low design } \\
\text { value } \\
\end{array}$ \\
\hline \multicolumn{3}{|c|}{$\begin{array}{l}\text { ROADWNAY WIDTH } \\
\text { INCLUDING PAVED } \\
\text { SHOULDEAS }\end{array}$} & 44 feet & 36 feet & 28 feet & 20 feet \\
\hline \multirow{2}{*}{$\begin{array}{l}G \\
E \\
O \\
L \\
O \\
G \\
1 \\
C\end{array}$} & \multirow{2}{*}{$\begin{array}{l}C \\
A \\
S \\
E \\
1\end{array}$} & $\begin{array}{l}\text { STRUCTURAL } \\
\text { CONDITION }\end{array}$ & $\begin{array}{c}\text { Discontinuous } \\
\text { joints, } \\
\text { favorable } \\
\text { orientation } \\
\end{array}$ & $\begin{array}{c}\text { Discontinuous } \\
\text { joints, } \\
\text { random } \\
\text { oriontation } \\
\end{array}$ & $\begin{array}{c}\text { Discontinuous } \\
\text { joints, } \\
\text { adverse } \\
\text { orientation } \\
\end{array}$ & $\begin{array}{l}\text { Continuous } \\
\text { joints, } \\
\text { adverse } \\
\text { orientation }\end{array}$ \\
\hline & & $\begin{array}{l}\text { ROCK } \\
\text { FRICTION }\end{array}$ & $\begin{array}{l}\text { Rough, } \\
\text { Irregular }\end{array}$ & Undulating & Planar & $\begin{array}{l}\text { Clay infilling. } \\
\text { or slickensided }\end{array}$ \\
\hline \multirow{2}{*}{$\begin{array}{l}\text { C } \\
\text { H } \\
\text { A } \\
\text { R } \\
\text { A } \\
\text { C } \\
\text { T } \\
\text { E } \\
\text { R }\end{array}$} & \multirow{2}{*}{$\begin{array}{l}\text { C } \\
\text { A } \\
\text { S } \\
\text { E } \\
2\end{array}$} & $\begin{array}{l}\text { STRUCTURAL } \\
\text { CONDITION }\end{array}$ & $\begin{array}{l}\text { Few differential } \\
\text { erosion teatures }\end{array}$ & $\begin{array}{l}\text { Occasional } \\
\text { erosion } \\
\text { features }\end{array}$ & $\begin{array}{c}\text { Many } \\
\text { erosion features }\end{array}$ & $\begin{array}{l}\text { Major } \\
\text { erosion } \\
\text { features }\end{array}$ \\
\hline & & $\begin{array}{l}\text { DIFFERENCE IN } \\
\text { EROSION RATES }\end{array}$ & $\begin{array}{c}\text { Small } \\
\text { difference }\end{array}$ & $\begin{array}{l}\text { Moderate } \\
\text { difference }\end{array}$ & $\begin{array}{l}\text { Large } \\
\text { difference }\end{array}$ & $\begin{array}{l}\text { Extreme } \\
\text { difference }\end{array}$ \\
\hline \multicolumn{3}{|c|}{ BLOCK SIZE } & 1 Foot & 2 Feet & 3 Feet & 4 Feet \\
\hline \multicolumn{3}{|c|}{$\begin{array}{c}\text { VOLUME OF } \\
\text { ROCKFALLEVENT }\end{array}$} & $\begin{array}{l}3 \text { cubic } \\
\text { yards }\end{array}$ & $\begin{array}{l}6 \text { cubic } \\
\text { yards }\end{array}$ & $\begin{array}{l}9 \text { cubic } \\
\text { yards }\end{array}$ & $\begin{array}{l}1 \overline{2 \text { cubic }} \\
\text { yards }\end{array}$ \\
\hline \multicolumn{3}{|c|}{$\begin{array}{l}\text { CLIMATE AND } \\
\text { PRESENCE } \\
\text { OF WATER } \\
\text { ON SLOPE }\end{array}$} & $\begin{array}{c}\text { Low to } \\
\text { moderate } \\
\text { precipitation; } \\
\text { no freezing } \\
\text { periods; no } \\
\text { water on slope }\end{array}$ & $\begin{array}{l}\text { Moderate } \\
\text { precipitation } \\
\text { or short } \\
\text { freozing } \\
\text { periods or } \\
\text { intermittent } \\
\text { water on } \\
\text { slope } \\
\end{array}$ & $\begin{array}{c}\text { High } \\
\text { precipitation } \\
\text { or long freezing } \\
\text { periods or } \\
\text { continual water } \\
\text { on slope }\end{array}$ & $\begin{array}{l}\text { High precipi- } \\
\text { tation and long } \\
\text { freezing } \\
\text { periods or } \\
\text { continual water } \\
\text { on slope and } \\
\text { long freezing } \\
\text { periods }\end{array}$ \\
\hline \multicolumn{3}{|c|}{ ROCKFALL HISTORY } & Few falls & $\begin{array}{l}\text { Occasional } \\
\text { falts }\end{array}$ & Many falls & Constant talls \\
\hline
\end{tabular}

In applying this system to an entire transportation corridor, a preliminary rating system is required. A primary rating system is based on both the potential for 
rocks falls but also on the historical activity at all sites. A detailed rating system, used for more specific analysis, has several categories, each with four choices. Each choice is exponentially worse than the previous to distinguish more hazardous sites. The majority of the 10 categories, however, are subjective in nature. The only details that involve something other than engineering judgment are the "average vehicle risk" and the "decisions sight distance", which are calculations that result in an average value for the location. Most information about specific locations can be found in historical records, and in publicly available data logs.

The RHRS was developed in 1991, and was commissioned by the Oregon DOT for relatively varied topography. The system, however, is not applicable for more mountainous terrain. Because of this, modifications have been proposed. One of the more popular rating systems is the Colorado RHRS, which take into account more geological and climatic factors than does the Oregon RHRS system. The slope, climate, geologic, and traffic conditions all contribute to the overall hazard score of any particular location (15). This modification accounts for different rock types, rainfall and seepage conditions, and the effect on the transportation infrastructure. While this system has not been adopted by all state DOTs, it is an improvement on the Oregon rating system. It is, however, still an empirical system, relying heavily on historical data and engineering judgment. For example, several categories, such as average vehicle risk, are repeated from the original RHRS.

Another modification to the RHRS system was suggested by Budetta, P., \& Nappi (2013) which focuses on a single category in an attempt to reduce the subjectivity. This modified RHRS is identified as mRHRS in this report (16). While not necessarily better or worse than systems such as RHRS, this system focuses on statistics for a single landslide site. The site could be of interest because of triggering events, such as earthquakes or flash floods. A modification that analyzes the frequency-volume statistics can determine locations where defensive structures could mitigate damage due to rockfalls (17). Study of rockfalls along transportation networks is an ongoing process to improve the RHRS (18-19). 
There has not been a significant amount of research in the use of remote sensing for hazard rating systems. This is likely because remote sensing requires special equipment and knowledge to implement. The importance of remote sensing, however, is that it can replace the need for an engineer to travel to the site and to rate it based on engineering judgment. For example, many of the categories in the Oregon RHRS can be determined without visiting the rockfall location but can be determined using remote sensing techniques. Even in more detailed rating systems, because of the subjective nature of these systems, remote sensing techniques can be used to determine a relative hazard rating. Research by MJ Lato (5) into the use of LiDAR for many aspects of slope identification and hazard rating is an important step in using remote sensing for these aspects of geotechnical asset management. This work, however, is for individual locations using only LiDAR, and is not applicable to transportation corridors. Table 2-2 illustrates the criteria for a hazard rating system using LiDAR technology. The systems evaluated are the RHRS, the Rockfall Hazard Risk Assessment (RHRA), and the Rockfall Hazard Rating system for Ontario (RHRON), all of which are commonly used. The input parameters, or categories, for three different hazard rating systems are able to be measured or estimated by LiDAR data, showing that remote sensing can be used to perform

TABLE 2-2: HAZARD RATING SYSTEM CATEGORIES THAT CAN BE DETERMINED USING ONLY LIDAR INFORMATION (5). THE RHRS, ROCKFALL HAZARD RISK ASSESSMENT (RHRA), ROCKFALL HAZARD RATING SYSTEM FOR ONTARIO (RHRON) ARE EVALUATED. THE LIDAR INFORMATION IS COMPARED TO THAT OF AN EXX_ERIENCED ENGINEER.

\begin{tabular}{|c|c|c|c|c|c|c|}
\hline \multirow[b]{2}{*}{ Input Variable } & \multirow[b]{2}{*}{ Description/use } & \multirow[b]{2}{*}{$\underset{\cong}{\stackrel{a}{\Xi}}$} & \multirow[b]{2}{*}{ 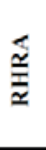 } & \multirow[b]{2}{*}{$\begin{array}{l}\underset{0}{\underline{y}} \\
\overline{\underline{a}}\end{array}$} & \multicolumn{2}{|c|}{ Evaluation Method } \\
\hline & & & & & $\begin{array}{l}\text { Field } \\
\text { engineer }\end{array}$ & $\begin{array}{l}\text { Extracted } \\
\text { from LiDAR }\end{array}$ \\
\hline $\begin{array}{l}\text { Discontinuity } \\
\text { structures }\end{array}$ & $\begin{array}{l}\text { Dip/dip direction measurements for } \\
\text { kinematic evaluation }\end{array}$ & $\mathrm{X}$ & $\mathrm{X}$ & $\mathrm{X}$ & measured & measured \\
\hline $\begin{array}{l}\text { Discontinuity } \\
\text { spacing }\end{array}$ & $\begin{array}{l}\text { Distribution of interval between } \\
\text { discontinuities }\end{array}$ & $\mathrm{X}$ & $\mathrm{X}$ & $\mathrm{X}$ & $\begin{array}{r}\text { measured/ } \\
\text { estimated }\end{array}$ & measured \\
\hline $\begin{array}{l}\text { Discontinuity } \\
\text { persistence }\end{array}$ & $\begin{array}{l}\text { Persistence and interaction between } \\
\text { discontinuity sets }\end{array}$ & $\mathrm{X}$ & $\mathrm{X}$ & $\mathrm{X}$ & $\begin{array}{l}\text { measured/ } \\
\text { estimated }\end{array}$ & measured \\
\hline $\begin{array}{l}\text { Block shape } \\
\text { distribution }\end{array}$ & $\begin{array}{l}\text { Distribution of potential failed rock } \\
\text { block shapes }\end{array}$ & & $\mathrm{X}$ & & estimated & modelled \\
\hline $\begin{array}{l}\text { Block volume } \\
\text { distribution }\end{array}$ & $\begin{array}{l}\text { Distribution of potential failed rock } \\
\text { block volume }\end{array}$ & $\mathrm{X}$ & $\mathrm{X}$ & & estimated & modelled \\
\hline Curvature & $\begin{array}{l}\text { Corridor curvature and line of sight } \\
\text { at any given point }\end{array}$ & $\mathrm{X}$ & $\mathrm{X}$ & $\mathrm{X}$ & estimated & measured \\
\hline $\begin{array}{l}\text { Holistic sense of } \\
\text { hazard potential }\end{array}$ & Intuition or "feel" for the hazard & $\mathrm{X}$ & $\mathrm{X}$ & $\mathrm{X}$ & visualized & $\mathrm{n} / \mathrm{a}$ \\
\hline $\begin{array}{l}\text { Rockfall run out } \\
\text { distance }\end{array}$ & $\begin{array}{l}\text { Distance failed rock blocks will } \\
\text { travel }\end{array}$ & $\mathrm{X}$ & $\mathrm{X}$ & $\mathrm{X}$ & estimated & modelled \\
\hline $\begin{array}{l}\text { Slope angle and } \\
\text { ditch } \\
\text { configuration }\end{array}$ & $\begin{array}{l}\text { Slope geometry and corridor } \\
\text { interaction }\end{array}$ & $\mathrm{X}$ & $\mathrm{X}$ & $\mathrm{X}$ & $\begin{array}{l}\text { basic } \\
\text { profile }\end{array}$ & $\begin{array}{l}\text { detailed } \\
\text { profile }\end{array}$ \\
\hline $\begin{array}{l}\text { Zones of } \\
\text { accumulation }\end{array}$ & $\begin{array}{l}\text { Zones where failed rock blocks } \\
\text { accumulate or travel through }\end{array}$ & $\mathrm{X}$ & $\mathrm{X}$ & $\mathrm{X}$ & $\mathrm{n} / \mathrm{a}$ & measured \\
\hline $\begin{array}{l}\text { Zones of rock } \\
\text { block release }\end{array}$ & $\begin{array}{l}\text { Zones where failed blocks have } \\
\text { been released from }\end{array}$ & $\mathrm{X}$ & & & $\mathrm{n} / \mathrm{a}$ & measured \\
\hline
\end{tabular}


hazard analysis based on systems already in use.

Figure 2-3 illustrates how to use LiDAR technology in evaluating rockfall hazards at a single rockfall location, resulting in metrics that can be applied to an asset management program.

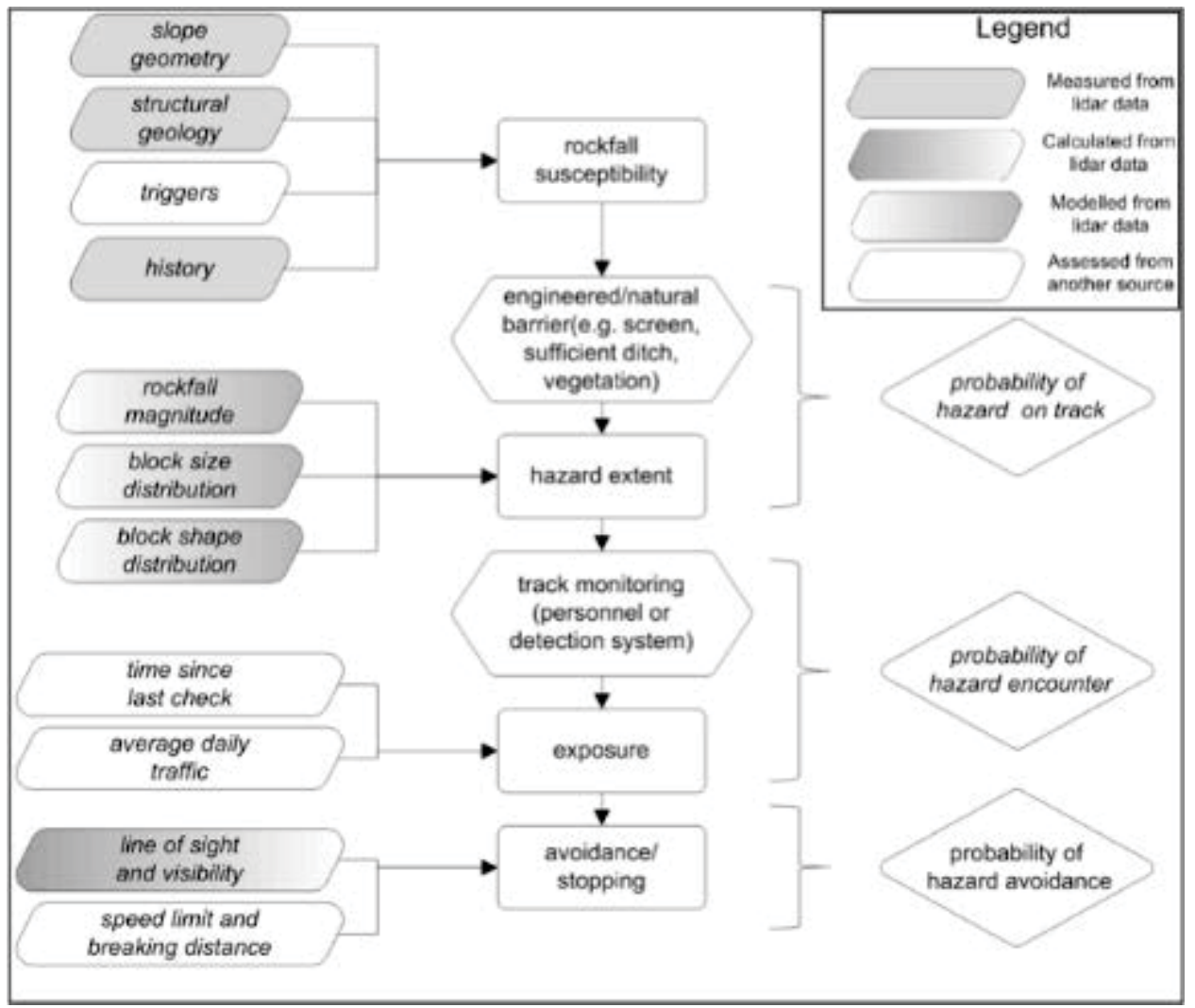

FIGURE 2-3: A FLOWCHART DESCRIBING HOW TO USE LIDAR TO DETERMINE THE HAZARD RATING OF A ROCK SLOPE (5). THIS IS A MODIFICATION OF THE WORKFLOW PRESCRIBED FOR THE RHRS.

An important item to consider when using LiDAR to evaluate a rockfall hazard is to account for different geologies and possible failure mechanisms. A field engineer already does this, based on engineering judgment, at each site investigated. LiDAR will not automatically do this, so adjustments must be made. The geology of the slope, whether for example it has high or low anisotropy or horizontal banding, affects the structures present and the types of failure modes likely to take place. LiDAR, therefore, must be used in conjunction with modeling programs, such as rockfall software modeling programs, to assess potential failures such as rock runout by creating a geometric profile of the slope. 
The use of LiDAR has several significant benefits over the traditional evaluation methods. The first is that there is less room for judgment bias when the rock slopes are automatically extracted from a complete coverage map. An engineer in the field might not be able to accurately measure the length or aperture of a joint, but those aspects can generally be identified in point clouds. Second, there is a permanent record of the slope topography at the time of recording. With repeated data collections, it is possible to see slope deformations that might otherwise be overlooked. And finally, it takes the field engineer out of harm's way, avoiding potentially dangerous conditions when evaluating a serious slope hazard.

\subsection{Analysis of Rock Slope Stability}

\subsubsection{Rock Slope Properties}

During the initial stages of investigation rock slopes for potential hazards, it is beneficial to use a rock mass classification system to assess the condition of the rock that comprises the slope. A rock mass classification system provides a quantitate measure of the slope's rock mass properties, when in-situ and laboratory tests are not available. Rock mass classification can range from simple checklists to more complicated schemes that provide numerical values for rock properties.

An important criteria used in rock mass classifications is the degree of fracturing of the rock mass. A solid rock with no fractures will be stronger and more stable than a highly fractures rock mass. There are two methods used to quantify rock fractures: (1) the Rock Quality Designation Index (RQD) and (2) the volumetric joint count $\left(\mathrm{J}_{\mathrm{v}}\right)$. The RQD requires rock core drilling, and provides a "rock mass quality" termed a RQD (2). The volumetric joint count, $\mathrm{J}_{\mathrm{v}}$, is used when boreholes are not drilled. The $J_{v}$ is the number of joints per unit length of the rock mass, and it is correlated to the RQD by the equation:

$$
R Q D=115-3.3 * J_{v}
$$

The most commonly used rock mass rating (RMR) system used the United States was developed by Bieniawski in 1976, and revised in 1989. The RMR system uses five criteria, shown in Table 2-3, to classify a rock mass as shown in equation:

$$
R M R=A_{1}+A_{2}+A_{3}+A_{4}+A_{5}
$$


The sum of all the criteria values gives a class number, and general characteristics for the rock mass. This system can be used for most rock masses, with adjustments must be made for specific projects., (20).

TABLE 2-3: PARAMETERS FOR BEINIAWSKI (1989) ROCK MASS RATING (RMR) SYSTEM (2). THE RATING VALUE FOR EACH OF THE FIVE CATEGORIES COMBINES TO DETERMINE AND OVERALL RMR SCORE.

\begin{tabular}{|c|c|c|c|c|c|c|c|c|c|}
\hline \multicolumn{10}{|c|}{ A. CLASSIFICATION PARAMETERS AND THEIR RATINGS } \\
\hline \multicolumn{3}{|r|}{ Parameter } & \multicolumn{4}{|c|}{ Range of values } & & & \\
\hline \multirow{3}{*}{1} & \multirow{2}{*}{$\begin{array}{l}\text { Strength } \\
\text { of } \\
\text { intact rock } \\
\text { material }\end{array}$} & \multirow{2}{*}{\begin{tabular}{|l|}
$\begin{array}{l}\text { Point-toad } \\
\text { strength index }\end{array}$ \\
$\begin{array}{l}\text { Uniaxial comp. } \\
\text { strength }\end{array}$ \\
\end{tabular}} & \multirow{2}{*}{$\begin{array}{l}>10 \mathrm{MPa} \\
>250 \mathrm{MPa}\end{array}$} & \multirow{2}{*}{$\begin{array}{c}4 \cdot 10 \mathrm{MPa} \\
100 \cdot 250 \mathrm{MPa}\end{array}$} & \multirow{2}{*}{$\begin{array}{c}2 \cdot 4 \mathrm{MPa} \\
50-100 \mathrm{MPa}\end{array}$} & \multirow{2}{*}{$\begin{array}{c}1-2 \mathrm{MPa} \\
25-50 \mathrm{MPa}\end{array}$} & \multicolumn{3}{|c|}{$\begin{array}{l}\text { For this low range - uniaxial } \\
\text { compressive test is preferred }\end{array}$} \\
\hline & & & & & & & $\begin{array}{l}5 \cdot 25 \\
\mathrm{MPa} \\
\end{array}$ & $\begin{array}{l}1.5 \\
\mathrm{MPa} \\
\end{array}$ & \begin{tabular}{c|}
$<1$ \\
$\mathrm{MPa}$ \\
\end{tabular} \\
\hline & \multicolumn{2}{|r|}{ Rating } & 15 & 12 & 7 & 4 & 2 & 1 & 0 \\
\hline & \multicolumn{2}{|r|}{ Drill core Quality RQD } & $90 \%-100 \%$ & $75 \%-90 \%$ & $50 \%-75 \%$ & $25 \%-50 \%$ & \multicolumn{3}{|c|}{$<25 \%$} \\
\hline 2 & \multicolumn{2}{|r|}{ Rating } & 20 & 17 & 13 & 8 & \multicolumn{3}{|c|}{3} \\
\hline & \multicolumn{2}{|r|}{ Spacing of } & $>2 \mathrm{~m}$ & $0.6-2 \cdot \mathrm{m}$ & $200.600 \mathrm{~mm}$ & $60.200 \mathrm{~mm}$ & \multicolumn{3}{|c|}{$<60 \mathrm{~mm}$} \\
\hline 3 & \multicolumn{2}{|r|}{ Rating } & 20 & 15 & 10 & 8 & \multicolumn{3}{|c|}{5} \\
\hline \multirow[t]{2}{*}{4} & \multicolumn{2}{|c|}{$\begin{array}{l}\text { Condition of discontinuites } \\
\text { (See E) }\end{array}$} & $\begin{array}{l}\text { Very rough surfaces } \\
\text { Not continuous } \\
\text { No separation } \\
\text { Unweathered wall rock }\end{array}$ & $\begin{array}{l}\text { Slightly rough surfaces } \\
\text { Separation < } 1 \mathrm{~mm} \\
\text { Slightly weathered walls }\end{array}$ & $\begin{array}{l}\text { Slightly rough surfaces } \\
\text { Separation < } 1 \mathrm{~mm} \\
\text { Highly weathered walls }\end{array}$ & $\begin{array}{l}\text { Slickensided surfaces } \\
\text { or Gouge }<5 \mathrm{~mm} \text { thick } \\
\text { or Separation } 1-5 \mathrm{~mm} \\
\text { Continuous }\end{array}$ & \multicolumn{3}{|c|}{$\begin{array}{l}\text { Soft gouge }>5 \mathrm{~mm} \text { thick } \\
\text { or Separation }>5 \mathrm{~mm} \\
\text { Continuous }\end{array}$} \\
\hline & \multicolumn{2}{|r|}{ Rating } & 30 & 25 & 20 & 10 & \multicolumn{3}{|c|}{0} \\
\hline \multirow{4}{*}{5} & \multicolumn{2}{|r|}{$\begin{array}{l}\text { Inflow per } 10 \mathrm{~m} \\
\text { tunnel length }(\mathrm{l} \mathrm{m})\end{array}$} & None & $<10$ & $10-25$ & $25-125$ & \multicolumn{3}{|c|}{$>125$} \\
\hline & \multirow[t]{2}{*}{$\begin{array}{c}\text { Groundwa } \\
\text { ter }\end{array}$} & \begin{tabular}{|l}
$\begin{array}{l}(J o i n t \\
\text { (Major principal } \sigma \text { ) }\end{array}$ \\
\end{tabular} & 0 & $<0.1$ & $0.1,-0.2$ & $0.2 \cdot 0.5$ & \multicolumn{3}{|c|}{$>0.5$} \\
\hline & & General conditions & Completely dry & Damp & Wet & Dripping & \multicolumn{3}{|c|}{ Flowing } \\
\hline & & Rating & 15 & 10 & 7 & 4 & \multicolumn{3}{|c|}{0} \\
\hline
\end{tabular}

The GSI was developed by E. Hoek to provide a visual method to assess the strength of a rock mass given a rock masses "blockiness and the conditions of the discontinuities” (21). In order to have a more quantitative measure for the GSI value, Sonmez and Ulusay (2002) (22) proposed a method that takes into account the size and the roundness of the rock block. As illustrated in Figure 2-4, the Surface Condition Rating (SCR) and the Structure Rating (SR) combine to give a more precise value for a rock masses GSI.. The SRC is based on the roughness, weathering, and infilling of joints throughout the mass. The SR can be determined through a visual inspection of the rock mass, or an equation based on the volumetric joint count of the mass. A GSI value should be determined for each joint set, with the average of all values resulting in the GSI for the rock mass as a whole. This chart gives a more accurate value for GSI than the unmodified chart because of the more rigorous approach in visual assessment. 


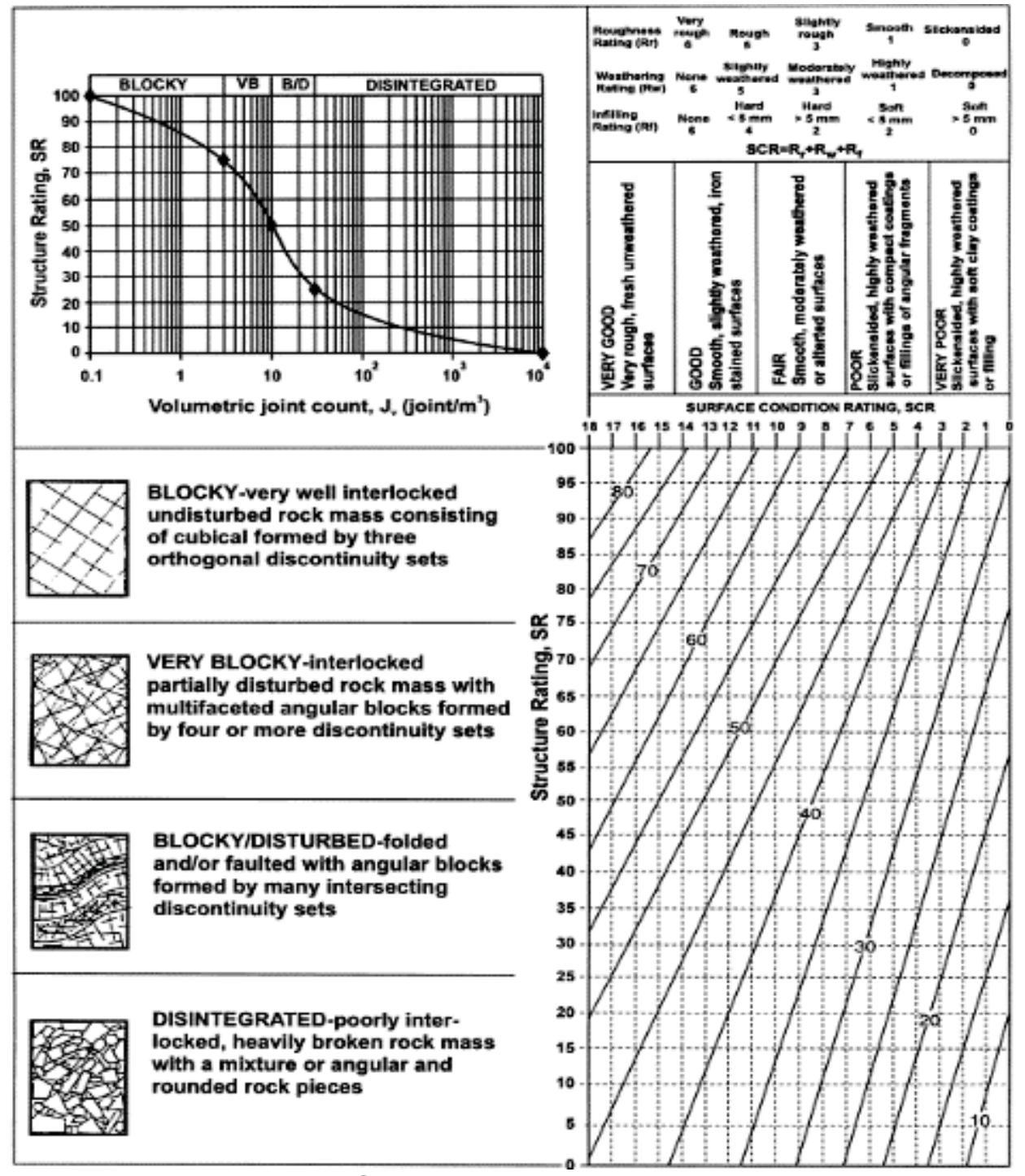

FIGURE 2-4: THE MODIFIED GSI CHART USING VISUAL ESTIMATES OF THE SURFACE CONDITION AND THE STRUCTURE OF THE ROCK MASS (23). THIS SYSTEM ALLOWS FOR MORE PRECISE GSI VALUES TO BE DETERMINED FOR ROCK MASSES.

The RMR requires two in-situ tests, one for the compressive strength of the rock mass, and one for the RQD. When in-situ tests are not available, the RMR can be determined from the GSI. The conversion between the two is provided by:

$$
R M R_{89}=G S I+5
$$


This equation is valid for GSI greater than 18 (20). Figure 2-5 (21) shows the correlation between RMR and GSI values. There are several ways to use the rock mass classification schemes, and different ways to correlate the results from multiple methods (2,27-28).

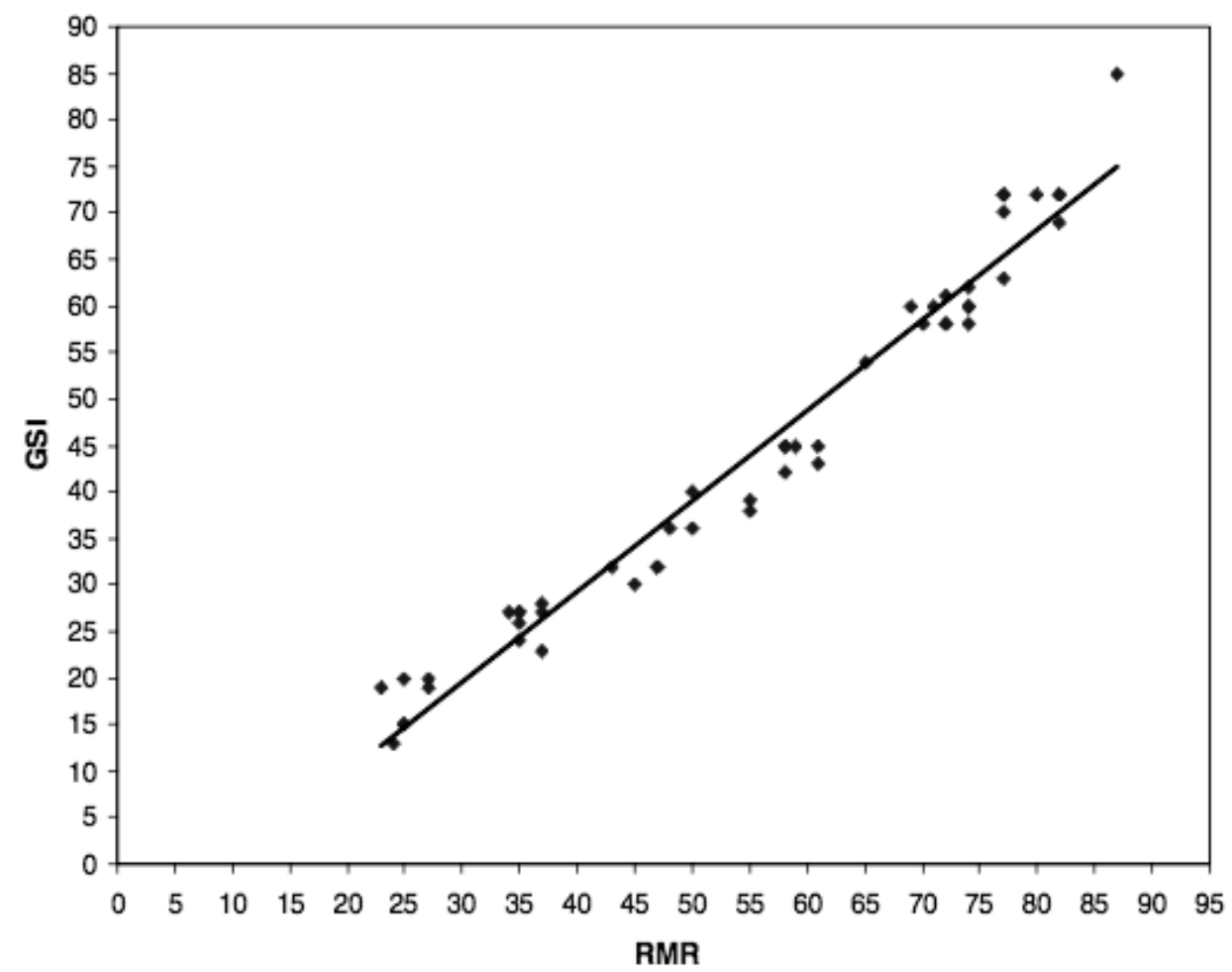

FIGURE 2-5: THERE IS A STRONG CORRELATION BETWEEN GSI AND RMR VALUES (21). THE LINE INDICATES AN EQUATION RMR = GSI + 5 .

While the RMR is acceptable for use in many geotechnical applications, it is not optimized for use on rock slopes for stability analysis. Consequently, the RMR was modified by M. Romana, M. in 1993 for rock slopes to the Slope Mass Rating (SMR) system (29). This system uses the RMR value from Bieniawski (1989) and applies a series of adjustment factors including an excavation factor, as seen in Table 2-4. This method includes probable types of failure, and support measure necessary to predict stability. The adjustment factors include the parallelism between joints and slope face strike, joint dip angle in the planar mode of failure, and the relationship between slope and joint dips. The excavation factor is an empirically fixed value. The values for adjustment factor F3 are taken directly from Bieniawski’s 1976 RMR classification system (30). 
The less subjective nature of the SMR means that it is better adapted to be applied to slopes over a large area. It is possible to know the parameters at a single site, and scale the SMR model to a larger area, or it is possible to use geology-based estimates to apply directly to a large area. Perhaps the most efficient way to accomplish this is through the use of a Geographic Information Software (GIS) system (31). All variables necessary to create a GIS SMR map are available from a digital elevation model (DEM) or are established based on those variables $(3,32)$. SMR maps therefore are a way of identifying the hazard of individual slopes along a transportation corridor. Discrete maps such as these can also be created based on field knowledge or estimated variables. It is important, however, to understand the accuracy of the input parameters, to understand how conservative the SMR values are or are not. It is also possible to use continuous functions, based on a range of values for all parameters, to create an SMR map in a GIS system (33). Continuous function maps have the same level of accuracy as discrete maps at specific failure sites, and make it simpler to create predictive models should site conditions change.

\begin{tabular}{|c|c|c|c|c|c|c|c|}
\hline \multicolumn{3}{|c|}{ Type of failure } & \multirow{4}{*}{$\begin{array}{l}\text { Very } \\
\text { favorable } \\
>30^{\circ}\end{array}$} & \multirow{4}{*}{$\begin{array}{l}\text { Favorable } \\
30-20^{\circ}\end{array}$} & \multirow{4}{*}{$\begin{array}{l}\text { Normal } \\
20-10^{\circ}\end{array}$} & \multirow{4}{*}{$\begin{array}{l}\text { Unfavorable } \\
10-5^{\circ}\end{array}$} & \multirow{4}{*}{$\begin{array}{l}\text { Very } \\
\text { unfavorable } \\
<5^{\circ}\end{array}$} \\
\hline $\mathrm{P}$ & \multirow[t]{3}{*}{ A } & $\left|a_{j}-a_{s}\right|$ & & & & & \\
\hline $\mathrm{T}$ & & $\begin{array}{l}\mid \alpha_{j}-\alpha_{s} \\
-180 \mid\end{array}$ & & & & & \\
\hline W & & $\left|\alpha_{1}-\alpha_{s}\right|$ & & & & & \\
\hline $\mathrm{P} / \mathrm{T} / \mathrm{W}$ & \multicolumn{2}{|l|}{$F_{1}$} & 0.15 & 0.40 & 0.70 & 0.85 & 1.00 \\
\hline $\mathrm{P} / \mathrm{W}$ & B & $\left|\beta_{j}\right| \circ \beta_{\mid \beta} \mid$ & $<20^{\circ}$ & $20-30^{\circ}$ & $30-35^{\circ}$ & $35-45^{\circ}$ & $>45^{\circ}$ \\
\hline $\mathrm{P} / \mathrm{W}$ & \multirow{2}{*}{\multicolumn{2}{|c|}{$F_{2}$}} & 0.15 & 0.40 & 0.70 & 0.85 & 1.00 \\
\hline T & & & 1.00 & & & & \\
\hline$P$ & \multirow[t]{3}{*}{ C } & $\beta_{\mathrm{j}}-\beta_{\mathrm{s}}$ & \multirow[t]{2}{*}{$>10^{\circ}$} & \multirow[t]{2}{*}{$10-0^{\circ}$} & \multirow[t]{2}{*}{$0^{\circ}$} & \multirow[t]{2}{*}{$0-\left(-10^{\circ}\right)$} & \multirow[t]{2}{*}{$<\left(-10^{\circ}\right)$} \\
\hline W & & $\beta_{1}-\beta_{\mathrm{s}}$ & & & & & \\
\hline T & & $\beta_{\mathrm{j}}+\beta_{\mathrm{s}}$ & $<110^{\circ}$ & $110-120^{\circ}$ & $>120^{\circ}$ & - & - \\
\hline $\mathrm{P} / \mathrm{T} / \mathrm{W}$ & $F_{3}$ & & 0 & -6 & -25 & -50 & -60 \\
\hline \multicolumn{8}{|c|}{ Excavation method $\left(F_{4}\right)$} \\
\hline \multicolumn{3}{|c|}{ Natural slope } & +15 & \multicolumn{3}{|c|}{ Blasting or mechanical } & 0 \\
\hline \multicolumn{3}{|c|}{ Presplitting } & +10 & \multicolumn{3}{|c|}{ Deficient blasting } & -8 \\
\hline \multicolumn{3}{|c|}{ Smooth blasting } & +8 & & & & \\
\hline \multicolumn{8}{|c|}{$\begin{array}{l}\mathrm{P} \text { : planar failure; T: toppling failure; W: wedge failure. } \alpha_{\mathrm{j}} \text {. dip direction of the discontinuity; } \alpha_{\mathrm{s}} \text { : dip } \\
\text { direction of the slope; } \alpha_{\mathrm{i}} \text { : dip direction of the intersection line of two sets of discontinuities; } \beta_{\mathrm{j}} \\
\text { discontinuity dip; } \beta_{\mathrm{i}} \text { : angle of plunge of the intersection line of two sets of discontinuities; } \beta_{\mathrm{s}} \text { : slope } \\
\text { dip. }\end{array}$} \\
\hline
\end{tabular}




\subsubsection{Remote Sensing}

Remote sensing is a well-established technology that includes LiDAR, INSAR, and optical photogrammetry, among others. Applicable to many different fields, there has been significant research into the use of remote sensing technologies in the geotechnical fields (6-8). These different techniques can be used stand alone or in combination with each other to determine a wide variety of useful surface characteristics of a rock slope. These techniques have been proven to be faster and safer than manual field estimates, and provide more accurate characterization of the rock masses being studied (35). There are many studies (3639) on how remote sensing technologies can be used by transportation agencies to analyze transportation corridors for hazards due to rock slope failures.

LiDAR has two main capture methods, airborne and terrestrial scanning, which can be further separated into mobile and stationary scanning. Both methods can produce high quality datasets, called point clouds, of the surface they are mapping. It is important to take into consideration the angle from which the laser is oriented to the slope face in order to achieve the best image. A benefit of terrestrial laser scanning is the ability to capture dense point clouds even from a large distance, which enables the identification of smaller structures in the rock face (35). Static laser scanning along transportation corridors is the traditional method, and has a demonstratively proven track record of successful analysis (Figure 2-6). Mobile LiDAR has recently been utilized in this capacity, and, while innovative, still requires more research before becoming a standard (40).

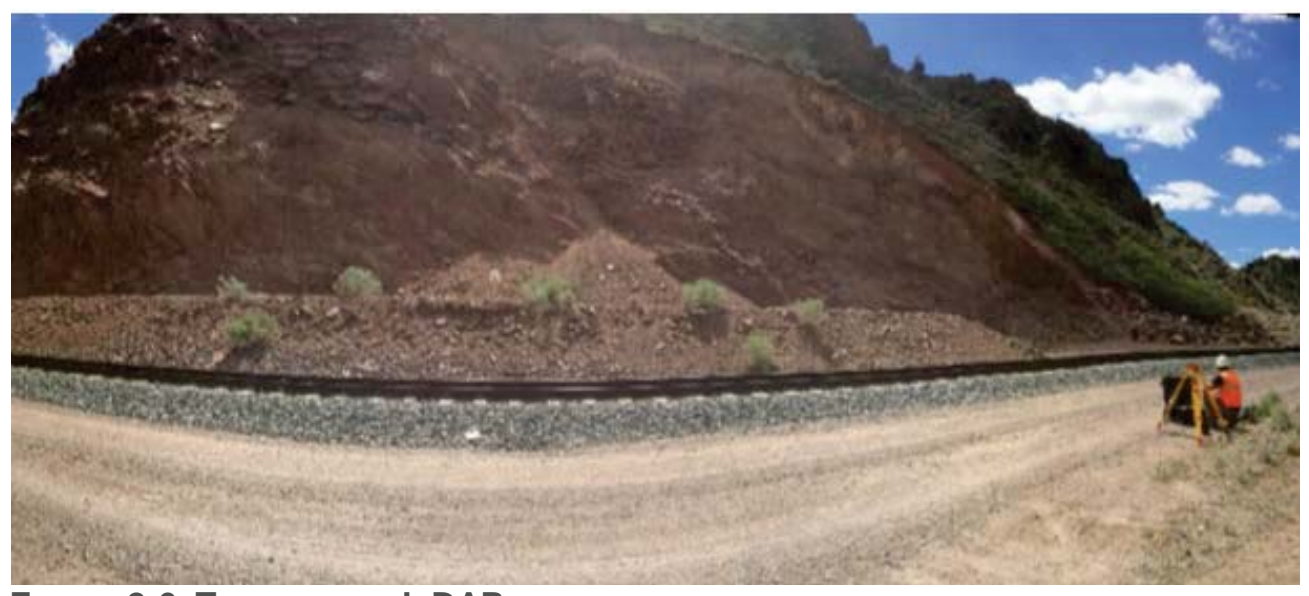

FIGURE 2-6: TERRESTRIAL LIDAR SCANNER USED AT THE STUDY LOCATION IN SOUTHERN NEVADA. THIS IS A STATIC SCANNER, AND WAS SET UP TO SCAN THE ENTIRE SLOPE HEIGHT. LOCATION MUST BE ADJUSTED TO SCAN THE ENTIRE LENGTH OF THE 
Optical photogrammetry can be performed with non-specialized equipment, but is heavily influenced by shadows and changing light conditions.

Photogrammetry is able to capture more of the site, and is able to access multiple angles, which LiDAR might not be able to scan. Photogrammetry requires ground control points at the site for reference and scaling objects A noteworthy benefit for using photogrammetry is that the point clouds are already rendered in true-color RGB (red, green, blue) color space. This distinction allows for easier identification of geological and structural features. Photogrammetry also offers advantages in cost and ease-of-use over LiDAR, with commercial equipment and software available, and light, more portable equipment than laser scanners (41). Photogrammetry can be captured either from the ground, or from the air using manned (helicopter) or unmanned flight vehicles, such as the unmanned aerial vehicle in Figure 2-7.

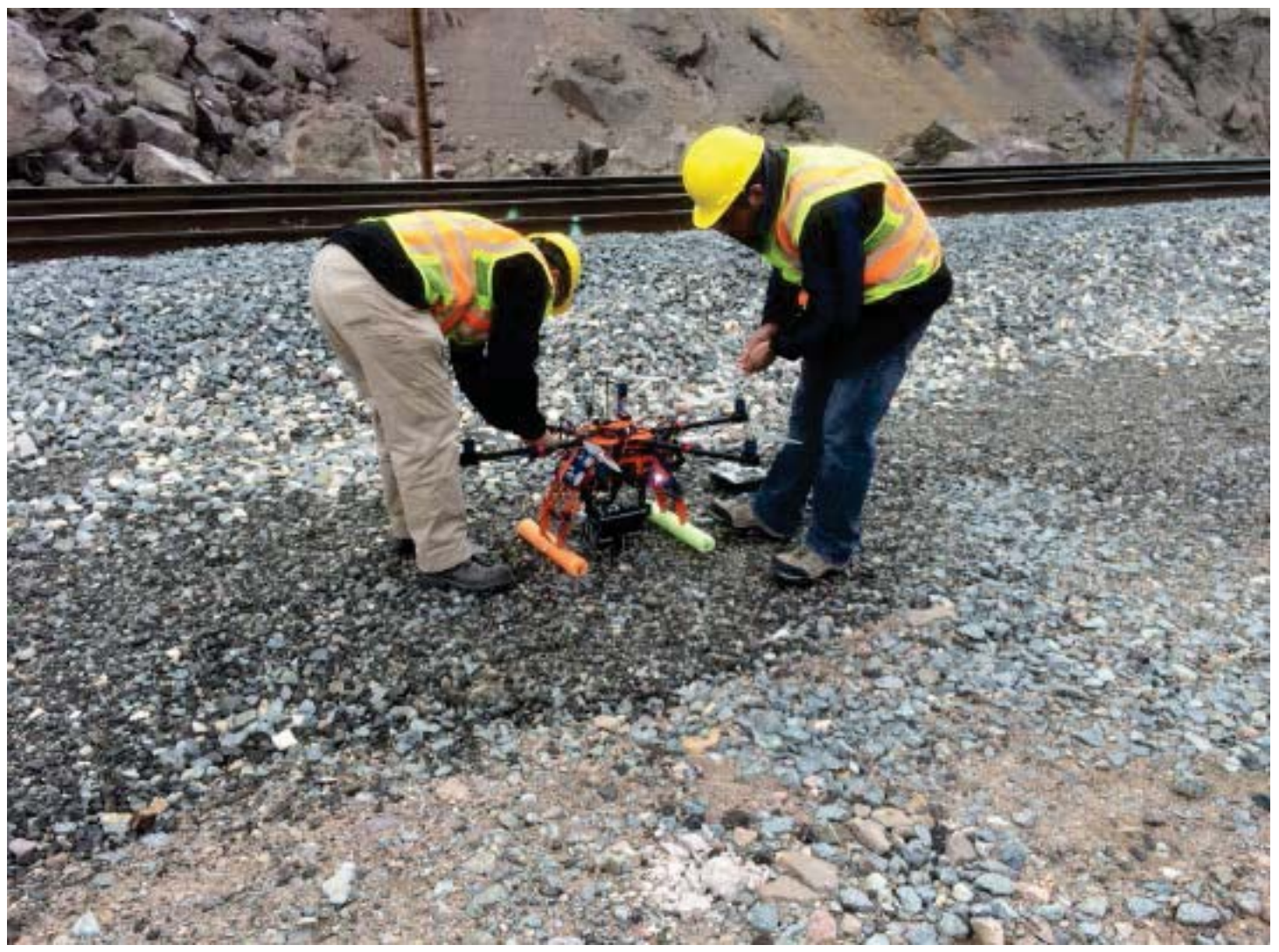

FIGURE 2-7: OPTICAL PHOTOGRAMMETRY SET-UP USE AT THE STUDY SITE LOCATION IN SOUTHERN NeVAdA. THE CAMERA WAS ATTACHED to AN UNMANNED AERIAL VEHICLE, TO CAPTURE THE SLOPE FROM ABOVE. 
The information from the remote sensing data can be used to create stereonets, digital elevation models (DEMs), kinematic stability models, and a wide variety of other useful tools for geological and geotechnical investigation. Much of this information can be used as input data for rock property and for modeling rock slope failures (19). This information can be used to establish a relative hazard rating system that can be applied along transportation corridors.

Remote sensing has been optimized to assess geomorphological information, but there has been some research into the use of remote sensing to quantify geological information (42-43) such as rock type. In some cases, LiDAR is capable of distinguishing between different rock types in a rock slope. This is done through scanner intensity measurements correlated with known wavelengths of different rock types. This is relatively new use for LiDAR technologies, and should be used in conjunction with field studies. There is also a way to distinguish between rock types based on thermal information. Infrared Radiation temperature and infrared radiation spectral radiation intensity are the key properties in the new field of remote sensing rock mechanics (RSRM). RSRM is used as a measure to identify and forecast mechanical rock failures based on earthquake data. This method should also be used with other, more proven methods, until more research can be performed.

Structural feature extraction is possible from LiDAR and photogrammetry point clouds (44). In most cases, the spatial resolution of these point clouds allows for the identification of both macro- and microstructures. Macro-structures can be identified even in lower resolution images, and are typically the controlling features for slope stability. Microstructures can heavily influence the failure type and damage, but require a finer resolution image for identification. Joint persistence and spacing are determining factors in the type and severity of rocky slope failures. It can be difficult to measure the true persistence of a joint in the field, resulting is underestimations of the rock mass strength (45). Using remote sensing, discontinuities of medium persistence can in some cases be identified, which might not be able to be identified during field investigations. The discontinuities can also be measured for their orientation and the overall joint density. The joints are manually identified and extracted from the point clouds (46). Both techniques are capable of determining the orientation of the discontinuities that they identify, and can measure failure planes that are unfavorably oriented with the slope face. An example of an unfavorably oriented rock fractures is illustrated in the photo in Figure 2-8 B. Photogrammetry point clouds can help identify qualitative 


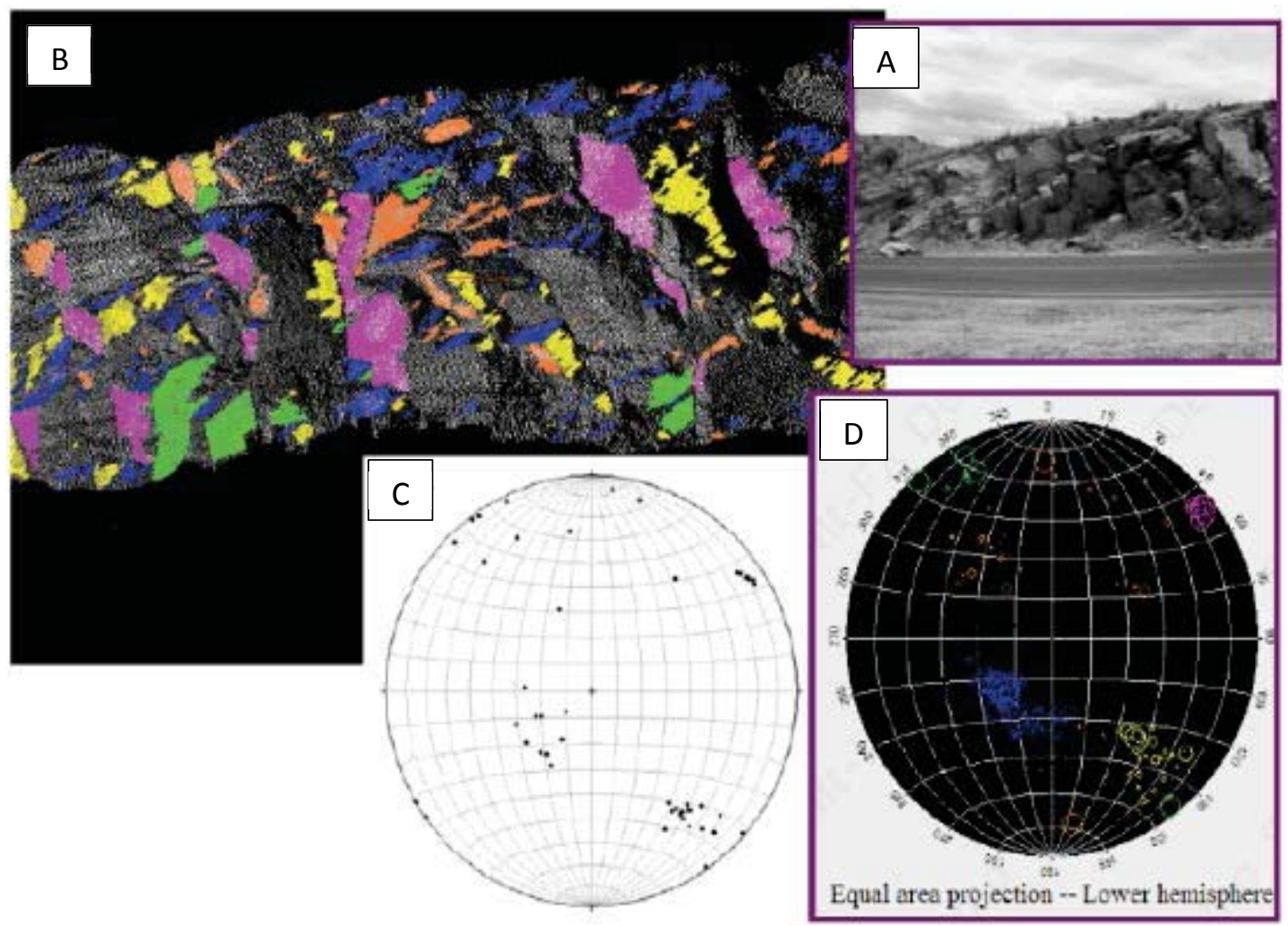

Figure 2-8: The Federal Highway Administration's uSE OF LiDAR to DETERMine STRUCTURAL DISCONTINUITIES IN OUTCROPS (48). A, PHOTOGRAPH OF AN OUTCROP SCANNER BY LIDAR, $B$, STRUCTURAL FEATURES EXTRACTED FROM THE LIDAR POINT CLOUD, $C$, STEREONET OF FIELD MEASURED DISCONTINUITIES, D; STEREONET OF LIDAR MEASURED DISCONTINUITIES.

information of a rock slope based on color, including joint infilling, joint roughness, and surface weathering.

The point clouds can also be transformed into high-resolution digital elevation models (HRDEMs) that can be imported into geographic information software such as ArcGIS. The HRDEMs can be created since the point clouds have a high point density relating to measured elevations. Currently, the resolution of the HRDEMs can achieve an accuracy on a ten cm scale, significantly higher resolution than publicly available DEMs at 10- and 30-m resolutions. Highly accurate slope profiles can then be generated from the HRDEMs, along with geometry maps of the site, such as slope aspect and angle. Pseudo-3D images show good detail, and can assist in the identification of structural features.

At sites that meet the requirements for use of the different remote sensing techniques, LiDAR and optical photogrammetry both return accurate results within 
their respective spatial resolutions. Terrestrial laser scanning can combine well with photogrammetry to enhance the final product of both techniques. They have similar abilities to access slope conditions that allow for fusion of the two point clouds (35). There are two general types of major structural discontinuities on rock slopes, fracture traces and fracture surfaces, called 'traces' and 'facets,' respectively (48). LiDAR is optimized to capture the facets, while optical photogrammetry is best at identifying the traces. In order to detect both types of discontinuities in the rock face, LiDAR and photogrammetry can be used in concert. The point clouds generated by both techniques can be registered to each other to correctly orient the data. The structural features can then be measured from the combined point cloud. This method provides a way to overcome the limitations of each specific method, without compromising their own abilities (49).

Both types of remote sensing, however, have a significant drawback in the fact that even minimal vegetation can obscure the rock face and can cause "noise" in the point clouds. It is very important to take measurements with both LiDAR and optical photogrammetry at multiple angles to the slope face. This helps generate the most accurate slope geometry and limits the amount of occlusions, areas of missing information, in the point clouds (26). Another potential drawback for large-scale use of the remote sensing technologies is the user-intensive requirements for data processing. The extraction of geologic and structural features is time-consuming and subject to user error. There has been some research into the automation of feature extraction and analysis (49-50). It is important to understand that, other than measurable properties such as persistence, information on rock properties is qualitative in nature, and should be verified with field investigations when precise values are required. 


\section{Study Site - Southern Nevada rock slope}

\subsection{Study Site Location}

The case study site is located along a railway in southeastern Nevada and is illustrated in Figure 3-1. The railway is located within a small canyon where it is aligned along a small creek. There are two significant rock slope failure located along railroad. The transportation assets in the area are the railroad tracks and the access road, while the geotechnical assets are the cut slope, the embankment, and the railway tunnels. The case study investigated a 25 mile stretch of railroad, which is identified by a blue box in Figure 3-1. The yellow marker indicates where Slides 1 and Slide 2, which are relatively close together are located in the corridor. A third

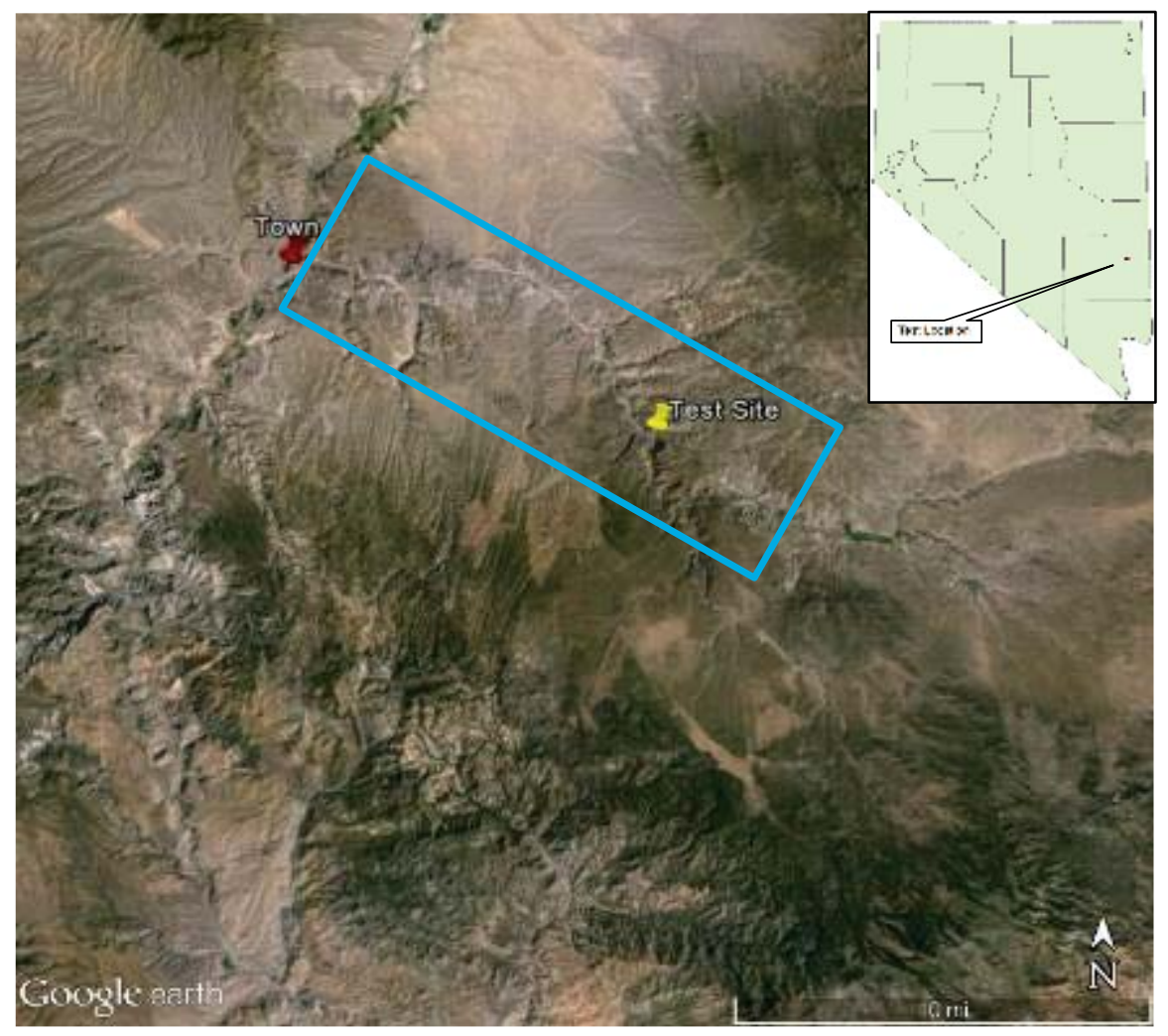

FIGURE 3-1: LOCATION OF THE TRANSPORTATION CORRIDOR AND STUDY SITES. INSET IS THE LOCATION IN THE STATE OF NEVADA.

slide (Slide 3) was also included in the study but was not visited during the initial field work in May 2014. Slide 3 is loacted further south along the railroad, and was chosen as a "undocumented site" for analysis 
The main slope failure, Slide 1 , is the result of excavation work performed in 2006 using explosives. The slope's inclination is approximately 65 degrees from horizontal, and the slope averages between 70 and 120 feet in height. Above the area of the slope failure, the slope has an inclination of 20 to 30 degrees above horizontal, and is an additional 120 feet in height. The nearest the toe of the slope is to the railway tracks is approximately 70 feet, while an access road is located between the railway and the slope, immediately adjacent to the rail (51).

In May 2011, a large landslide occurred, after several years of slope deformation being observed. The slide covered the entire width of the cut slope, and “extended approximately 100 feet horizontally up the slope” (51). The debris from the rock slide completely filled the catchment ditch, and encroached the access road. No major damage was done to the railroad tracks. The slide encompassed a total of 300 feet in width, and 175 feet in height, from the toe to the resulting head scarp. The railroad agency installed a 10-foot high multi-wire fence after the rock slide as prevention measure. Field monitoring has shown slope movements are still occurring at the site.

Less than one mile south of Slide 1 is Slide 2. This slope failure is similar to Slide 1 , in that it is also on the southwest facing side of the canyon, and also was subject to blasting excavation in 2006. It has not caused any problems with the railroad or access road in the past, although it continues to have rock falls. At this site, however, the falling rock blocks are relatively small and are contained in a berm surrounding the slide.

\subsection{Geology}

The geology of the study area consists of sediments of Quaternary alluvial deposits, while the rock types include volcanic tuffs, sedimentary, metamorphic, and intrusive igneous rocks. Tertiary age rocks, volcanic and sedimentary, are the most common (52). It is known that the buildup of volcanic rock in southeastern Nevada averages 3,000 feet thick, with localized areas reaching up to 10,000 feet thick. (53). 
The alluvial deposits in the basins are present in a narrow strip in the center of the valley. The bedrock on the slopes is exposed and there is little to no vegetation. Because the area is a main drainage path for the adjacent mountains, the sediments are deposited in the middle of the valley, while the sides are kept relatively free. The creek along the railroad, which runs through the center of the valley is fed primarily from several large springs at its head, and intermittently through surface runoff. The rock mass is mostly felsic to intermediate volcanic rocks, of middle Tertiary age with tuff sediments interbedded with the volcanic units (54), as seen in Figure 3-2.

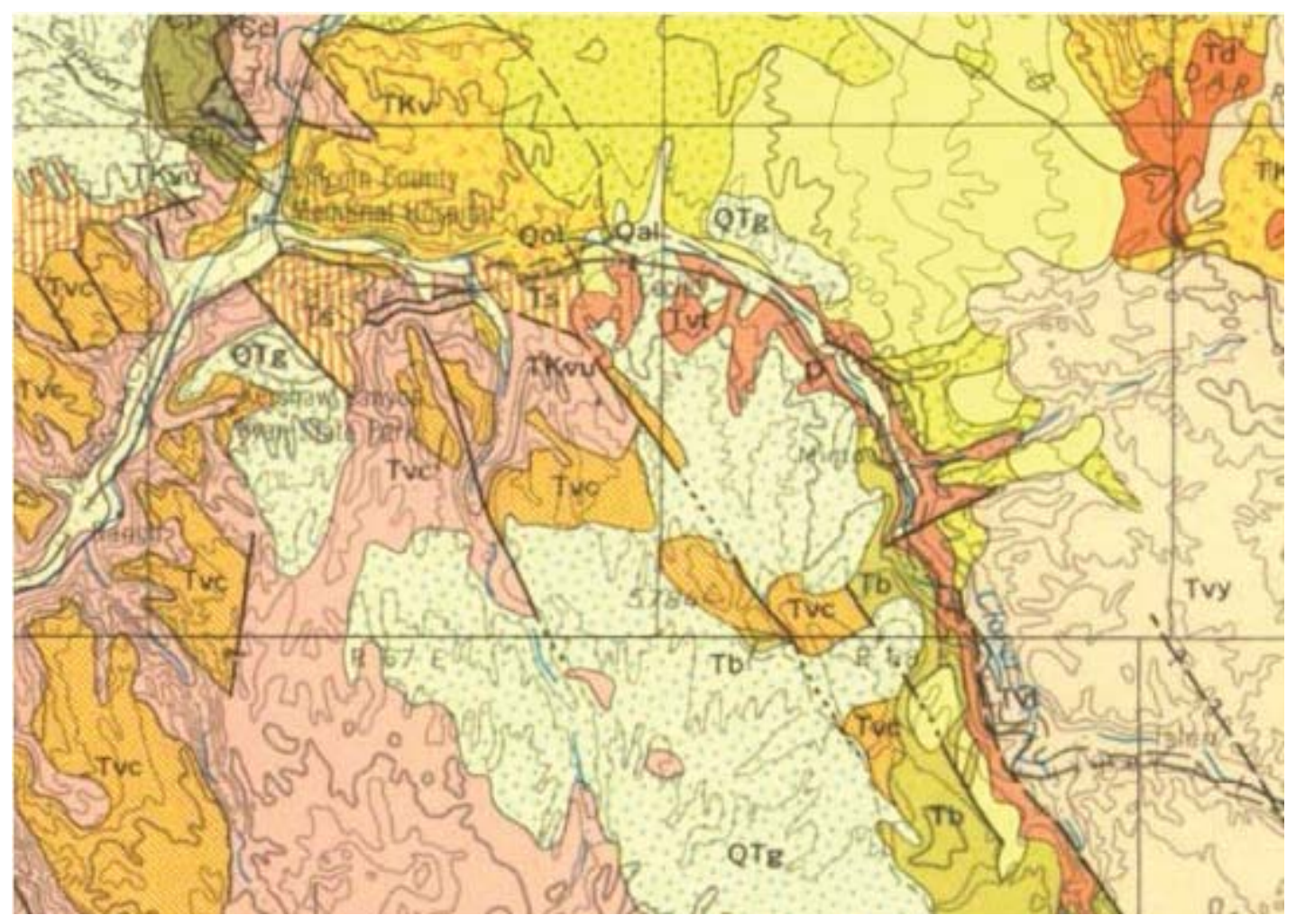

Figure 3-2: NeVADA BUREAU OF Mines GEOLOGY MAP OF THE TRANSPORTATION CORRIDOR AND STUDY SITES (55). THICK BLACK LINES INDICATE FAULT STRUCTURES. THE STUDY SITES ARE LOCATED IN THE TVY FORMATION, WHICH INDICATES VOLCANIC ROCKS, AND THE TVT FORMATION, WHICH INDICATES TUFF SEDIMENTS.

Specifically, the two rockslides at the study site are comprised entirely of the Tertiary volcanic rock. There are two varieties of bedrock, a rhyolite tuff and welded tuff breccias (Tvtw), and a white, crystalline welded tuff (Tvt). Shannon and Wilson, Inc. in their 2011 Rock Slide Report measured the details of the site geology (51). The main rock slide for Slide 1 study occurred in the rhyolite tuff and 
welded tuff breccia. The contact between the two units creates the head scarp for Slide 1. The geology is the same for Slide 2, as seen in Figure 3-3. The rock varies from low to moderate strength for the rhyolite tuff to moderate to high strength for the crystalline welded tuff. The crystalline tuff is found in a 100-foot thick band across the top of the head scarp. The units Tvt and Tvtw are bounded between the alluvial sediments at the center of the valley, and the geologic unit Tvy, undivided volcanic rocks. This is a relatively high strength rhyolite mixed with a low strength yellow tuff. This unit is much more prevalent than the Tvt or Tvtw, and is significantly less weathered than the other two units. An older landslide can be seen in this unit, suggesting that all the volcanic units in this area are prone to some rock failures. The 2011 landslide at Slide 1 is seen in figure 3-3, and occurred in the Qls rock formation. It is immediately north of a fault also seen in Figure 3-3.

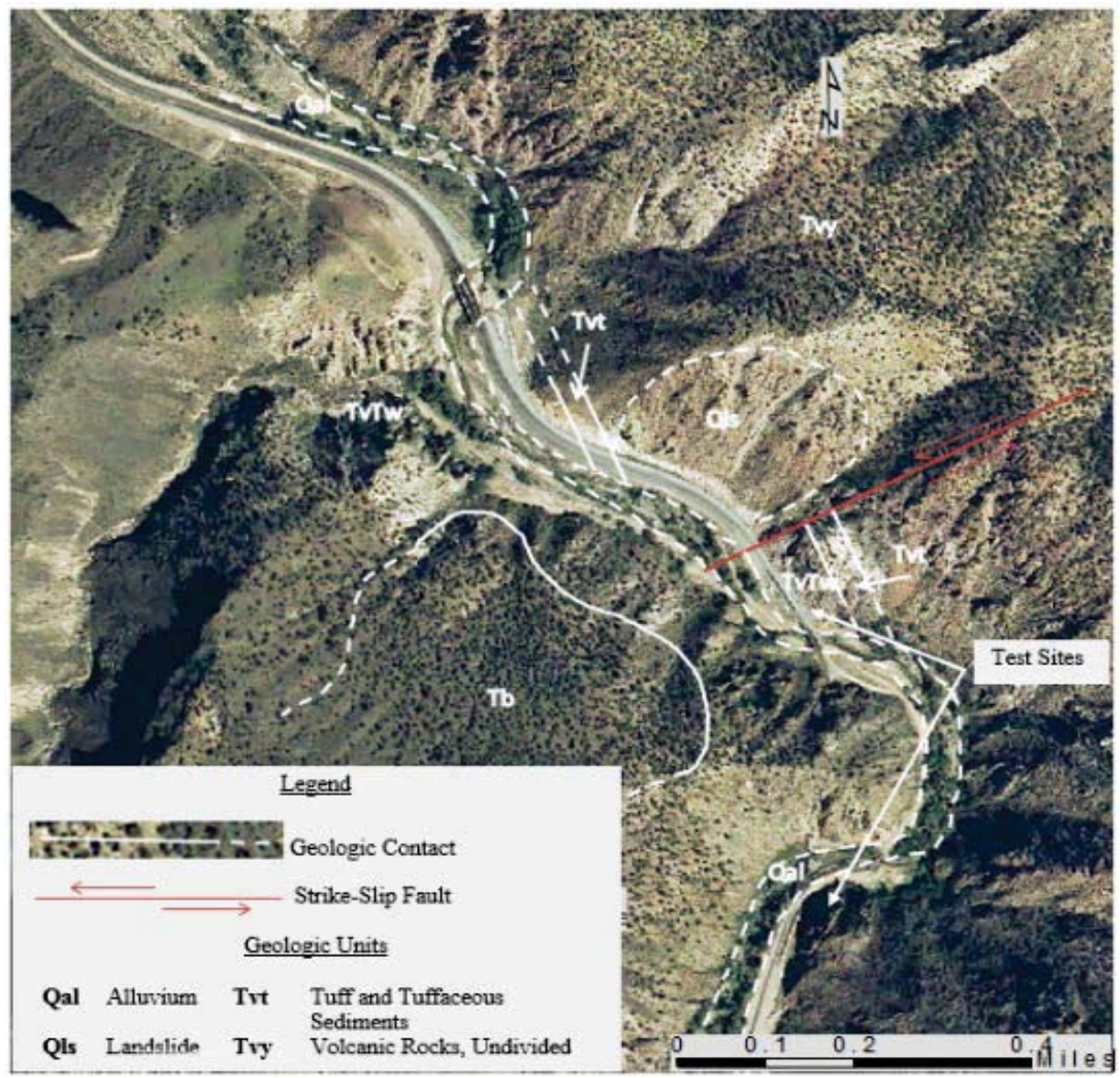

Figure 3-3: ReleVANT Geology mAP OF THE STUdy Sites SLIDE 1 AND SLIDE 2. 
The geology is similar on both sides of the creek, and throughout the approximately 25-mile stretch of railroad corridor that delineates the study area (51). The only other geologic unit identified in this area is a Tertiary basalt (Tb). Basalt deposits in this region are generally limited in thickness and distribution, and have little effect on the regional hydrology (54).

\subsection{Rock Structure}

A field investigation was performed on Slide 1 after the 2011 rock slide, along with monitoring of the site using terrestrial LiDAR. The field investigation identified the rock structure of Slide 1, and the ongoing LiDAR data was used to verify the movement of the slope since 2011. Though the use of LiDAR (47,56-57), and photogrammetry (2), it has been determined that the combination of LiDAR and photogrammetry $(15,57-58)$ results in the best possible image for identifying discontinuities and their orientation. This is generally accepted to be a manual, user intensive process, though advancements are being made in automatic registration of discontinuities (35). For the purposes of this study, the use of a blend of photogrammetry and LiDAR was used to verify the field tests measurements, in order to show that remote sensing can be used for future hazardous sites.

The field mapping revealed the structures that were contributing to the continual rock slope movements. Only surface observations were made, no geotechnical borings were performed. Point-load tests were performed at a number of locations on several different rock types. The field work focused on the discontinuities that were observed at the surface. This is because the field work needed to correlate with the observations that can be made with remote sensing technologies, which are limited to surface observations. All of the properties, such as discontinuity orientation and surface roughness, are required for the RMR and SMR analysis for the strength and stability of the slope.

The field mapping classified rock structure into two types, major structure, such as faults and shear zone, and minor structure, such as surface discontinuities. For example, the major structures can easily be seen in LiDAR and photogrammetry point clouds, while the minor structures are more difficult to identify.

Since there is a significant amount of rock structure at Slide 1, this results in a high potential for rock blocks to form, which are critical to the stability of the slope. The important item to note about the discontinuity orientation is whether it is favorably or unfavorably oriented in respect to the slope face. Adverse orientations 
have the potential to form kinematically admissible rock blocks with other rock structures. The major rock structures are the controlling factor in the size of the rock slope failure. The rock properties of each joint set can influence whether failure will occur, though the size of the failure is mostly dependent on the major structure.

There is one fault at the western boundary of the rock slide. This fault is a left-lateral strike-slip fault striking southwest-northwest. It is a very highly persistent fault, on the order of several thousand feet, and is greater than 10 feet in width. The filling is crushed rock down to soil-size material.

There are three shear zones in the area. Shear zone 1 is very highly persistent with planar, smooth discontinuity surfaces. The JRC is 5 . The shear is approximately two four feet wide and is filled with fractured volcanic rock. This zone is favorably oriented with the slope face. Shear zone 2 is highly persistent with rough, undulating surfaces $(J R C=20)$. Shear 2 does form kinematically admissible wedges with several of the minor rock structures. Shear zone 3 is very highly persistent with rough, undulating surfaces $(\mathrm{JRC}=20)$. This shear is also favorably oriented with the rock face. Figure 3-5 shows the locations of all the major structures.

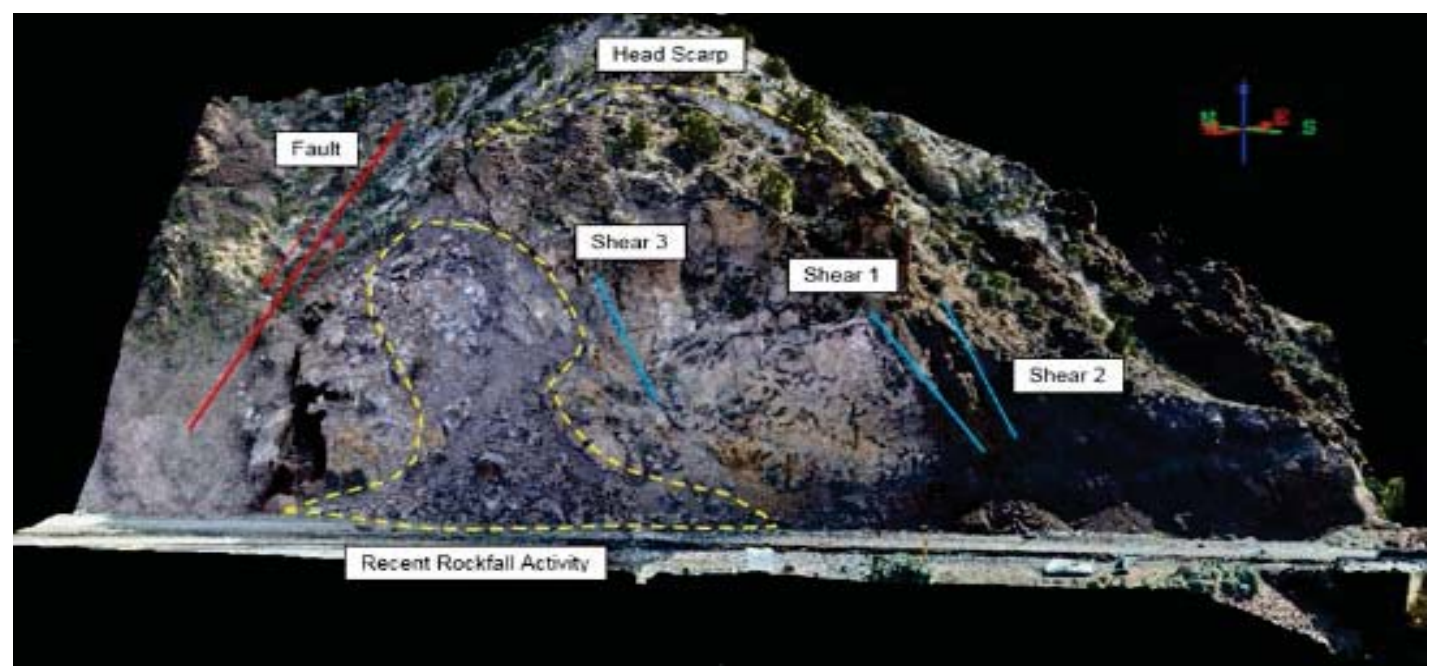

FIGURE 3-4: LOCATION OF MAJOR ROCK STRUCTURES FOR SLIDE 1, INCLUDING THE AREA THAT FAILED IN 2011.

The minor rock structures are surface discontinuities, are generally not persistent as are the major structures. These structures are grouped into sets with similar joint orientations. The six sets are plotted on the stereonet in shown in 
Figure 3-6. Set 1 is favorably oriented with the rock slope, but is a release joints for a plane shear failure in sets 2 and 5, and can form wedge failures with sets 2 and 3 . Set $2 \mathrm{~A}$ is unfavorably oriented with the rock slope, and forms the head scarp that developed after the 2011 rock slide. It forms plane shear failures. Set 2B forms wedge failures with set 3 . Set 3 forms wedge failures with set 2 , and has similar orientations to shear zones 1 and 2. Set 4 is favorably oriented for slope stability, but forms a release joint for plane shear failures in sets 2 and 5 , and forms wedge
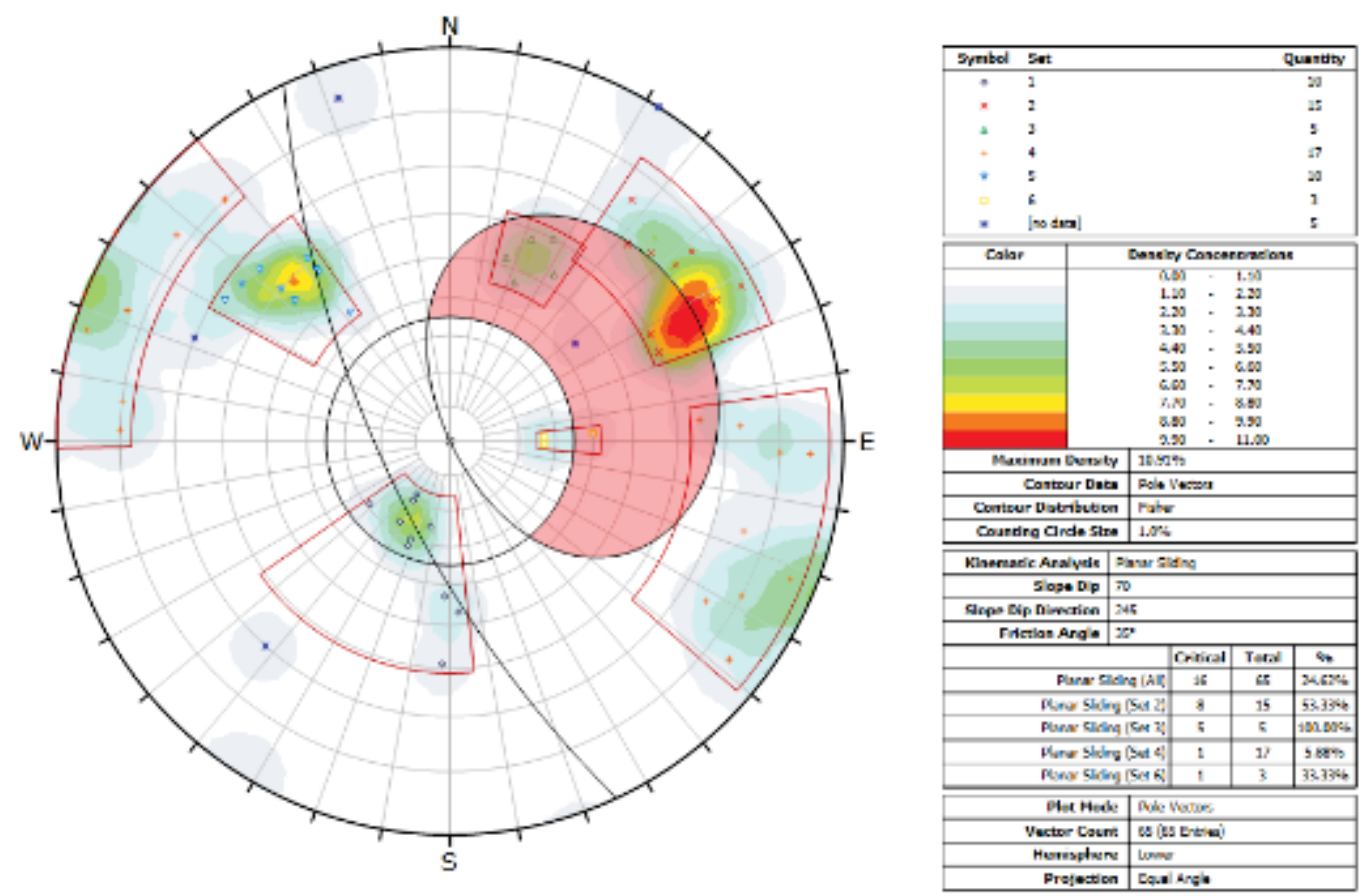

FIGURE 3-5: SLIDE 1 STRUCTURES PLOTTED, WITH THE PLANAR FAILURE AREA HIGHLIGHTED. THIS STEREONET WAS CREATED USING ROCSCIENCE DIPS SOFTWARE, AND MATCHES VERY WELL WITH STEREONETS CREATED FROM FIELD MEASUREMENTS.

failures with sets 3 and 5 . Set 5 is unfavorably oriented for slope stability and forms plane shear failures.

Slide 2, shown in Figure 3-7 has less rock structures then Slide 1 and has generally more favorably oriented structure with the slope face. The slope face runs nearly parallel to the railroad tracks at this location, and has two faults that strike parallel to the slope face. Their dips are very similar to each other, diverging slightly. Both faults are rough and undulating, with very little infilling. Fault 1 is slightly more weathered than fault 2, likely due to the gulley running from the top of the slope, which intermittently fills with water during the wet season. 

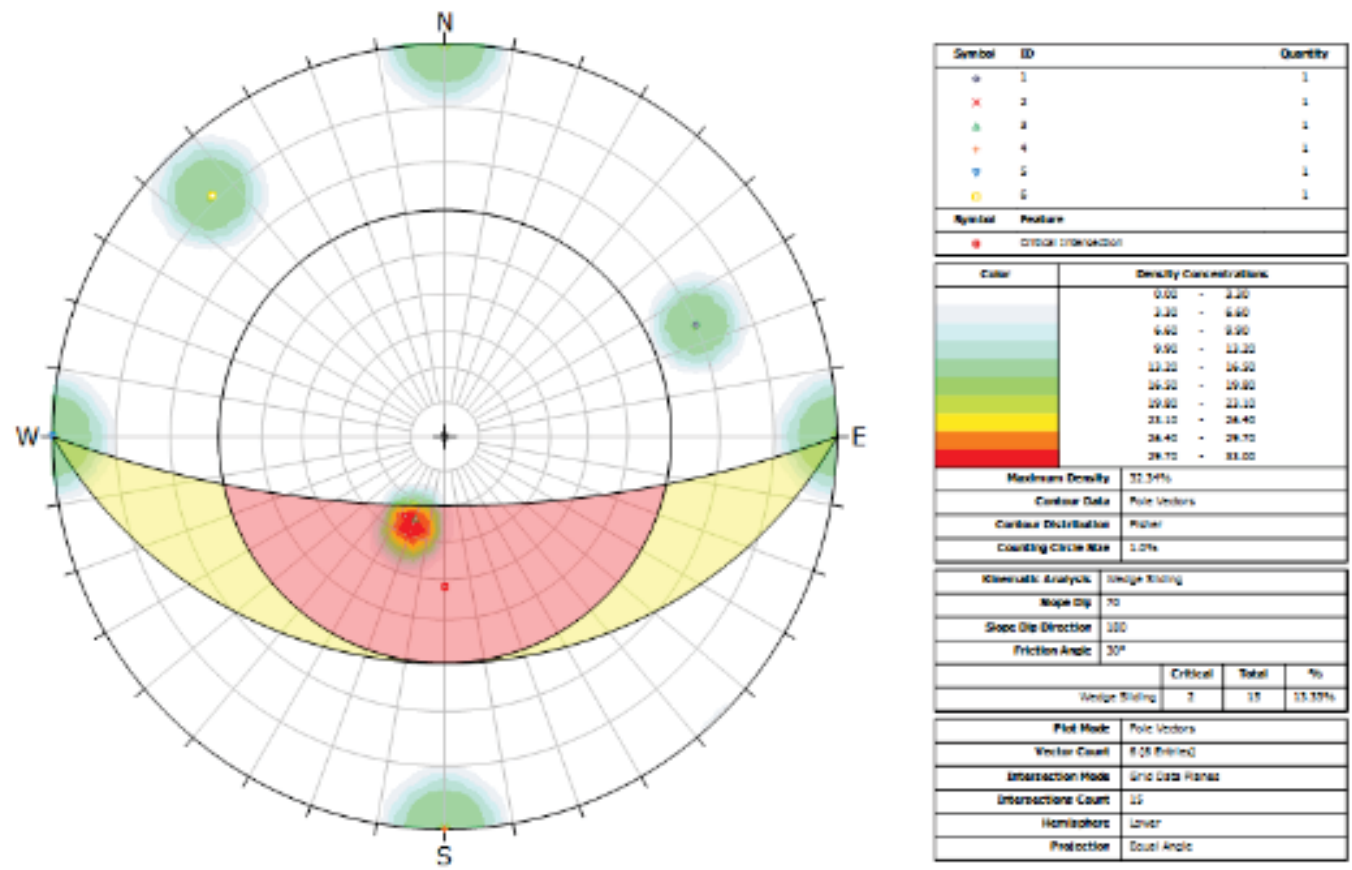

FIGURE 3-6: SLIDE 2 STRUCTURES PLOTTED, WITH WEDGE FAILURE AREA HIGHLIGHTED. IT CAN BE SEEN THAT SLIDE 2 HAS COMPARATIVELY FEWER STRUCTURES THAN SLIDE 1.

Slide 2 also has three joint sets. Joint set 1 and 2 are orthogonal to each other, and both have relatively low volumetric joint counts. The joints are smooth, but not very weathered and have no infill. Set 3 has a very low volumetric joint count, very little weathering, and moderate infilling. The joints at Slide 2 are forming very cubic rock blocks, as seen in Figure 3-8. The vertical joint can be seen repeated across the entire slope face. 


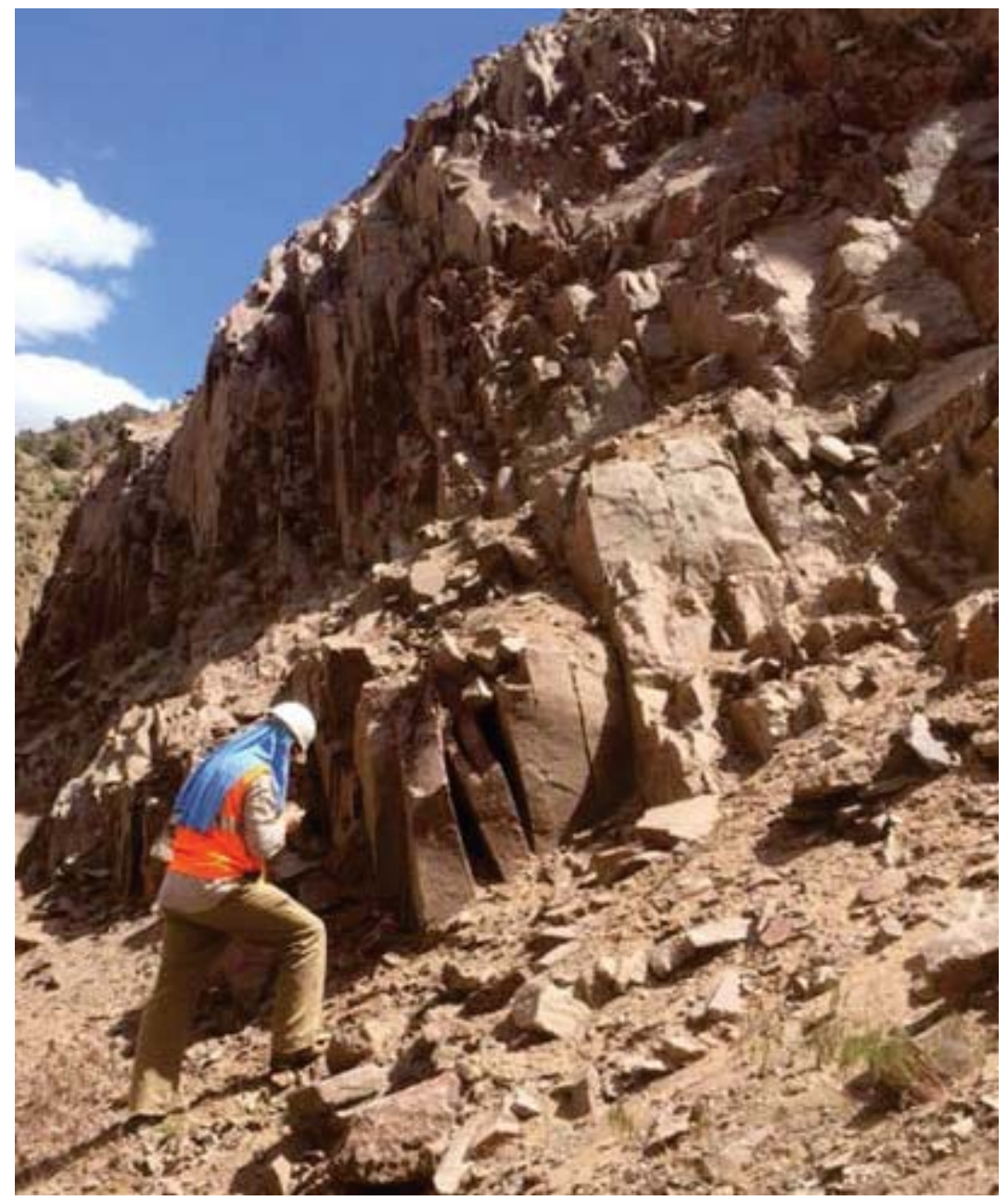

FIGURE 3-7: ROCK STRUCTURES AT SLIDE 2 CAN BE SEEN IN THIS PHOTOGRAPH. ONE OF THE MAJOR STRUCTURES IN THE ALMOST VERTICAL PLANE. ROCK BLOCKS APPEAR TO MOSTLY BE FAILING ALONG THIS PLANE.

\subsection{Slope Excavation Effects}

Prior to the rock excavation at Slide 1 site, the toe of the rock slope was just a few feet away from the railroad tracks. The space was too narrow for the access road to go between the tracks and slope. In an effort to widen the space between the tracks and slope, the rock slope was excavated in 2006 using explosives. In addition to increasing the area between the railroad track and the slope, the slope was excavated for a source of riprap and to improve the stability of the railroad slope adjacent the creek. The excavation work in 2006 was performed using drilling and 
blasting techniques, and was completed over the course of the first half of 2006. The existing cut slope inclination ranged from 65 to $70^{\circ}$. The design of the excavated cut slope was $0.5 \mathrm{H}: 1.0 \mathrm{~V}$ or $63^{\circ}$.

Observations by agency personnel indicate that slope movements began soon after excavation work was complete. However, it was not until May 2011 that a large rock slide occurred on the western side of the slope. Small slope movements, measured in the field, have continued since the 2011 rock slide (51).

Blasting was also performed on Slide 2, under similar conditions. The blasting at this site opened the many tension cracks in the slope, but otherwise successfully excavated the slope, and created a catchment berm. The release of pressure on the tension cracks is slowly causing them to topple-over, but the blasting has not led to any significant problems for the railroad.

\section{Methodology Applied to the Transportation Corridor}

LiDAR data collection has been performed annually at Slide 1 since the major landslide, while optical photogrammetry was taken in 2014. Point clouds were generated from both data sets. Field tests were conducted to compliment the remote sensing for verification purposes. Slide 2, which does not pose a significant threat to the railroad or access road, had optical photogrammetry taken in May 2014 but has no LiDAR data. The most recent data collection, using remote sensing and traditional field techniques, was in May 2014, and the point clouds from that trip are the main source of information for this analysis. The methodology is laid out in the flowchart in Figure 4-1.

\subsection{Initial Conditions Assessment}

Figure 4-1 illustrates the methodology used to analyze the rockfall hazard for the 25 mile transportation corridor. The methodology requires, a digital elevation model was, which in this study was obtained from the National Elevation Dataset, with a resolution of 10 meter. To narrow the focus of the search criteria, initial conditions were chosen to represent the exposure risk. This is the risk that a hazardous slope failure would interact with the transportation infrastructure. These conditions were chosen to represent the corridor in question and to meet the rock 
fall hazard requirements. In general the initial conditions will include the following three criteria: (1) a bounding area on either side of the railroad, (2) the slope angle (59), which is an indication of the potential stability of the slope, and (3) the Heightto-Length $(\mathrm{H} / \mathrm{L})$ ratio (60-62), which serves as an indicator of slope failure propagation. These criteria allow the transportation agency to delineate an area from which a slope hazard might exist and are discussed in more detail below

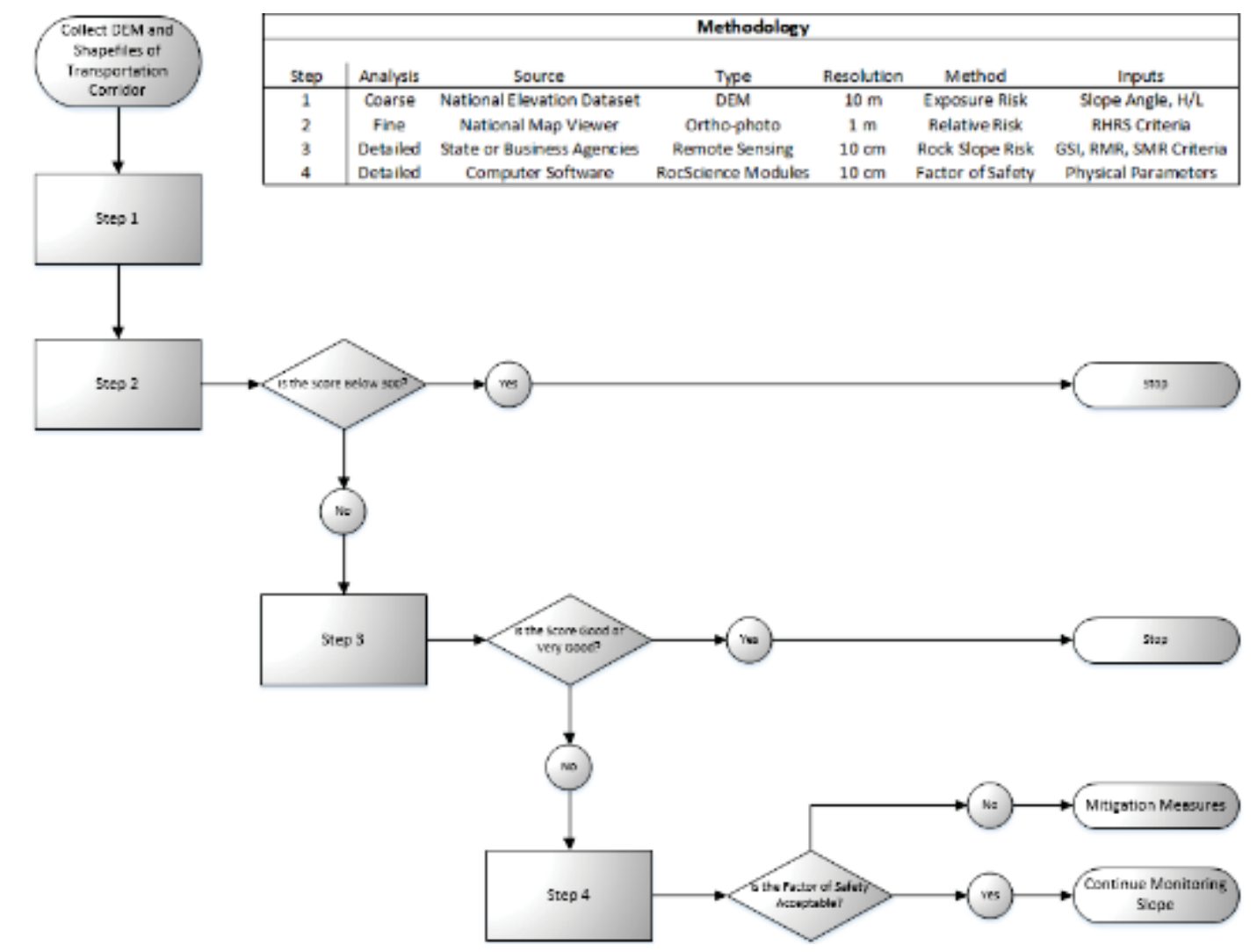

FIGURE 4-1: METHODOLOGY FLOWCHART FOR DETERMINING THE HAZARD SCORE AND STABILITY OF A ROCK SLOPE ALONG A TRANSPORTATION CORRIDOR. INSET TABLE INDICATES RELEVANT INFORMATION FOR EACH STEP OF THE PROCESS.

The first criteria to be applied to the railroad corridor was the bounding condition. This includes an area on either side of the railroad track that a rock slope failure could propagate from. This criterion excludes slopes that are far enough away from the railroad that they will not cause damage. 
The second criterion is the slope angle. This criterion selects slopes that are above the chosen angle, within the bounded area delineated by the first criteria. Choosing a slope angle excludes flat or very gentle terrain. This angle was based on the lowest average friction angle of the materials at the site (59).

The third criterion is the H/L ratio, which provides the final threshold values for risk exposure. Each pixel highlighted by the previous two criteria is analyzed for the chosen $\mathrm{H} / \mathrm{L}$ value in all directions. This effectively creates a "cone of propagation" around each pixel. The threshold values count the number of time a pixel is crossed by a cone from another pixel. Areas of the corridor that are steep and narrow will see higher threshold values, because each pixel can be reached by more cones.

A medium and high exposure map was generated to highlight areas that were the focus of additional analysis, as seen in Figure 4-2. This figure shows the 95 and 99 percent probability that a failure could happen within the 25 mile corridor.

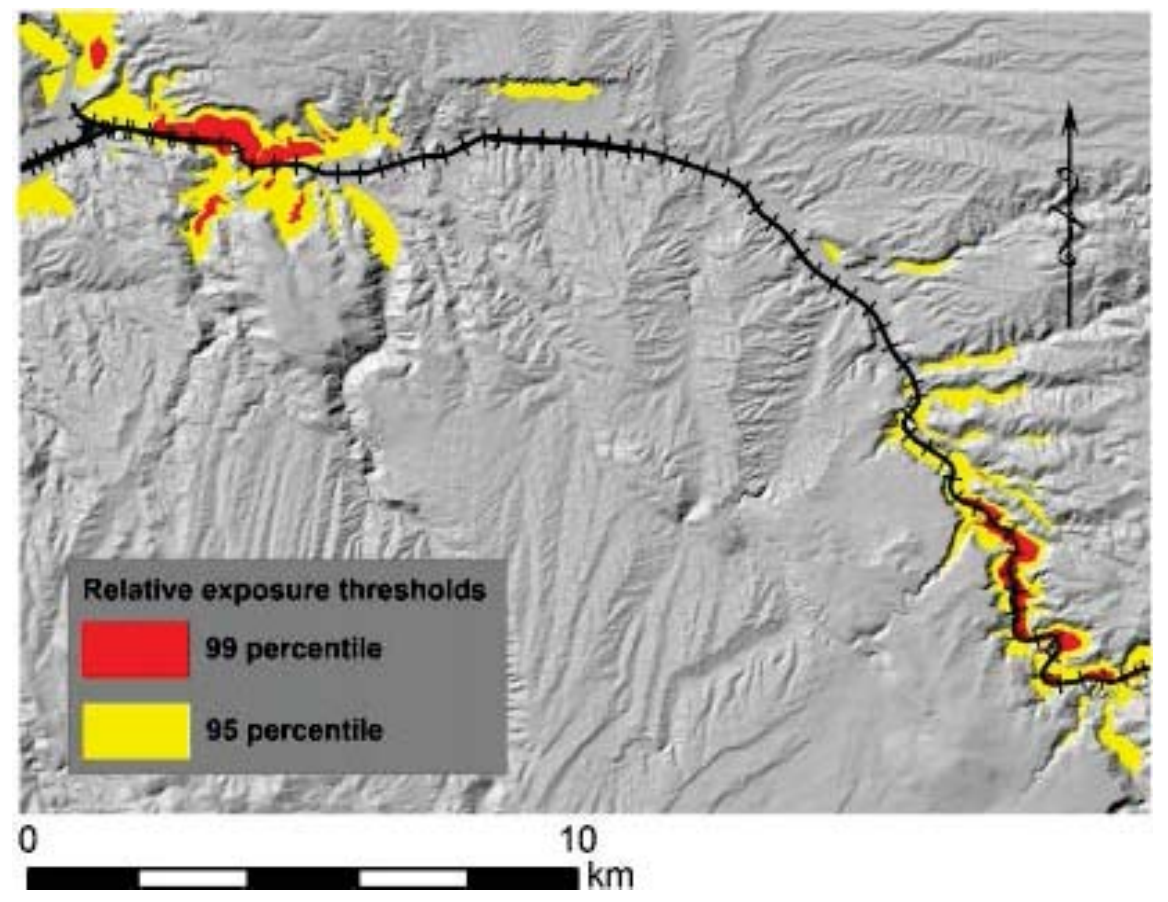

FIGURE 4-2: A RELATIVE EXPOSURE RISK MAP FOR A TRANSPORTATION CORRIDOR FOR ROCK FALLS AND SLIDES, BASED ON USER-CHOSEN INITIAL CONDITIONS. A ROCK FAILURE COULD PROPAGATE TO ANY OF THE COLORED AREAS, BUT WILL NOT NECESSARILY REACH THE TRANSPORTATION INFRASTRUCTURE. 


\subsection{Assessment of Rock Slope Hazard}

The second step of the methodology was to determine the hazard score of the slope. This score determines the priority of remediation and can provide a firstpass estimate of the economic cost of repair. The RHRS method is meant to be a relative rating system, based on a large database of slopes within the United States. Applying the system to a large inventory would allow slopes that are more hazardous to be identified and then dealt with accordingly. Applying the RHRS to a single slope requires a score range to indicate relative hazard. Pierson noted that slopes with a rating of less than 300 should be assigned a very low priority, and slopes with a rating of over 500 should be identified for urgent remedial action (4).

For this analysis, the 1991, unmodified version of the RHRS was used to determine a rockfall hazard score. This version has basic criteria, and is not considered as rigorous. It does, however, still gives reliable estimates of hazard, and is the version that the Nevada Department of Transportation (NDOT) uses to assess rock slopes. This method is also the most visual based, which is appropriate for this study. Because of the length of the railroad corridor, it is not economically feasible to use LiDAR or photogrammetry to determine a RHRS score.

An attempt was made to use the publicly available DEMs to determine the RHRS scores. Because of the low resolution of these DEMs, the RHRS scoring system would have to be modified. Only information that could be obtained through 10 meter DEMs, or through maintaining agencies, would be acceptable. Specifically, the geologic and rock fall event categories would have to be eliminated. The results from this modified system would then be normalized to the unmodified score sheet, so that hazard values would be comparable to those found through traditional field measurements. However, the RHRS, and rock fall propagation in general, is highly sensitive to the geologic conditions of the slope, and to the size of the rock fall event. The average size or volume of the rock fall event is critical in determining the extent of the failure, and the amount of affecting the transportation infrastructure. The geologic measurements are also key in controlling whether the slope failure will occur. The high degree of sensitivity to these parameters means that they cannot be reasonably ignored when determining relative hazard. Thus, the RHRS scoring should be completed using a higher resolution image than can be provided by publicly available DEMs.

For this analysis then, the use of publicly available, high-resolution orthophotos, as shown in Figure 4-3, which were obtained from the National Map 
Viewer, were used to determine an RHRS score. The resolution of the ortho-photos was estimated to be at 1 meter, which is on the same scale as required by the RHRS.

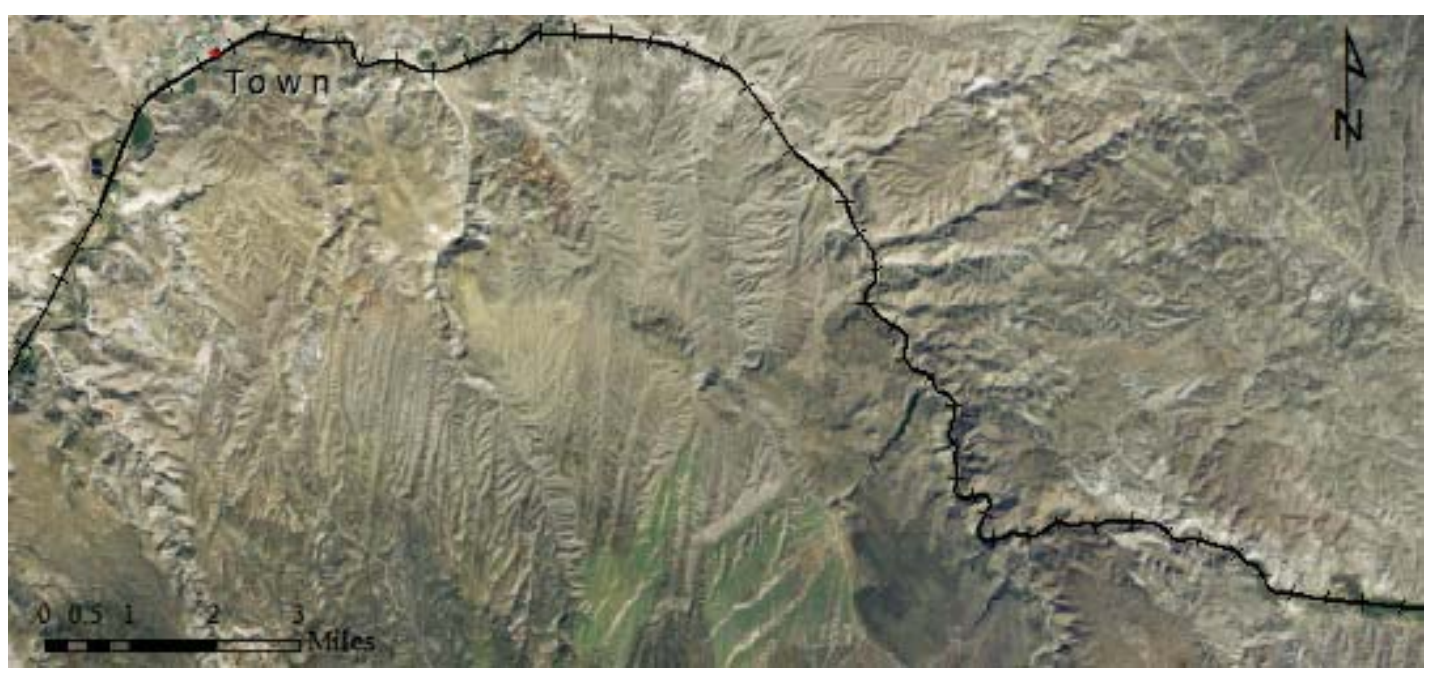

FIGURE 4-3: A 1 METER RESOLUTION ORTHO-PHOTO OF THE STUDY CORRIDOR IN SOUTHERN

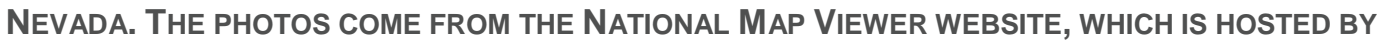
Us GEOLOGICAL SOCIETy (USGS).

There are several categories in the RHRS that require historical information, such as the climate conditions and the rockfall history. There is also a category that requires knowledge of the current use of the transportation infrastructure. The information for these categories is easily accessible from the agency in charge of the maintenance of the infrastructure. The Rockfall Hazard Rating System Participant's Manual (4) was used as a guide for assigning values to the slides being examined. It gives detailed explanations and examples for each category score. Table 4-1 below shows the RHRS score sheet used for this analysis, along with basic information on how values are selected.

For validation purposes, the RHRS score for Slide 1 and Slide 2 were determined using the 2014 point clouds generated from remote sensing techniques. This shows that the scale and imagery in the ortho-photos is close enough to determine relative hazard scores. The RHRS does not determine exact measures of hazard, so the slightly lower resolution scale was acceptable. The ortho-photos used to determine the RHRS score are shown in Figure 4-4 and Figure 4-5. It should be noted that the zoomed-in photos can look somewhat pixelated, and thus require some interpretation. An experienced field engineer should be able to assess the image and determine a RHRS score. 
TABLE 4-1: RHRS SCORING SHEET FOR ROCK SLOPES ALONG A TRANSPORTATION CORRIDOR, BASED ON 1 METER RESOLUTION PHOTOGRAPH DATA. INFORMATION THAT CANNOT BE DETERMINED FROM THE ORTHO-PHOTOS WILL NEED TO COME FROM THE TRANSPORTATION AGENCY.

\section{Rockfall Hazard Rating Score}

Category $\quad$ Value $\quad$ Score $\quad$ Remarks

\begin{tabular}{|ll|}
\hline Slope Height [ft] & Take the highest measurement a rock can fall from, \\
& not the average \\
Is there a ditch or catchment present? How eff ective & is the catchment? \\
Ditch Effectiveness & speed $=\mathrm{X}$ mph, rate $=\mathrm{Y}$ trains a day, slope length $=\mathrm{Z}$ \\
Average Vehicle Risk & $\mathrm{ft}$ \\
Site Distance [ft] & Measured on the LiDAR point cloud \\
Percent Decision Site Distance & decision sight distance $=\mathrm{D} \mathrm{ft}$ (Table 5.1 \\
Roadway width & implementation manual) \\
\hline
\end{tabular}

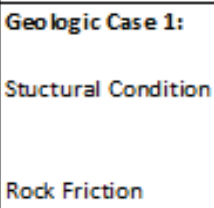

Focusing on adverse joint sets, continuous means greater than $10 \mathrm{ft}$ in length (take average of joint sets) Condition of the joint roughness, for both macro and micro structures. Tale the average of all the roughnesses of all the joint sets.

Based on erosional features throughout the entire slope including oversteepening and overhangs How quickly erosion is occuring and how is creating possible rockfall features.

\begin{tabular}{|ll}
\hline Rockfall Event: & Choose One \\
Block Size [ft] & $\begin{array}{l}\text { Measure on optical photogrammetry point cloud } \\
\text { (average rock block size) }\end{array}$ \\
Block Volume [yd^3] & $\begin{array}{l}\text { Measure on optical photogrammetry point cloud } \\
\text { (average rock block volume) }\end{array}$ \\
\hline
\end{tabular}

\begin{tabular}{|ll|}
\hline Climate Conditions: & NOAA annual data \\
Precipitation & Average annual precipitation plus average annual \\
Freezing Period & snowfall \\
Water on Slope & Possible freezing periods \\
Average Climate & Amount of time water is on the slope \\
\hline
\end{tabular}

Rockfall History How many rock fall occur each year, and major historical landslides must be included

Total Score $=$ 


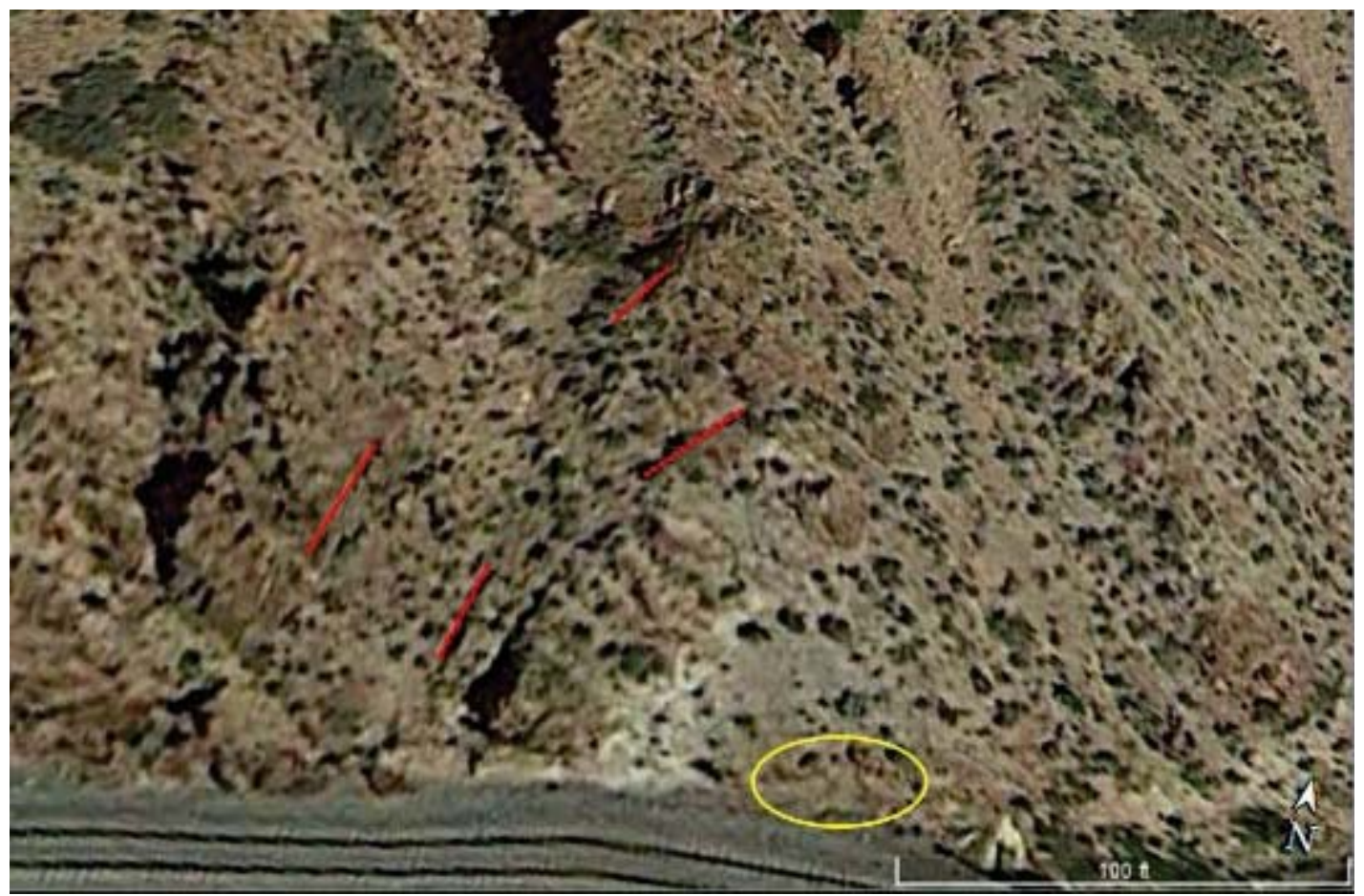

FIGURE 4-5: ZOOMED IN ORTHO-PHOTO OF SLIDE 3 FOR GEOLOGICAL CONDITION. THE RED LINES ARE FRACTURES IDENTIFIED IN THE SLOPE. THEY CAN BE MEASURED FOR LENGTH AND ASSESSED FOR WEATHERING. THE YELLOW OVAL IDENTIFIES FALLEN ROCK BLOCKS. THESE CAN BE MEASURED AND ASSESSED FOR THE "ROCKFALL EVENT" CATEGORY.

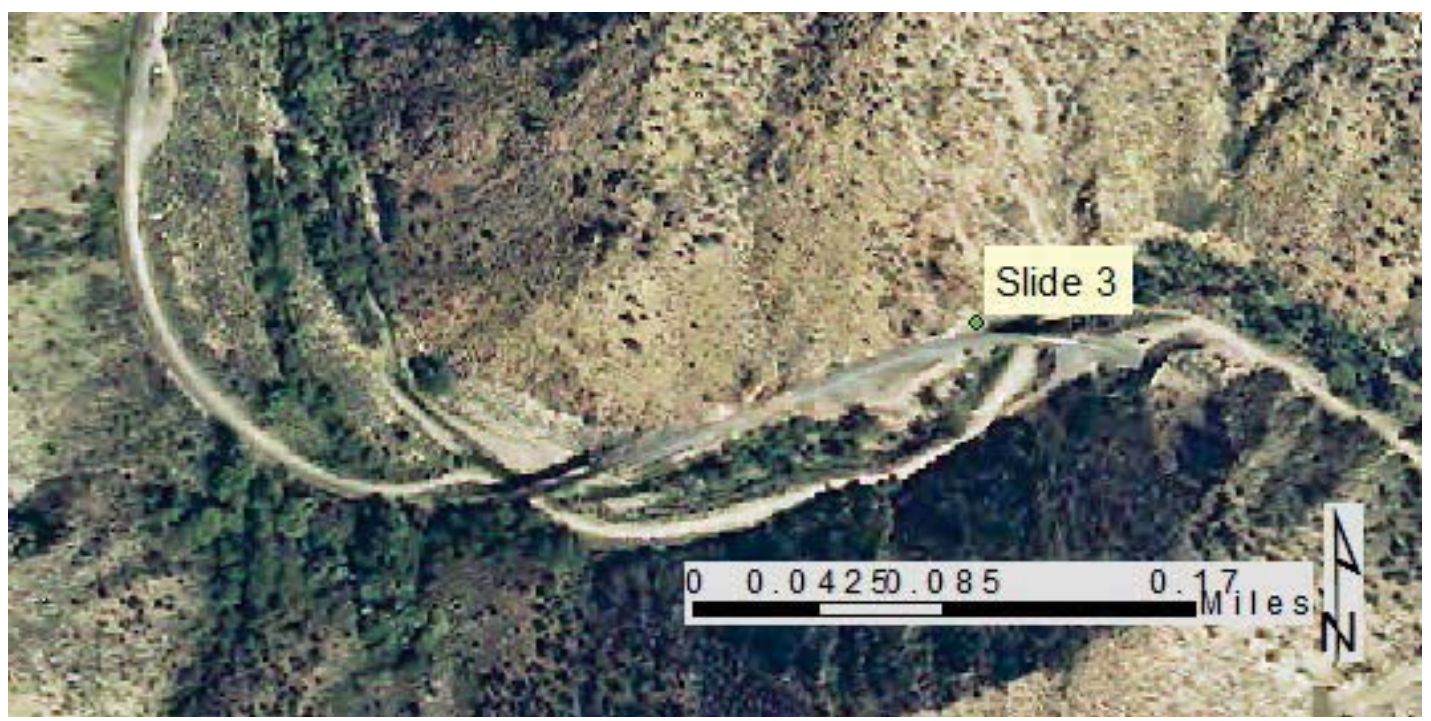

FIGURE 4-4: ZOOMED IN ORTHO-PHOTO OF SLIDE 3. FROM THIS PHOTO, MEASUREMENTS OF "SITE DISTANCE" AND "ROAD WIDTH" CAN BE DETERMINED FOR THE RHRS CATEGORIES. 


\subsection{Application of SMR to the Transportation Corridor}

Once the relative hazard of rock slope was determined, a more detailed hazard analysis was performed. When analyzing multiple slopes at the same time, the analysis investigated the most hazardous slope first. The SMR was then determined for this slope.

For Slide 1, the SMR rating was determined using the 2014 remote sensing data, at the $10 \mathrm{~cm}$ scale resolution. Because remote sensing data is limited to visual interpretation, the final SMR value was not as accurate as an SMR rating determined through field measurements. The RMR requires the uniaxial compressive strength and the RQD for fracturing at depth. These values cannot be determined by point cloud data, and are highly variable and site specific, so no accepted database exists for estimating these values. In order to use remote sensing to determine an SMR value, a more visual indicator of strength and rock mass fracturing was required. Fortunately, the GSI can be correlated to determine the RMR, allowing for further analysis.

The use of both LiDAR and optical photogrammetry allowed for accurate measurements of minor structures in the rock mass. The orientations of the major and minor structures are key to the SMR analysis. This allows for the identification of joint sets that are unfavorably oriented with the slope face, which are of interest in hazard analysis. The addition of color to the point clouds was vital in determining the characteristics of the joint sets and overall conditions of the surface of the slope face.

For the GSI results, the modified version of the GSI chart by Sonmez and Ulusay (23) was used. The surface condition rating (SCR) and the structural rating (SR) were the first parameters determined. The joint roughness, weathering, and infilling were determined by the colored photogrammetry point cloud, while the volumetric joint count was determined from the LiDAR point cloud. From these values, the GSI values were determined. A relatively simple relationship was used to relate the GSI to the corresponding RMR (24). The relationship used was

$$
R M R=G S I+5
$$

Table 4-2 shows the how the GSI value for each of the major and minor structures in the rock mass was determined. , The RMR was then calculated using the correlation. The structures identified in the LiDAR point clouds have been verified by field measurements. 
TABLE 4-2: GSI SCORE SHEET, USED TO DETERMINE AN RMR VALUE. THE STRUCTURAL INFORMATION SHOULD BE EXTRACTED FROM REMOTE SENSING POINT CLOUDS.

PHOTOGRAMMETRY CAN BE USED TO DETERMINE SCR AND SR VALUES.

\begin{tabular}{|c|c|c|c|c|c|c|c|c|c|c|c|}
\hline & $\begin{array}{c}\text { Dip } \\
\text { Direction }\end{array}$ & Dip & $\begin{array}{l}\text { Roughness } \\
\text { Rating (Rr) }\end{array}$ & $\begin{array}{l}\text { Weathering } \\
\text { Rating (Rw) }\end{array}$ & $\begin{array}{l}\text { Infilling } \\
\text { Rating (Rf) }\end{array}$ & $\begin{array}{l}\text { Surface Condition } \\
\text { Rating (SCR) }\end{array}$ & $\begin{array}{l}\text { Volumetric } \\
\text { Joint Count (Jv) }\end{array}$ & $\begin{array}{l}\text { Structural } \\
\text { Rating (SR) }\end{array}$ & $\begin{array}{l}\text { Structural } \\
\text { Condition }\end{array}$ & GSI & RMR \\
\hline \multirow{2}{*}{\multicolumn{12}{|c|}{ Slope Face }} \\
\hline Set 1 & & & & & & & & & & & \\
\hline \multicolumn{12}{|l|}{ Set 2} \\
\hline Set 3 & & & & & & $\mathrm{SCR}=\mathrm{Rr}+\mathrm{RW}+\mathrm{Rf}$ & \multirow{3}{*}{\multicolumn{3}{|c|}{$S R=-17.5^{*} \ln (J \mathrm{v})+79.8$}} & \multirow{2}{*}{\multicolumn{2}{|c|}{$\mathrm{RMR}=\mathrm{GSI}+5$}} \\
\hline Set 4 & & & & & & & & & & & \\
\hline Set 5 & & & & & & & & & & & \\
\hline
\end{tabular}

From the RMR, the SMR was found with four adjustment factors. The adjustment factors were based on the orientation of joint sets to the slope face, and were ranked from 'very favorable' to 'very unfavorable.' Factors one and two have relationship equations, while factor three is determined directly from the Bieniawski (1976) RMR chart. Factor four is based on the method of excavation for the slope. The main excavation method assumed by the SMR method was blasting, and it gives ratings according to the proficiency of the blasting work. There is also a rating for mechanical excavation, and unaltered slopes.

Only the structures that are unfavorably oriented with the slope face were considered while calculating the SMR value, because the favorably oriented structures will not contribute to failure propagations (63). The final SMR value is calculated for both planar and toppling failures, and is assigned a class number. This was done for each structural feature. There are five classes, with two subclasses in each main class. The classes indicate the overall stability of each joint set, potential failure modes to expect, and possible support solutions, as seen in Table 4-3.

The calculations of the SMR along the transportation corridor for three rock slides along are provided in Chapter 6.

TABLE 4-3: SMR CLASS NUMBERS AND DESCRIPTIONS (29). THESE DESCRIPTIONS CAN BE USED TO DETERMINE STABILITY AND POSSIBLE SUPPORT MEASURES FOR ROCK SLOPES.

\begin{tabular}{|c|c|c|c|c|c|c|c|c|c|c|}
\hline \multirow[t]{2}{*}{ Class no. } & \multicolumn{2}{|l|}{$\mathrm{V}$} & \multicolumn{2}{|l|}{ IV } & \multicolumn{2}{|l|}{ III } & \multicolumn{2}{|l|}{ II } & \multicolumn{2}{|l|}{ I } \\
\hline & b & a & b & a & b & a & b & a & b & a \\
\hline SMR & $0-10$ & $11-20$ & $21-30$ & $31-40$ & $41-50$ & $51-60$ & $61-70$ & $71-80$ & $81-90$ & $91-100$ \\
\hline Description & \multicolumn{2}{|c|}{ Very bad } & \multicolumn{2}{|l|}{ Bad } & \multicolumn{2}{|l|}{ Normal } & \multicolumn{2}{|l|}{ Good } & \multicolumn{2}{|c|}{ Very good } \\
\hline Stability & \multicolumn{2}{|c|}{ Completely unstable } & \multicolumn{2}{|c|}{ Unstable } & \multicolumn{2}{|c|}{ Partially stable } & \multicolumn{2}{|l|}{ Stable } & \multicolumn{2}{|c|}{ Completely stable } \\
\hline Failures & \multicolumn{2}{|c|}{ Large planar or soil-like } & \multicolumn{2}{|c|}{ Planar or large wedges } & \multicolumn{2}{|c|}{ Some joints or many wedges } & \multicolumn{2}{|c|}{ Some blocks } & \multicolumn{2}{|l|}{ None } \\
\hline Support & \multicolumn{2}{|c|}{ Re-excavation } & \multicolumn{2}{|c|}{ Important/corrective } & \multicolumn{2}{|c|}{ Systematic } & \multicolumn{2}{|c|}{ Occasional } & \multicolumn{2}{|l|}{ None } \\
\hline
\end{tabular}


In addition to identifying the structures and discontinuities in the rock mass, the remote sensing point clouds were valuable in determining factors of safety for rock slopes. This was done by first converting the LiDAR, shown in Figure 4-6 for Slide 1, or photogrammetry, shown in Figure 4-7, also for Slide 1, into a HRDEM.

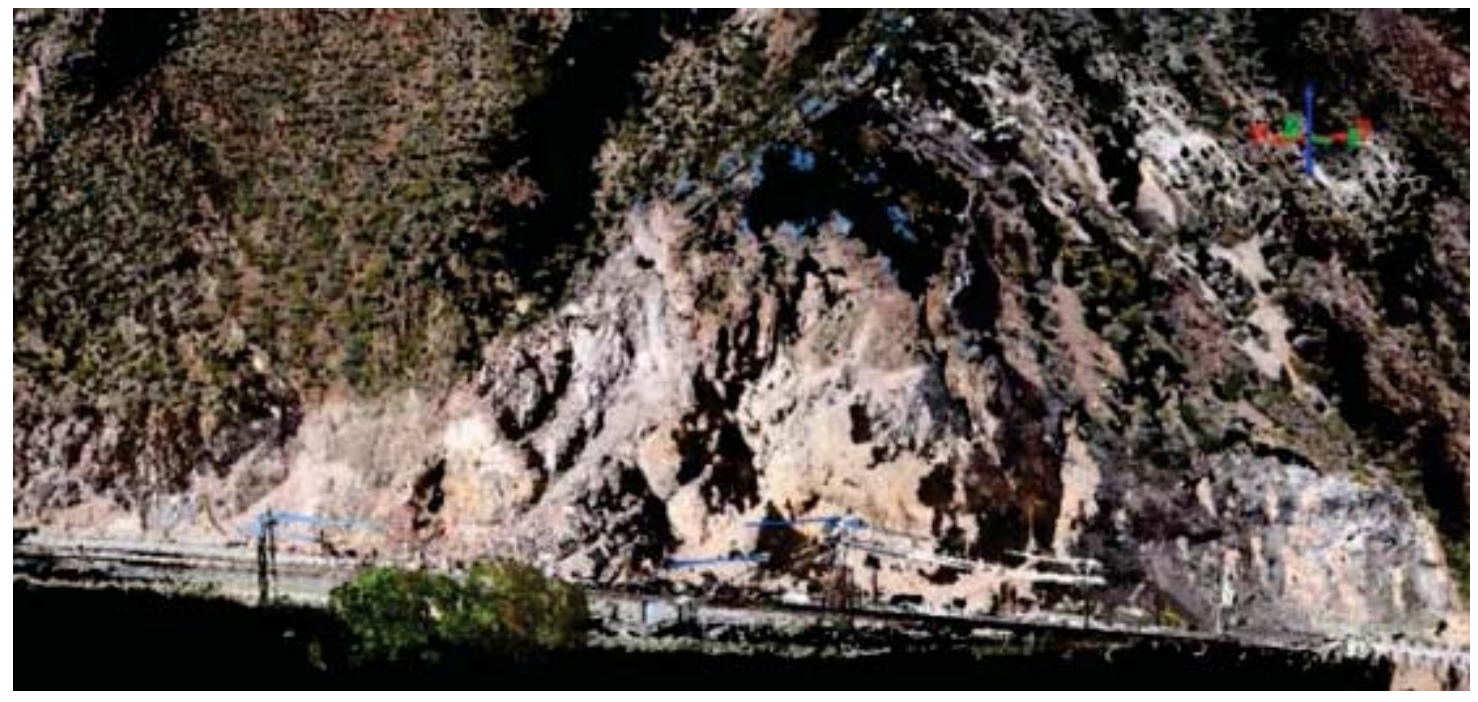

FIGURE 4-6: TERRESTRIAL LIDAR POINT CLOUD OF STUDY SITE SLIDE 1. THE RAILROAD CAN BE SEEN AT THE TOE OF THE SLOPE. THERE IS A HOLE IN THE IMAGE INDICATED WHERE THE LIDAR SCANNER COULD NOT SEE, BECAUSE OF A CHANGE IN THE ANGLE OF THE SLOPE.

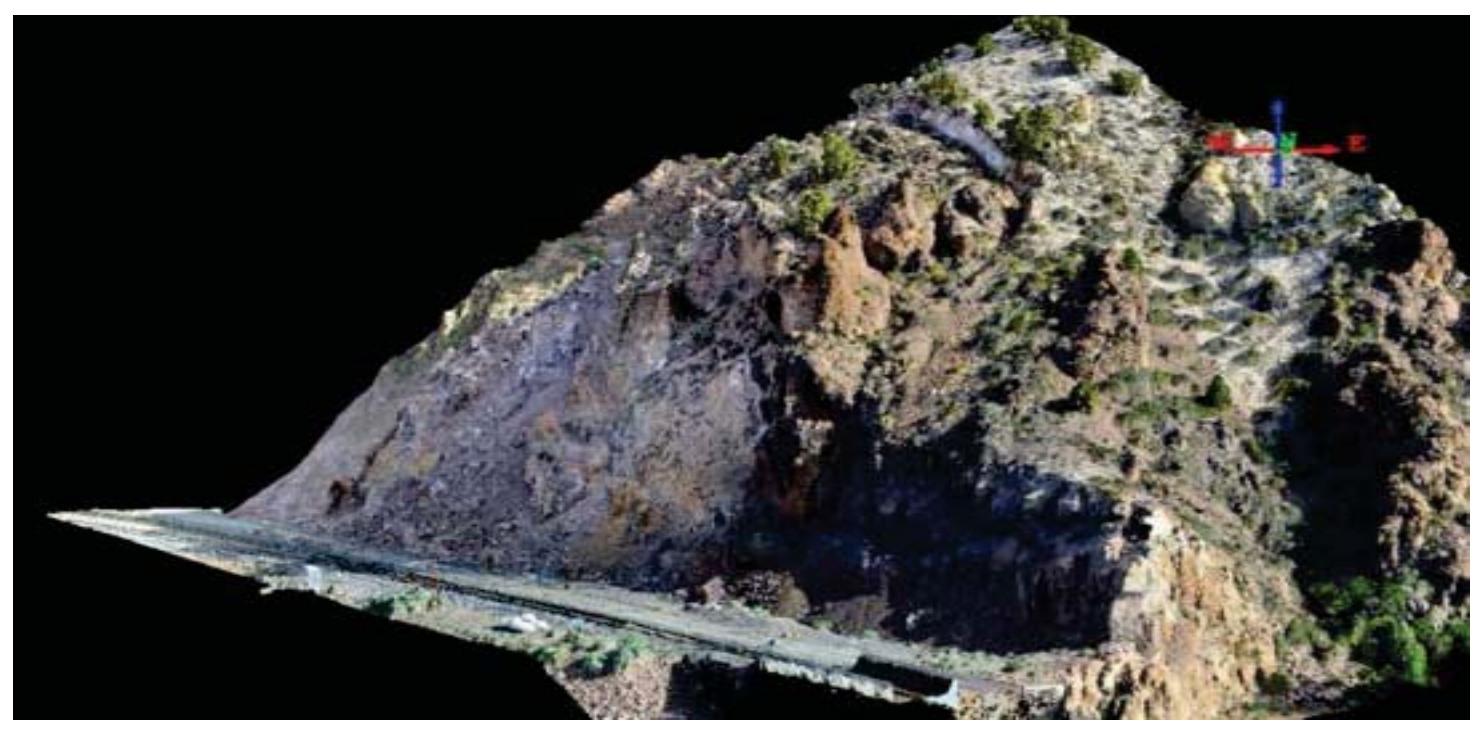

Figure 4-7: Optical PHOTOGRAMMETRY POINT CLOUd OF STUdY SITE SLIDE 1. A SMALLER AREA IS MODELED, BUT THE COVERAGE IS MORE COMPLETE THAN THE LIDAR POINT CLOUD.

The resolution of the HRDEMs (Figure 4-8) was accurate to about ten cm, which is significantly more accurate that the publicly available $10 \mathrm{~m}$ DEM. The 
HRDEMs also provided a psuedo-3D image to better visualize slope characteristics, such as height, aspect, and spacing from transportation infrastructure. Using visualization software such as ArcGIS can be a good way of presenting the information obtained by remote sensing to state DOTs. Creating a hazard map based on LiDAR or optical photogrammetry point clouds is also an efficient way to quantify where the hazards are greatest and remediation is necessary.

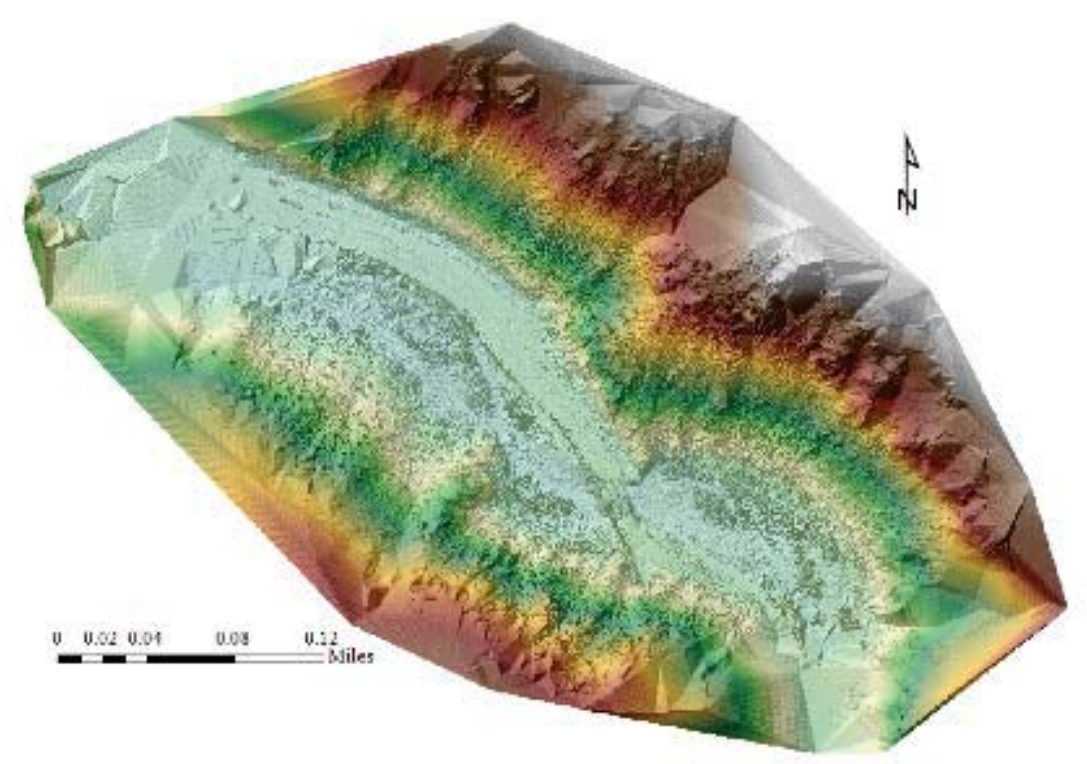

FiguRE 4-8: HRDEM OF THE STUdY SITE, SLIDE 1, IN SOUTHERN NEVADA. THE RESOLUTION OF THE HRDEM IS $10 \mathrm{CM}$. THE ELEVATION INCREASES FROM LIGHT GREEN TO DARK RED. THE HIGH RESOLUTION DATA CAPTURED FROM REMOTE SENSING RESULTS IN VERY DETAILED MODELS, WHERE INDIVIDUAL

The SMR value for each joint set also gives the possible failure modes for the joint set. The SMR class is separated into three failure modes (1) planar, (2) toppling and (3) wedge failures. The charts associated with the SMR system, however, do not give estimates of the factor of safety for the failure modes.

From the HRDEMs, slope profiles were extracted and imported into a failure modeling software for analysis (Figure 4-9). One such program is RocScience that can be used to evaluate the failure modes identified by the SMR system. RocScience has different modules for different failure methods, including the necessary toppling, wedges, planar, and rock fall failure models, among others. The properties of the rock slope can entered in the RocScience suite of software programs. The modules Swedge, for wedge failures, and RocPlane, for planar failures, can be used 
for determining the factor of safety of the rock slopes. The module RocFall can also be used for modeling the propagation of potential rockfalls on the slopes.

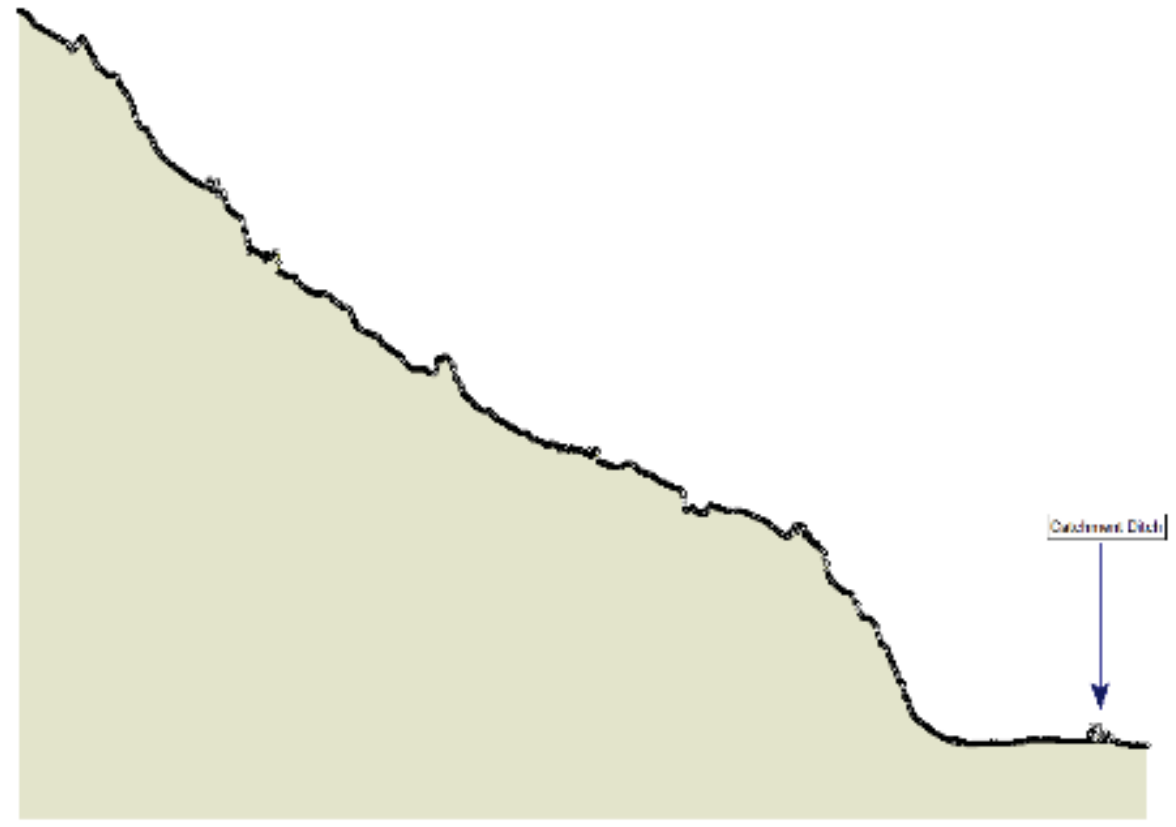

FIGURE 4-9: HIGH RESOLUTION SLOPE PROFILE MEASURED FROM THE REMOTE SENSING HRDEM, MODELED IN ROCSCIENCE ROCFALL. THE SMALL CATCHMENT DITCH AT THE TOE OF THE SLOPE IS IDENTIFIED.

\section{Application to a Transportation Corridor}

As noted above the corridor being analyzed is along a 25 mile railroad corridor located in southeastern Nevada. While initial attention has focused on Slide 1 due to its history of failure, there is also concern of possible failures along the rest of the corridor. Because the terrestrial laser scanning was performed using a static scanner, it would take time and effort to collect the remaining LiDAR and optical photogrammetry data for the entire 25-mile corridor.

Fortunately, the evaluation techniques of RHRS, GSI, and SMR can be applied to the transportation corridor. There are, however, some categories in each system that prevents direct calculations such as those performed for with highresolution point clouds from remote sensing. So instead, a test site must be 
inspected in great detail, with remote sensing techniques, so that the data collected can be "scaled up" and applied to all areas in the corridor.

In order to apply the conditions at the test site to the entire corridor, conditions must be the same or very similar to those found at test slide locations. This refers to both the geology and geomorphology of the corridor. In terms of topography, the entire transportation corridor is similar; steep, rocky slopes closely spaced to a railway. The climatological conditions will not vary over such a small area, and the same standards for maintenance are in effect throughout the transportation corridor. Historical data was obtained for the corridor in the same manner it was for the test site.

In terms of geology, it is similar throughout the canyon, consisting of volcanic tuff deposits, although the composition of the tuffs varies as do the rock strength properties. However, they are similar enough that the GSI method utilized in the detailed analysis of the slopes should result in equitable values.

At the test sites, LiDAR and optical photogrammetry data was collected and transformed into HRDEMs. For the rest of the 25-mile stretch of railway, the DEMs were gathered from public sources, resulting in diminished resolution. The standard DEMs were not able to identify minor rock structures or all discontinuity sets. Major rock structures, however, were able to be identified, which generally control the overall stability of the rock mass, although minor structures can heavily influence the types of failure that can occur as well. To overcome this limitation the following assumption was used that the corridor is similar enough to the test site, the structural discontinuities seen there can be extrapolated and applied to the other rock slopes.

This method obviously has some limitations, but is, in the end, only an estimate of the hazard rating for the transportation corridor. The model would have to be reworked for major changes in geology and topography. Thus, the model can be adjusted and fitted to work in many locations, as long as there is one test site with remote sensing data to begin from.

The methods above do not apply to soil slopes, and are limited to slopes with a RMR value about 20 . 


\section{Results}

The hazard rating method was applied to three slopes within the transportation corridor, Slide 1, Slide 2, and Slide 3 as seen in Figure 6-1. Slides 1 and 2 were visited in 2014, and had remote sensing data collected on them. Slide 3 was chosen at a later data to emphasis the methodology. Slide 1 is the most important rock slide because of the reactivation of the rock slide in 2011and is the most hazardous location along the railroad corridor, with the greatest risk of failure impacting the transportation infrastructure. Slide 2 also underwent blasting excavation, increasing the relative hazard for the slope but having small rock falls presented a much lower rick to the railroad. In addition, a berm was constructed along the slide that contained much of the failed rock mass. Slide 3 was chosen because it is located within the high exposure risk zone delineated by the initial conditions. Each slide was analyzed using the method outlined in Figure 4-1.

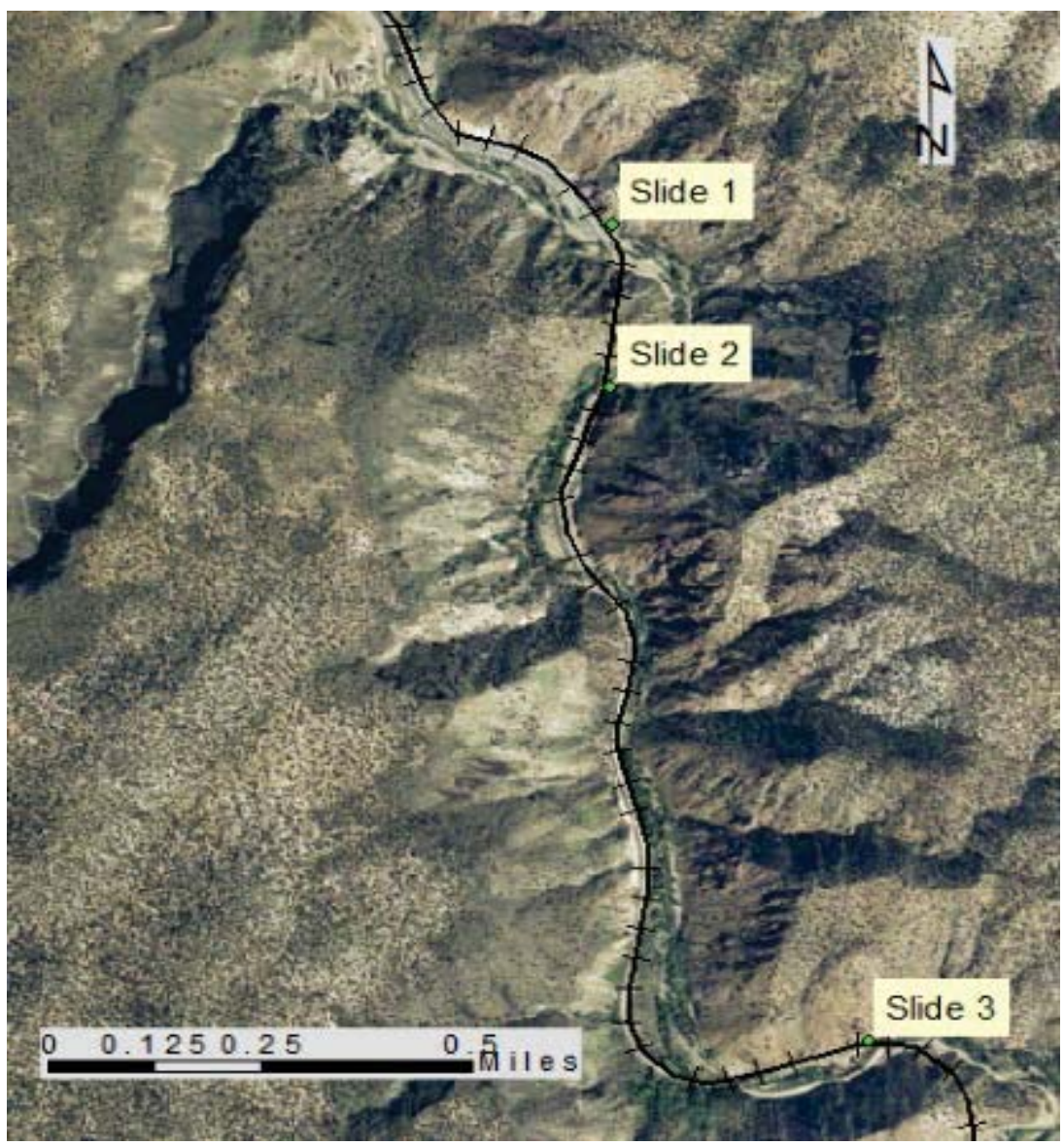

FIGURE 6-1: LOCATION OF THE THREE STUDY SITES ALONG THE TRANSPORTATION CORRIDOR. 


\subsection{Assessment of Initial Conditions}

This first step of the methodology was to assess the initial conditions for risk assessment. These conditions are specific to the transportation corridor, and will narrow the search area from the entire corridor to high risk segments.

The first condition assessed therefore was the bounding area of interest, or the distance from the railroad to the top of a possibly failing slope. For this study, the bounding area was set to one mile on either side of the railroad, as seen in Figure 6-2. This allows for the inclusion of large, long propagating, failures, though they are not expected based on historical data along this corridor.

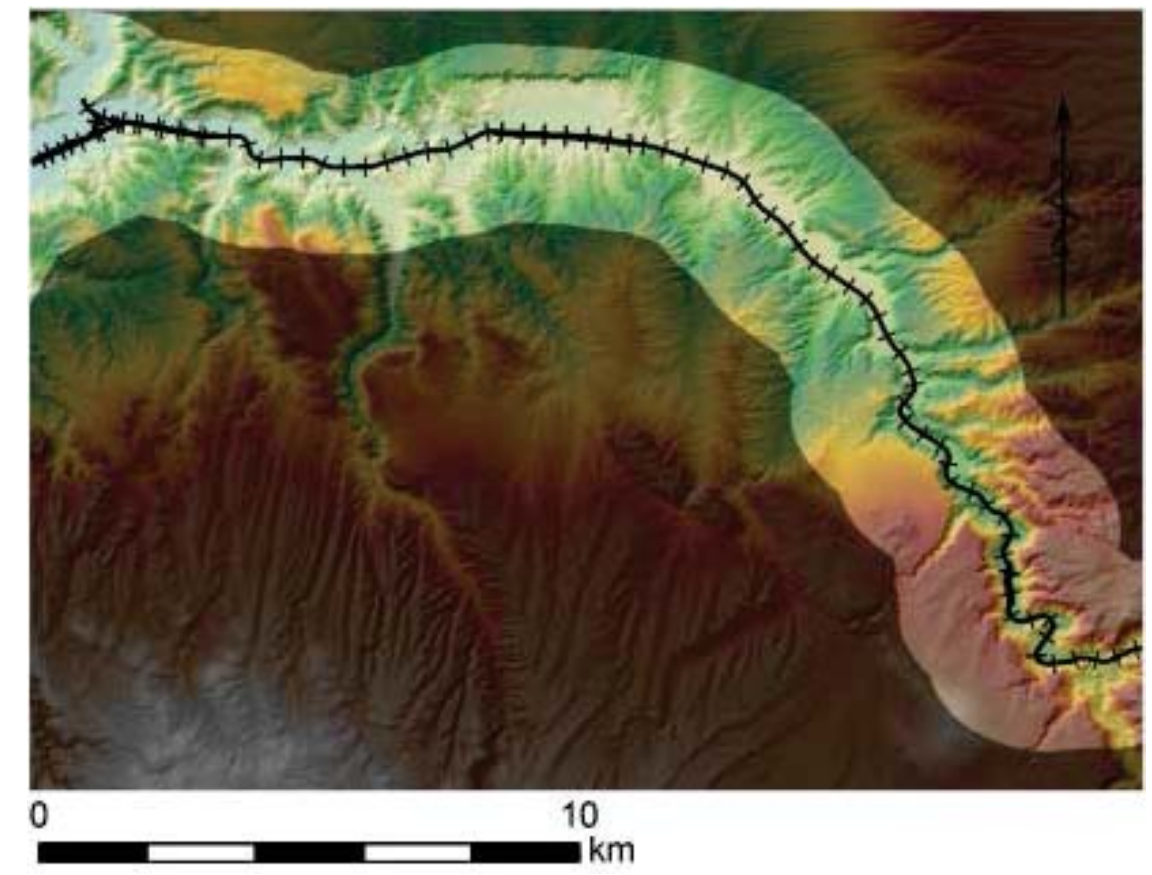

FIGURE 6-2: ONE MILE BOUNDING AREA ON BOTH SIDES OF THE RAILROAD TRACK ALONG THE TRANSPORTATION CORRIDOR.

The second condition assessed was the slope angle. This allows for the exclusion of flat or gently sloping terrain. In this way, it was possible to focus solely on very steep slopes or cliff faces, or to create a broad range for a high inclusion rate. For this corridor, a slope angle of $30^{\circ}$ was selected (Figure 6-3). This value is in agreement with other values in literature for similar rock types (64). It is also a relatively conservative value, since it is below the average angle of repose for most rock slopes. 


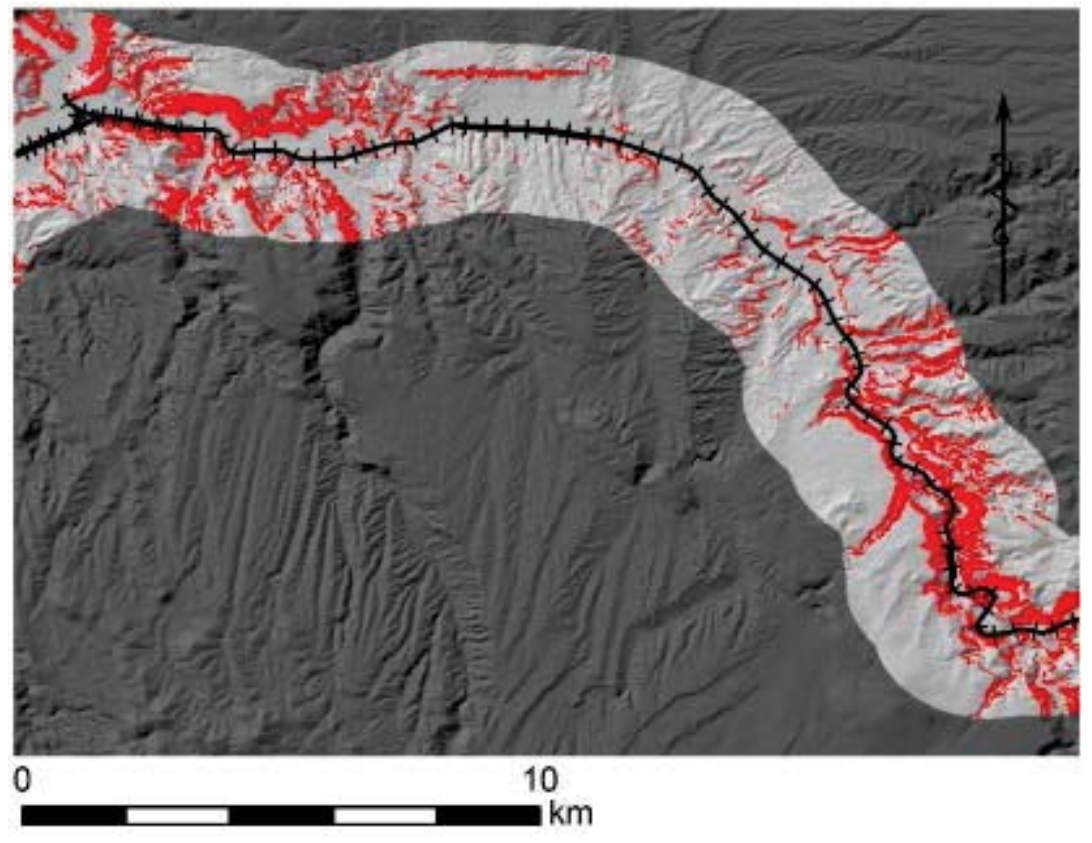

FIGURE 6-3: SLOPES WITH AN ANGLE GREATER THAN 30 DEGREES, WITHIN THE BOUNDING AREA OF THE TRANSPORTATION CORRIDOR.

The final initial condition assessed was the height-to-length ratio, the H/L. This ratio is a proxy for the expected propagation length of a slope failure. This is the most difficult of the initial conditions to estimate, and it is this author's opinion that a very conservative value be chosen. Because propagation depends on a number of factors, including triggering mechanisms such as rainfall and earthquakes, which are excluded from this model, it is difficult to achieve more than a rough estimate. The $\mathrm{H} / \mathrm{L}$ proxy allows for an average, conservative value to be applied across the entire transportation corridor. For the study area, the H/L was set at $1 / 4$ (Figure 6-4) (65).

From these initial conditions, a final exposure risk map was generated as shown in Figure 6-5. For the case study, medium exposure is the $95^{\text {th }}$ percentile, and the high exposure is the $99^{\text {th }}$ percentile of risk, as seen in Figure 6-5. 


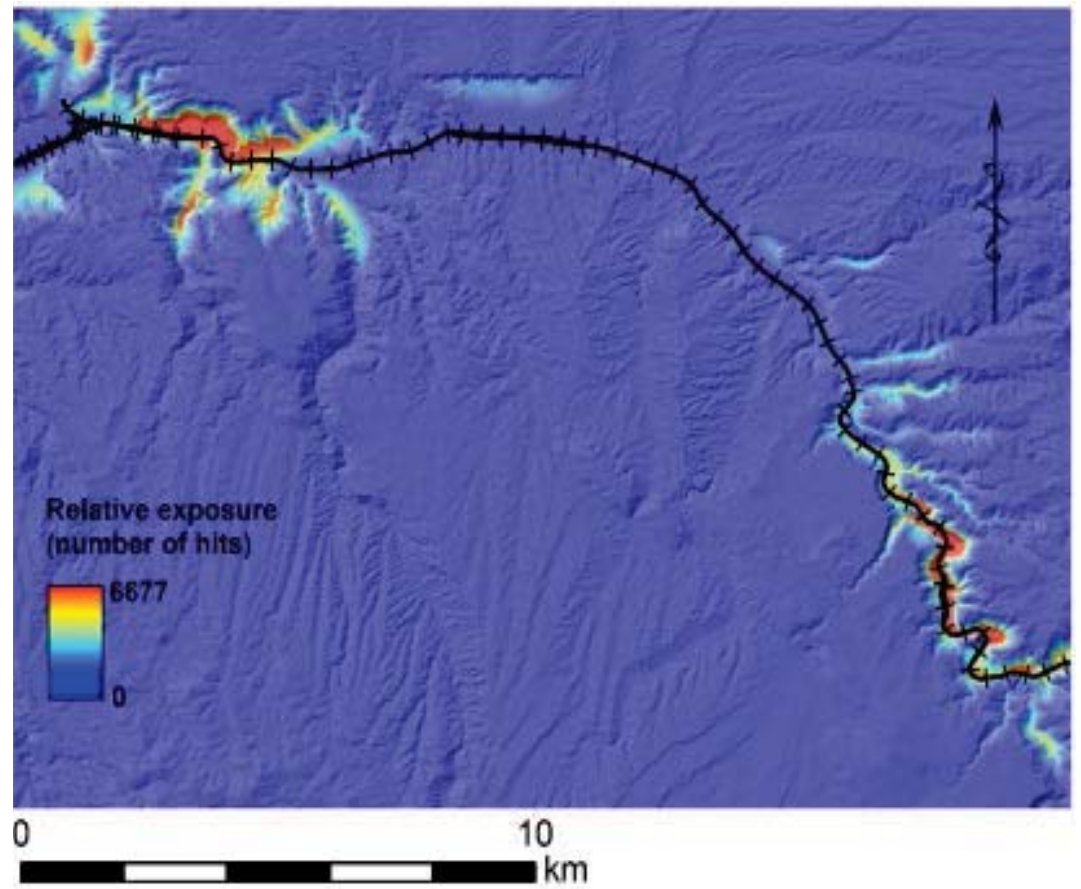

FIGURE 6-4: AREAS WITH AN H/L RATIO OF GREATER THAN 1/4, BASED ON THE LOCATIONS IDENTIFIED BY THE PREVIOUS TWO CRITERIA.

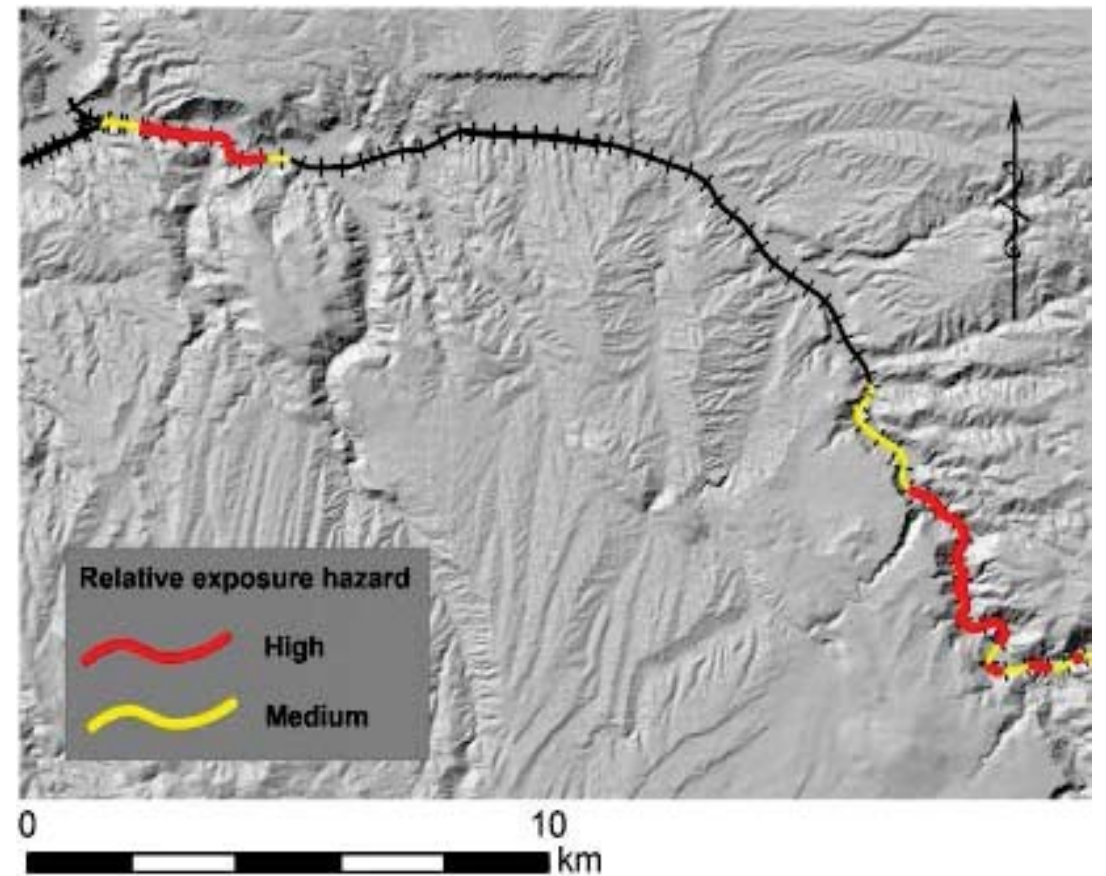

FIGURE 6-5: FINAL RISK EXPOSURE FOR THE RAILROAD TRACKS ALONG THE CORRIDOR. 


\subsection{Slide 1 Analysis}

Following the methodology flowchart (Figure 4-1), and the initial conditions described in section 6.1, the next step in the analysis of Slide 1 was to conduct a RHRS analysis with a 1-meter ortho-photo (Figure 4-3). Table 6-1 shows the scores for each category for the Slide 1 analysis. Section 4.2 provides an explanation of how to determine the score from the ortho-photos.

Following the 2006 blasting operation a catchment berm was placed around the slide. The berm's effectiveness was determined from historical knowledge of each site, and from the current remote sensing images of the site. The berm at Slide 1 was assessed to be moderately effective, catching most small rock falls. However, during the large landslide that occurred in 2011, there were many rock blocks that overcame the berm to fall on the access road and near the railway tracks. Also, the rock blocks, and rock fall volume was relatively large at this site, making it more difficult for the berm to effectively catch all the rock falls.

The 'Site Distance' parameter is not a category in the RHRS, and thus does not have a score. The site distance is a measurement necessary for the calculation of the 'Percent Decision Site Distance' score. Because the site distance changes for each slope evaluated, it must be measured and recorded for validation.

The geological conditions for Slide 1, using high resolution photographs, indicate that "Geologic Case 1" is most applicable case for Slide 1. The quality of the photographs provided a good visual estimate the structural condition and properties of the discontinuities of the slope. The resolution of the photographs is on the 1 meter scale, which allows for small discontinuities and minor structures to be identified, and for the condition of the structures to be assessed. Because Geologic Case 1 was used, Geologic Case 2 is considered 'not applicable.'

The "Rockfall Event" is meant as an indication of a single rockfall event. The event can be measured by block size, in feet, or block volume, in cubic yards. While both measurements should be taken and recorded on the score sheet, only one value can be used in the final score calculation.

The site's climate conditions used in the analysis are from NOAA annual database, and the rockfall history was provided by the transportation agency. The slope was evaluated with "intermittent water on slope," even though there are extended periods of time with little to no rainfall because of the possibility of water 
being trapped in the joints of the rock mass long after a rainfall event is certainly possible especially in the winter and spring time of the year.

TABLE 6-1: RHRS SCORE SHEET FOR SLIDE 1 USING THE 1 METER ORTHOPHOTOS. GEOLOGIC CASE 1 WAS USED, SO GEOLOGIC CASE 2 IS IGNORED. THE THREE CLIMATE VARIABLES ARE AVERAGED TOGETHER FOR THE CLIMATE SCORE. EACH CATEGORY SCORE IS COMBINED TO GET THE TOTAL SCORE.

Slide 1

$\underline{\text { Rockfall Hazard Rating Score }}$

\begin{tabular}{|c|c|c|c|}
\hline Category & Value & Score & Remarks \\
\hline Slope Height [ft] & 120 & 100 & $\begin{array}{l}\text { Height varies from } 70 \text { to } 120 \text { feet, manual says to } \\
\text { take the highest height from which rocks can fall. }\end{array}$ \\
\hline Ditch Effectiveness & Moderate & 9 & $\begin{array}{l}\text { During the main landslide, many rocks made it past } \\
\text { the ditch, but normally, most rocks are caught }\end{array}$ \\
\hline Average Vehicle Risk & 55 & 10 & $\begin{array}{l}\text { speed }=30 \mathrm{mph}, \text { rate }=\sim 12 \text { trains a day, slope length } \\
=300 \mathrm{ft}\end{array}$ \\
\hline Site Distance $[\mathrm{ft}]$ & 250 & - & Measured on the Ortho-photo \\
\hline Percent Decision Site Distance & 56 & 34 & $\begin{array}{l}\text { decision sight distance }=450 \mathrm{ft} \text { (Table } 5.1 \\
\text { implementation manual) }\end{array}$ \\
\hline Roadway width & 25 & 41 & Measured on the Ortho-photo \\
\hline
\end{tabular}

\begin{tabular}{|c|c|c|c|}
\hline \multicolumn{4}{|l|}{ Geologic Case 1: } \\
\hline Stuctural Condition & $\begin{array}{l}\text { Continuous } \\
\text { joints, adverse } \\
\text { orientation }\end{array}$ & 100 & $\begin{array}{l}\text { Focusing on adverse joint sets, continuous means } \\
\text { greater than } 10 \mathrm{ft} \text { in length (all joints sets are much } \\
\text { longer) }\end{array}$ \\
\hline Rock Friction & $\begin{array}{l}\text { Mostly planar } \\
\text { and smooth, } \\
\text { some } \\
\text { undualation }\end{array}$ & 20 & $\begin{array}{l}\text { Condition of the joint roughness, both macro and } \\
\text { micro. Majority of joints are smooth and planar (only } \\
\text { joint set } 3 \text { is smooth and undulating). Shear } 2 \text { is rough } \\
\text { and undulation. }\end{array}$ \\
\hline
\end{tabular}

Geologic Case 2:

Differential Erosion Features $\quad$ - $\quad 0 \quad$ Not Applicable

Difference in Erosion Rates $\quad$ - $\quad 00$ Not Applicable

\begin{tabular}{|lccl|}
\hline Rockfall Event: & $6+$ & Choose One \\
Block Size [ft] & 100 & $\begin{array}{l}\text { Measure on optical photogrammetry point cloud } \\
\text { (average rock block size) }\end{array}$ \\
Block Volume [yd^3] & $14+$ & 100 & $\begin{array}{l}\text { Measure on optical photogrammetry point cloud } \\
\text { (average rock block volume) }\end{array}$ \\
\hline
\end{tabular}

\begin{tabular}{|lccl|}
\hline Climate Conditions: & & & NOAA annual data \\
Precipitation & Moderate & 7 & $\begin{array}{l}\text { Average annual precipitation = } 10 \text { inches, average } \\
\text { annual snowfall = } 8 \text { inches }\end{array}$ \\
Freezing Period & Short & 3 & Freezing possible from December to March \\
Water on Slope & Damp & 10 & Intermittent Water on Slope \\
Average Climate & & 7 & Average all climate scores \\
\hline
\end{tabular}

\begin{tabular}{|c|c|c|c|}
\hline Rockfall History & $\begin{array}{c}\text { Significant } \\
\text { rockfall event }\end{array}$ & 40 & $\begin{array}{l}\text { Occasional falls occur all year round, many falls or } \\
\text { severe rockfall events have occurred }\end{array}$ \\
\hline
\end{tabular}

Total Score $=461$ 
The final score for Slide 1 is shown in Table 6-1 and comes to 461. This is on the high side of the score range, being much closer to 500 than 300 . This means that the slope will probably not catastrophically fail in the near future, but should receive remediation measures relatively soon.

This value was validated with field measurement taken during the 2014 data collection. Field engineers should collect field measurements for verification purposes while the remote sensing is being implemented.

The structural information for the slide was extracted from the point cloud data (Figure 6-6), and verified with the field measurements.

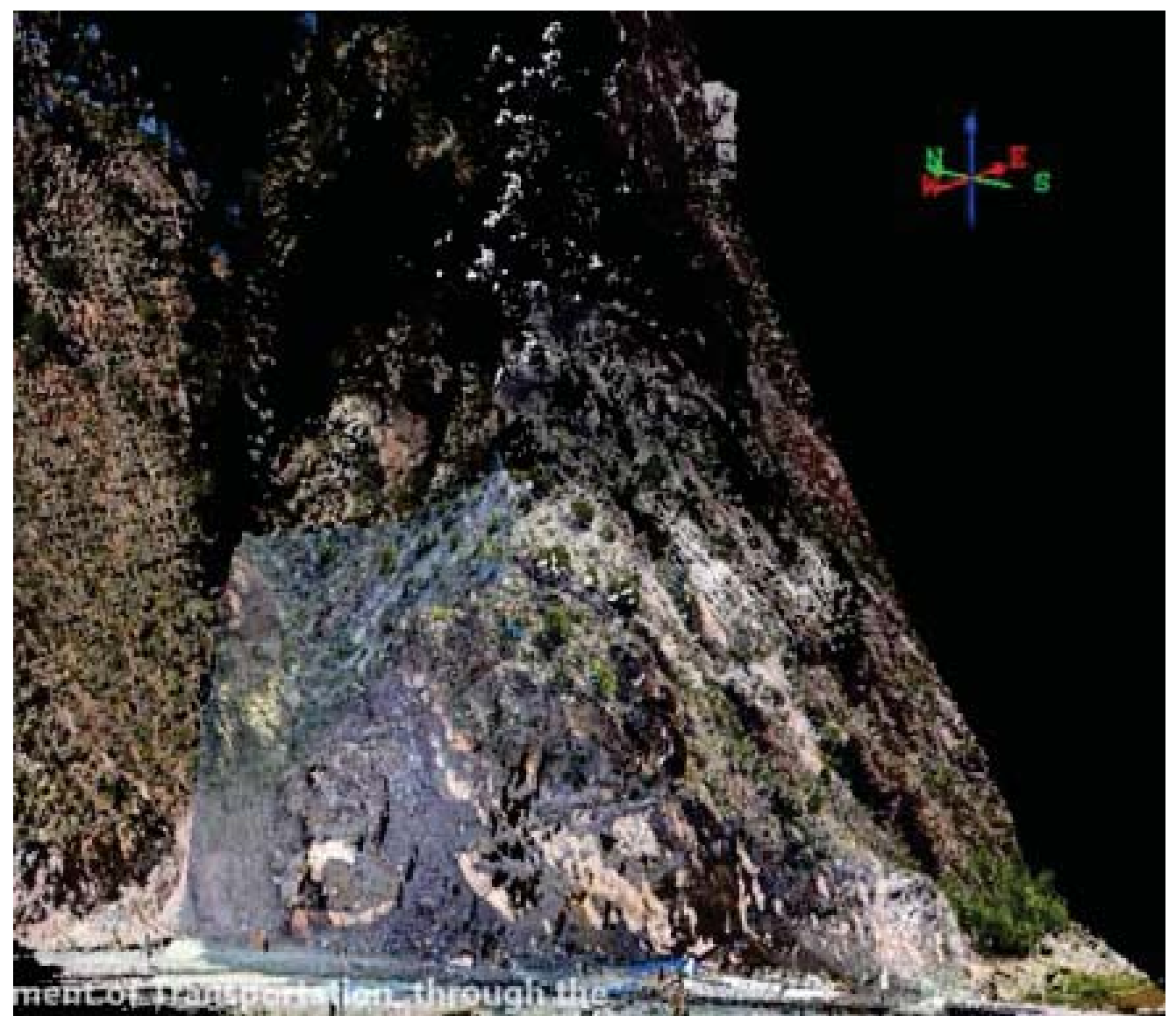

FIGURE 6-6: LIDAR AND OPTICAL PHOTOGRAMMETRY POINT CLOUDS FOR SLIDE 1 ARE COMBINED INTO A SINGLE IMAGE. THE INTEGRATED DATA SETS PROVIDES THE BEST POINT CLOUD FOR USE IN HAZARD ANALYSIS. 
Slide 1 has a RHRS score above the threshold value of 300 points, so a detailed analysis should be performed. In this study the SMR method was applied to Slide 1. Table 6-2 shows the tabulated values used in the SMR method for Slide 1. Refer to section 4.3 for explanation on how to determine SMR score from remote sensing.

TABLE 6-2: TABULATION OF THE GSI, RMR, AND SMR VALUES, AS WELL AS THE SMR CLASS FOR SLIDE 1 STRUCTURES. ONLY THE STRUCTURES HIGHLIGHTED IN YELLOW ARE INCLUDED IN THE DETERMINATION OF THE SMR CLASS FOR THE ENTIRE SLOPE.

\begin{tabular}{|c|c|c|c|c|c|c|c|}
\hline & Dip Direction & Dip & GSI & RMR & SMR & SMR Class & SMR Description \\
\hline Slope Face & 246 & 70 & & & & & \\
\hline Fault & 162 & 85 & 45 & 50 & 40 & IV & Bad \\
\hline Shear 1 & 92 & 80 & 40 & 45 & 35 & IV & Bad \\
\hline Shear 2 & 302 & 75 & 52 & 57 & 47 & III & Normal \\
\hline Shear 3 & 112 & 70 & 52 & 57 & 45 & III & Normal \\
\hline Set 1 & 205 & 40 & 45 & 50 & 38 & IV & Bad \\
\hline Set $2 A$ & 230 & 68 & 32 & 37 & 23 & IV & Bad \\
\hline Set $2 B$ & 203 & 55 & 35 & 40 & 26 & IV & Bad \\
\hline Set 3 & 200 & 78 & 33 & 38 & 28 & IV & Bad \\
\hline Set 4 & 125 & 58 & 37 & 42 & 28 & IV & Bad \\
\hline Set 5 & 268 & 33 & 52 & 57 & 41 & III & Normal \\
\hline
\end{tabular}

unfavorably oriented

For Slide 1, the excavation is being classified as 'deficient blasting.' This is because it appears that the blasting was performed with very poor adequate presplitting to minimize disturbance to the remaining slope. Since the blasting occurred, there has been continuous small rock falls, which indicates that the slope is still highly fractured and unstable. Deficient blasting is a negative adjustment to the SMR rating because it often contributes to the stability issues of the slope.

The stability of the slope is determined using the SMR evaluation of the unfavorably oriented joint sets. In this instance, there are six unfavorable sets, though the favorable sets were also calculated. Overall, Slide 1 is "Normal-to-Bad", which means the slope is at best, only partially stable. Another large failure could possibly occur, in addition to the continuing small rock falls and block movements already witnessed at the site. Wedge and planar failures are also possible failure modes. 
Because the overall determination of the stability of the slope is normal-tobad, step 4 of the methodology is required. The SMR indicates that there is a possibility of multiple types of failures, with planar and wedge failures being the most likely to occur. The most probable failure mode given the current conditions is a wedge-type failure. In addition to these failure modes, a rock fall analysis was performed to determine likelihood of rocks reaching the access road or railroad. Although the SMR does not specifically indicate those rock falls are a possible failure, there has been continual evidence of rock falls since site monitoring began. Figure 6-7 shows possible end locations for rock fall blocks as determined by the Rocscience RocFall program, including the possibility that the blocks will escape the catchment berm and land on the access road. For the current conditions, the catchment berm is likely to catch the vast majority of possible falling rock blocks.

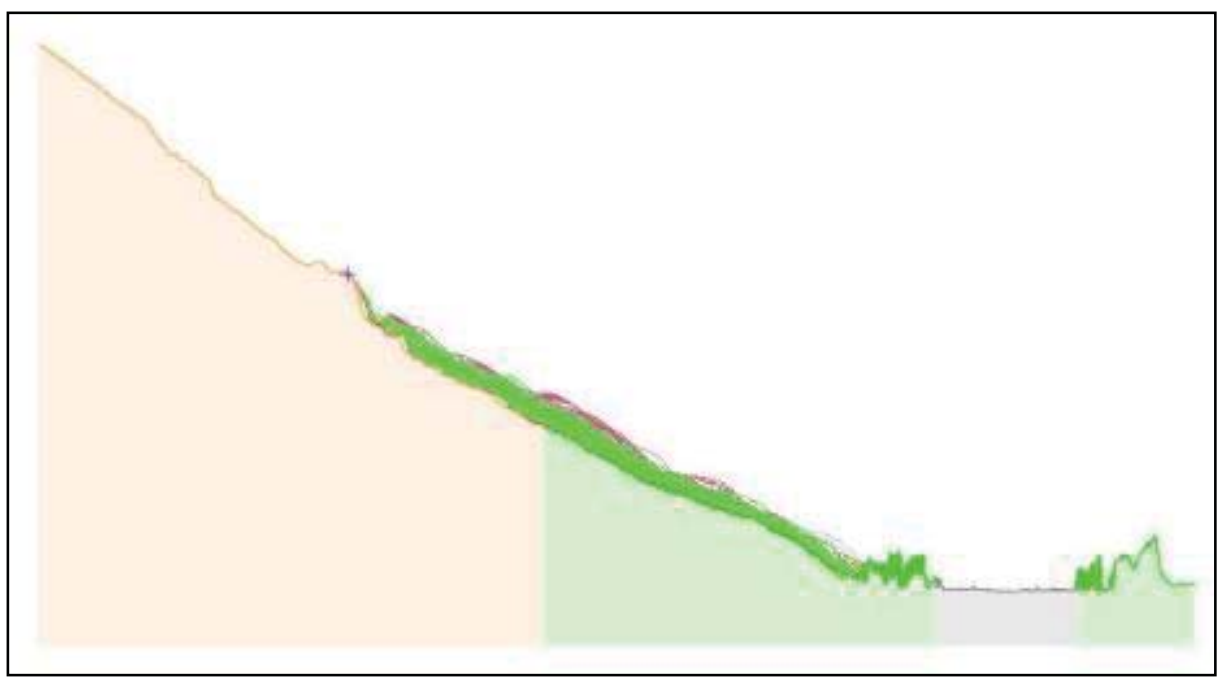

FIGURE 6-7: ROCKFALL PROPAGATION PATHS FOR SLIDE 1, MODELED USING ROCSCIENCE ROCFALL. IT CAN BE SEEN THAT UNDER CURRENT CONDITIONS, NO ROCK BLOCK ARE EXPECTED TO REACH THE RAILROAD OR SIDE ACCESS ROAD. THIS CAN CHANGE IF LARGER ROCK BLOCKS FAIL.

The wedge failure can be modeled using the Swedge program. Figure 6-8 shows a kinematically admissible wedge formed by two joint sets with a factor of safety less than 1.0, which means that the wedge is unstable and subject to failure. Another failure type revealed by the SMR calculations is a planar failure, which was modeled in RocPlane. This failure is dependent on the major structure in the rock 
mass, and there is uncertainty about the scale because of the lack of knowledge of any rock properties at depth. Figure 6-9 shows a possible planar failure along a large shear zone.

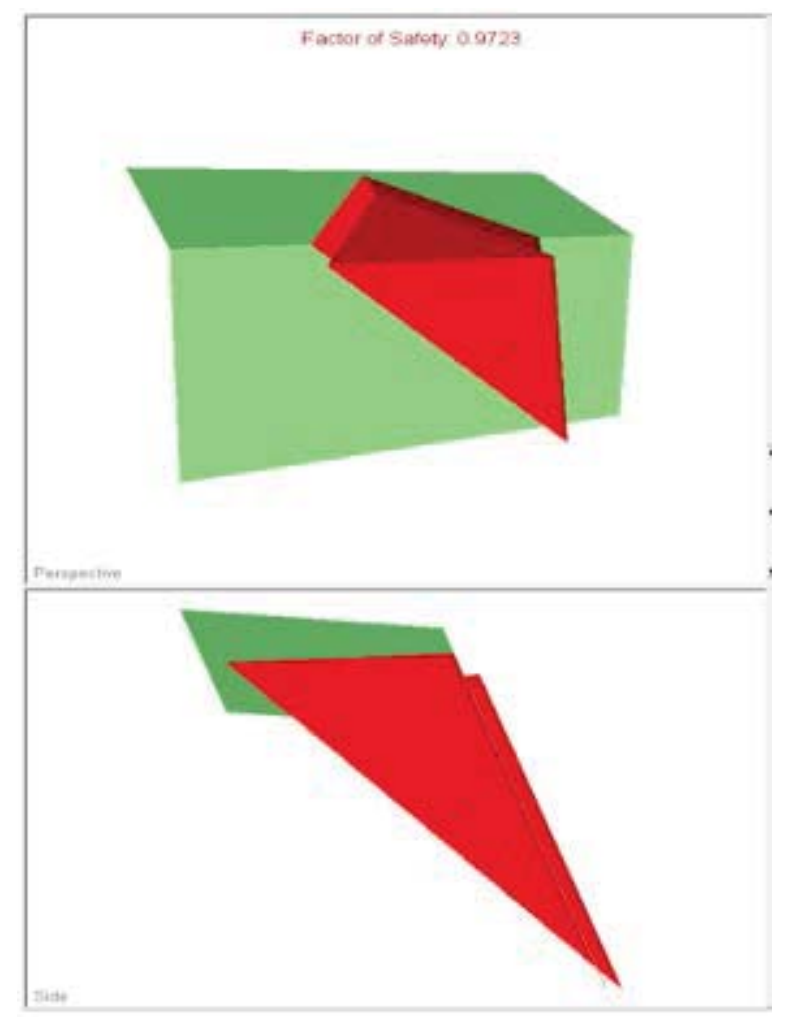

FIGURE 6-8: Wedge FAILURE FOR SLIDE 1 MODELED IN ROCSCIENCE SWEDGE. THE MOST UNFAVORABLY ORIENTED JOINT SETS WERE USED TO CREATE THIS MODEL. THE FACTOR OF SAFETY IS LESS THAN 1.0, SO THERE IS A SIGNIFICANT RISK OF WEDGE FAILURE.

The final step of the methodology is at the discretion of the transportation agency responsible for the corridor. If the factors of safety for each of the modeled failure types are estimated to be near or less than 1.0, it is the maintaining agency's decision whether to implement mitigation measures or to continue monitoring the slope to determine if failure might occur. Mitigation measures can be taken, including adding supports as proposed by the SMR calculations. Or the agencies can choose to continue monitoring the slide without adding supports, and reevaluate the hazard risk annually. 


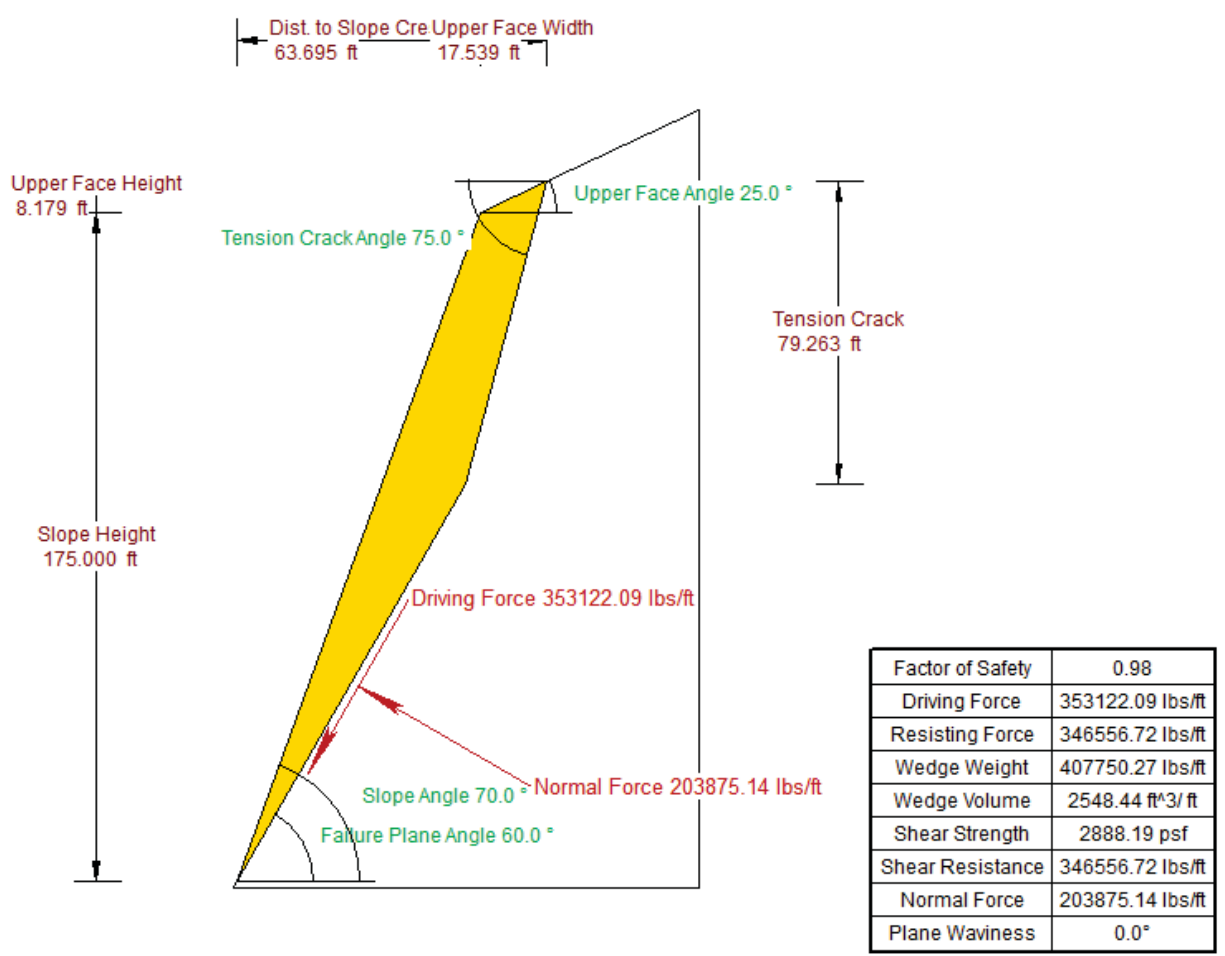

FiguRE 6-9: PLANAR FAILURE MOdELED FOR SLIDE 1, USING ROCSCIENCE ROCPLANE. THE MOST UNFAVORABLY ORIENTED JOINT SETS WERE USED TO CREATE THIS MODEL. THE FACTOR OF SAFETY IS LESS THAN 1.0, SO THERE IS A SIGNIFICANT RISK OF PLANAR FAILURE.

\subsection{Slide 2 Analysis}

The initial conditions for Slide 2 are the same as for Slide 1 as discussed in Section 6.1. Step 2 is the RHRS analysis, using the ortho-photo from Figure 4-3. Table 6-3 shows the scores for each category for the Slide 2 analysis.

Much of the criteria have a similar rational to that of Slide 1 . The berm effectiveness was determined from historical knowledge of each site. The catchment berm at Slide 2 is known to be very effective, catching most if not all falling rock blocks. There is no evidence of rocks reaching the access road at this location. 
The geological conditions of the slope indicate that Geologic Case 1 is most applicable case. The quality of the photographs gives a good visual estimate the structural condition and properties of the discontinuities of the slope. The resolution of the photographs is on the 1 meter scale, which allows for small discontinuities and minor structures to be identified, and for the condition of the structures to be assessed.

TABLE 6-3: RHRS SCORE SHEET FOR SLIDE 2 USING THE 1 METER ORTHO-PHOTOS. GEOLOGIC CASE 1 WAS USED, SO GEOLOGIC CASE 2 IS IGNORED. THE THREE CLIMATE VARIABLES ARE AVERAGED TOGETHER FOR THE CLIMATE SCORE. EACH CATEGORY SCORE IS COMBINED TO GET THE TOTAL SCORE.

Slide 2

Rockfall Hazard Rating Score

\begin{tabular}{|c|c|c|c|}
\hline Category & Value & Score & Remarks \\
\hline Slope Height [ft] & 110 & 100 & $\begin{array}{l}\text { Slope peak is around } 110 \text { feet, manual says to take } \\
\text { the highest height from which rocks can fall. }\end{array}$ \\
\hline Ditch Eff ectiveness & Good & 3 & $\begin{array}{l}\text { During the main landslide, many rocks made it past } \\
\text { the ditch, but normally, most rocks are caught }\end{array}$ \\
\hline Average Vehicle Risk & 55 & 10 & $\begin{array}{l}\text { speed }=30 \mathrm{mph} \text {, rate }=\sim 12 \text { trains a day, slope length } \\
=300 \mathrm{ft}\end{array}$ \\
\hline Site Distance [ft] & 180 & - & Measured on the Ortho-photo \\
\hline Percent Decision Site Distance & 40 & 81 & $\begin{array}{l}\text { decision sight distance }=450 \mathrm{ft} \text { (Table } 5.1 \\
\text { implementation manual) }\end{array}$ \\
\hline Roadway width & 25 & 41 & Measured on the Ortho-photo \\
\hline
\end{tabular}

\begin{tabular}{|c|c|c|c|}
\hline \multicolumn{4}{|l|}{ Geologic Case 1: } \\
\hline Stuctural Condition & $\begin{array}{l}\text { Continuous } \\
\text { joints, adverse } \\
\text { orientation }\end{array}$ & 81 & $\begin{array}{l}\text { Focusing on adverse joint sets, continuous means } \\
\text { greater than } 10 \mathrm{ft} \text { in length (all joint set are at least } \\
\text { this long) }\end{array}$ \\
\hline Rock Friction & $\begin{array}{l}\text { Mostly planar } \\
\text { and smooth }\end{array}$ & 20 & $\begin{array}{l}\text { Condition of the joint roughness, both macro and } \\
\text { micro. } M \text { ajority of joints are smooth and planar } \\
\text { (there is some minor undulation in some joints). }\end{array}$ \\
\hline
\end{tabular}

\begin{tabular}{|llll|}
\hline Geo logic Case 2: & & & \\
Differential Erosion Features & - & 0 & Not Applicable \\
Difference in Erosion Rates & - & 0 & Not Applicable \\
\hline
\end{tabular}

Rockfall Event: Choose One

\begin{tabular}{|lcccl}
$\begin{array}{l}\text { Rockfa ll Event: } \\
\text { Block Size [ft] }\end{array}$ & 1 & 3 & $\begin{array}{l}\text { Measure on optical photogramm etry point cloud } \\
\text { (average rock block size) }\end{array}$ \\
Block Volume [yd^3] & 3 & 3 & $\begin{array}{l}\text { Measure on optical p hotogramm etry point cloud } \\
\text { (average rock block volume) }\end{array}$ \\
\hline
\end{tabular}

\begin{tabular}{|c|c|c|c|}
\hline Climate Conditions: & & & NOAA an nual data \\
\hline Precip itation & Moderate & 7 & $\begin{array}{l}\text { Average annual precipitation = } 10 \text { inches, average } \\
\text { annual snowfall }=8 \text { inches }\end{array}$ \\
\hline Freezing Period & Short & 3 & Freezing possible from December to $\mathrm{M}$ arch \\
\hline Water on Slope & Damp & 10 & Interm ittent Water on Slope \\
\hline Average Climate & & 7 & Average all climate scores \\
\hline Rockfall History & Few Falls & 3 & $\begin{array}{l}\text { There is the occasional small rock fall, but there is no } \\
\text { history of any major landslide events }\end{array}$ \\
\hline & Total Score $=$ & 349 & \\
\hline
\end{tabular}

The climate conditions are from NOAA annual data, while the rockfall history was provided by the transportation agency. The slope was evaluated with "intermittent water on slope," even though there are extended periods of time with 
little to no rainfall because of the possibility of water being trapped in the joints of the rock mass long after a rainfall event is possible again in the winter and spring time of the year.

The final score for Slide 2 is 349 . This is on the low side of the score range, being much closer to 300 than 500. This means that a catastrophic failure is probably not imminent, but failure is still a possibility. Also, this is still above the 300 point threshold, so a detailed analysis should still be performed.

This value can be validated with field measurement taken during the 2014 data collection. Field engineers should collect field measurements for verification purposes while the remote sensing is being implemented.

The point clouds generated from LiDAR and optical photogrammetry were combined for structural analysis (Figure 6-10). Two fault structures and three joint structures were observed.

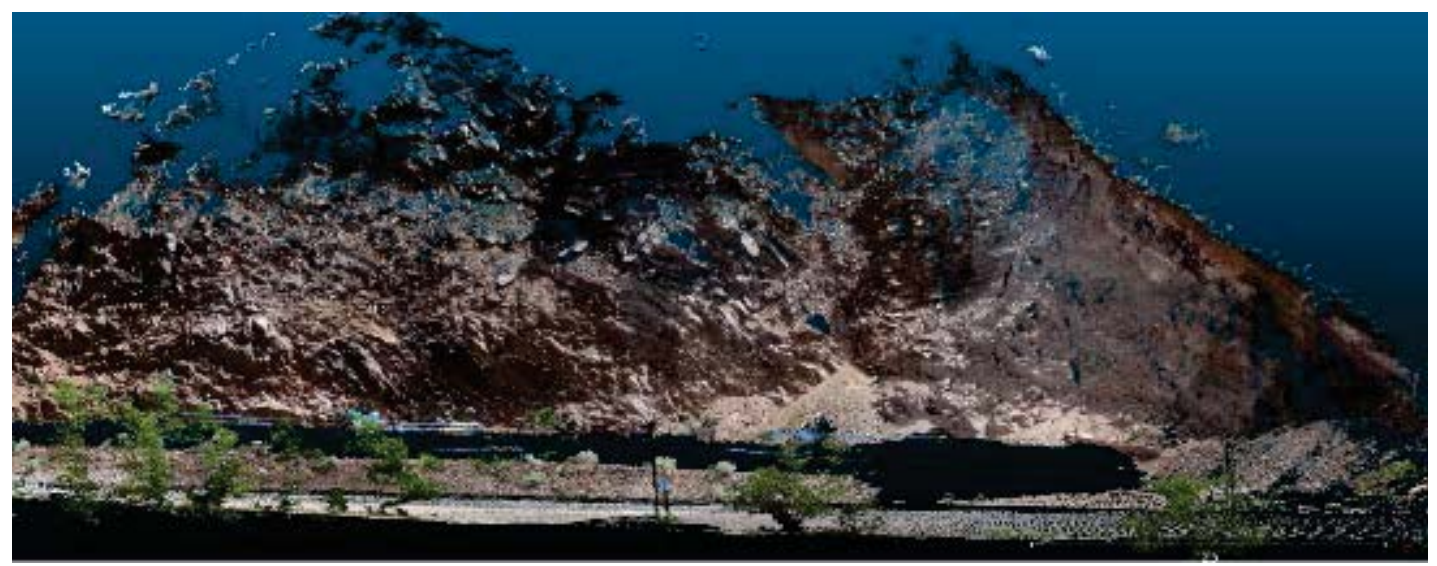

FIGURE 6-10: LIDAR POINT CLOUD GENERATED FOR SLIDE 2. THE ROCK STRUCTURES CAN BE EXTRACTED FROM THIS AND USED FOR ANALYSIS. THE HOLE AT THE TOE OF THE SLOPE IS DUE TO SLOPE ANGLE CHANGES THAT THE LIDAR SCANNER COULD NOT CAPTURE. THIS AREA IS NOT SIGNIFICANT TO THE OVERALL STRUCTURE OF THE SLOPE.

Step 3 is the detailed analysis is assessing the SMR classification, which is provided in Table 6-4. According to the methodology flowchart, this step uses remote sensing to determine the major structures of the rock mass and input them into the Slope Mass Rating equation. Because only Joint Set 1 was unfavorably oriented, it is the only classification that influences the stability of the slope in this 
TABLE 6-4: TABULATION OF THE GSI, RMR, AND SMR VALUES, AS WELL AS THE SMR CLASS FOR SLIDE 2 STRUCTURES. ONLY THE STRUCTURES HIGHLIGHTED IN YELLOW ARE INCLUDED IN THE DETERMINATION OF THE SMR CLASS FOR THE ENTIRE SLOPE.

\begin{tabular}{c|ccccccc} 
& Dip Direction & Dip & GSI & RMR & SMR & SMR Class & SMR Description \\
\hline Slope Face & 246 & 70 & & & & & \\
Fault 1 & 20 & 30 & 64 & 69 & 57 & III & Normal \\
Fault 2 & 20 & 25 & 70 & 75 & 63 & II & Good \\
Set 1 & 0 & 90 & 61 & 66 & 64 & II & Good \\
Set 2 & 90 & 90 & 59 & 64 & 62 & II & Good \\
Set 3 & 136 & 81 & 63 & 68 & 66 & II & Good
\end{tabular}

unfavorably oriented

analysis, and it is considered "Good," which means that the slope is relatively stable.

In Slide 2 it also appears that adequate pre-split method to protect the final highwall was not effective applied. However, there is minimal indication that blasting created significant backbreak and therefore the blasting was considered "normal” blasting, which carries an adjustment value of zero.

The analysis is complete at this point, since there is no need to conduct an analysis for individual failure modes. The slope is considered stable, and will likely remain that way unless triggered event such as an earthquake occurs. The analysis can be completed at this point, and it is up to the maintaining agency to implement support measures if they decide it is necessary to meet their safety standards. This hazard analysis should be repeated on an annual basis to ensure there is no change in risk to the transportation infrastructure.

\subsection{Slide 3 Analysis}

Slide 3 was not investigated during the 2014 field visit, and all analysis has been performed through publicly available remote sensing images and data. There is no site specific remote sensing or field data available. Following the methodology, with step 1 being determined in Section 6.1, the RHRS was determined using the ortho-photo in Figure 4-3. Table 6-5 shows the scores for each category for the Slide 3 analysis.

Much of the criteria have a similar rational to that of Slides 1 and 2. The berm effectiveness was determined from historical knowledge of each site. The 
berm at Slide 3 is known to be very effective, catching most if not all falling rock blocks. There is no evidence of rocks reaching the access road at this location.

The geological conditions of the slope again indicate that Geologic Case 1 is the most applicable case. The quality of the photographs gives a visual estimate the structural condition and properties of the discontinuities of the slope. Only major

TABLE 6-5: RHRS SCORE SHEET FOR SLIDE 3 USING THE 1 METER ORTHO-

PHOTOS. GEOLOGIC CASE 1 WAS USED, SO GEOLOGIC CASE 2 IS IGNORED. THE THREE CLIMATE VARIABLES ARE AVERAGED TOGETHER FOR THE CLIMATE SCORE. EACH CATEGORY SCORE IS COMBINED TO GET THE TOTAL SCORE.

Slide 3

Rockfall Hazard Rating Score

\begin{tabular}{|c|c|c|c|}
\hline Category & Value & Score & Remarks \\
\hline Slope Height [ft] & 120 & 100 & $\begin{array}{l}\text { Slope peak is at least } 120 \text { feet, manual says to take } \\
\text { the highest height from which rocks can fall. }\end{array}$ \\
\hline Ditch Effectiveness & Moderate & 9 & $\begin{array}{l}\text { During the main landslide, many rocks made it past } \\
\text { the ditch, but normally, most rocks are caught }\end{array}$ \\
\hline Average Vehicle Risk & 55 & 10 & $\begin{array}{l}\text { speed }=30 \mathrm{mph} \text {, rate }=\sim 12 \text { trains a day, slope length } \\
=300 \mathrm{ft}\end{array}$ \\
\hline Site Distance [ft] & 350 & - & Measured on the Ortho-photo \\
\hline Percent Decision Site Distance & 78 & 10 & implementation manual) \\
\hline Roadway width & 25 & 41 & Measured on the Ortho-photo \\
\hline
\end{tabular}

\begin{tabular}{|c|c|c|c|}
\hline \multicolumn{4}{|l|}{ Geologic Case 1: } \\
\hline Stuctural Condition & $\begin{array}{l}\text { Continuous } \\
\text { joints, adverse } \\
\text { orientation }\end{array}$ & 81 & $\begin{array}{l}\text { Focusing on adverse joint sets, continuous means } \\
\text { greater than } 10 \mathrm{ft} \text { in length (all joint set are at least } \\
\text { this long) }\end{array}$ \\
\hline Rock Friction & $\begin{array}{c}\text { Mostly planar } \\
\text { and smooth }\end{array}$ & 15 & $\begin{array}{l}\text { Condition of the joint roughness, both macro and } \\
\text { micro. Majority of joints are smooth and undulating } \\
\text { (some joints appear planar). }\end{array}$ \\
\hline
\end{tabular}

\begin{tabular}{|llll|}
\hline Geologic Case 2: & & & \\
Differential Erosion Features & - & 0 & Not Applicable \\
Difference in Erosion Rates & - & 0 & Not Applicable \\
\hline
\end{tabular}

\begin{tabular}{|lccc|}
\hline Rockfall Event: & \multicolumn{3}{c|}{ Choose One } \\
Block Size [ft] & 2 & 9 & Measure on ortho-photo (average rock block size) \\
Block Volume [yd^3] & 3 & 3 & Measure on ortho-photo (average rock block volume) \\
\hline
\end{tabular}

\begin{tabular}{|c|c|c|c|}
\hline Climate Conditions: & & & NOAA annual data \\
\hline Precipitation & Moderate & 7 & $\begin{array}{l}\text { Average annual precipitation = } 10 \text { inches, average } \\
\text { annual snowfall = } 8 \text { inches }\end{array}$ \\
\hline Freezing Period & Short & 3 & Freezing possible from December to March \\
\hline Water on Slope & Damp & 10 & Intermittent Water on Slope \\
\hline Average Climate & & 7 & Average all climate scores \\
\hline
\end{tabular}

\begin{tabular}{|lll|}
\hline Rockfall History $\quad$ Few Falls & 3 & $\begin{array}{l}\text { There is the occasional small rock fall, but there is no } \\
\text { history of any major landslide events }\end{array}$ \\
\hline
\end{tabular}


rock structures can be identified using the 1 meter resolution images, which is enough to assess the geological condition in terms of the RHRS criteria.

The climate conditions are from NOAA annual data, and the rockfall history was provided by the Nevada Department of Transportation (NDOT). The slope was evaluated with "intermittent water on slope," even though there are extended periods of time with little to no rainfall because of the possibility of water being trapped in the joints of the rock mass long after a rainfall event.

The final score for Slide 3 is 285. This is below the threshold value of 300, and the analysis can stop at this point. The slope is not considered a hazard for the transportation infrastructure. This indicates to the maintaining agency that the slope is not in danger of disrupting the transportation infrastructure, even in the unlikely event the slope were to fail. Annual monitoring should still take place to assess the risk in the future, at the discretion of the monitoring agencies.

\section{Discussion and future work}

\subsection{Summary}

The slope failure hazard rating has been determined for several locations along the transportation corridor. It has been determined using the method described in this study that the failure at Slide 1 has the greatest risk of impacting the railroad. Other sites in the high exposure risk areas were analyzed, and do not pose a significant threat to the transportation infrastructure. Table 7-1 compiles all the results from the case study analysis.

TABLE 7-1: FINAL RESULTS FOR ALL SLIDES ANALYZED. SLIDE 3 DID NOT UNDERGO A SMR CALCULATION, WHICH MEANS THAT THE SLOPE IS CONSIDERED STABLE.

\begin{tabular}{|c|cccc|}
\cline { 2 - 5 } \multicolumn{1}{c|}{} & Exposure Risk & RHRS & SMR & Stability \\
\hline Slide 1 & High & 461 & Bad & Partial \\
\hline Slide 2 & High & 349 & Good & Stable \\
\hline Slide 3 & High & 284 & N/A & Stable \\
\hline
\end{tabular}

Overall, Slide 1 is at best, only partially stable. Another large failure could occur at any time, in addition to the continuing small rockfall and block movements already witnessed at the site. Slide 2 was calculated to be a "good slope," which means that it is stable and unlikely to fail. Slide 3 is not in danger of disrupting the transportation infrastructure, even in the unlikely event the slope were to fail. 


\subsection{Assumptions and Limitations of the method}

The RHRS method is a relatively simple approach to creating hazard maps along a transportation corridor. There were a number of assumptions that were made, and that needed to be verified by manual field measurements. As the remote sensing technologies continue to improve, the basis for these assumptions will continue to be strengthened. For more accurate values, locations can be modeled with modified versions of the RHRS and SMR systems.

One assumption that was used was the lack of any external forces on the slope. The climate conditions were set at 'damp,' but that does not come into the analysis of the slope's safety factor. Indeed, there are a number of triggering possibilities that could cause failure, such as earthquakes. The failure models of Slide 1 indicate that the factor of safety is less than 1.0, so the slope is potentially unstable and could fail. Triggers could possibly cause failure for such slopes. Triggers can include high rainfall events, extended freeze/thaw periods, and earthquakes. These triggers are not part of the failure models or analysis, but agencies should be aware of the possibilities, and know the risks for such triggers to occur.

Another assumption that was used was due to the accuracy of the remote sensing technologies utilized. For example, no rock property information was known at depth. Historical geologic records were consulted, but no borings or insitu tests were performed. In many cases this assumption can be made due to the relatively consistent nature of areas geology, and historical knowledge of the site.

The risk exposure maps that have been created based on this data can be directly applicable to the agencies. The maps are meant to show areas where there is direct hazard to the transportation infrastructure, and areas that need monitoring or remediation. The models are a predictor of possible failure locations, but do not provide exact locations or failure modes.

This model is meant to be built upon, and there is much room for improvement, especially in the area of characterizing rock strength properties. While there is a good correlation between the GSI and RMR values for a rocky slope, it would be more accurate to calculate the RMR directly. This usually involves in-situ testing for strength and RQD. Finding a way to obtain these parameters through remote sensing would improve the final results for individual slopes. The deformation monitoring that was used in this case study should be 
researched in more detail. As of now, there is some concern about false negatives skewing the results, and possibility even missing slope movements entirely. While this was accepted for this report, the technique should be refined for more accurate results. Using other remote sensing techniques, such as InSAR might bring additional information to the model, including deformation and slope velocity modeling. As remote sensing technologies improve, this model should be updated to follow the trend.

\section{Conclusions and Recommendations}

A method was created that determines where the rockfall hazard risk is greatest along a transportation corridor using remote sensing techniques. This included publicly available data in the form of digital elevation models and ortho-photos, and site specific techniques. Through the use of the public remote sensing data, risk exposure maps can be created to narrow the focus from a large corridor to smaller areas of interest.

Site specific remote sensing techniques such as LiDAR and optical photogrammetry allow for very detailed analysis of rocky slopes for stability and failure. Through these techniques, several common strength characterization methods were utilized. The methods chosen were visual based, in order to be used with the remote sensing data. The GSI and RMR characterized the strength of the rock slope, and the SMR characterized the stability of the rock slope. The SMR also provided possible failure modes based on the calculated stability of the slope. Highly accurate slope profiles, determined from the site specific remote sensing data, can be used for failure modeling. The factor of safety for the slopes is one of the most understood values for stability for non-engineers.

This workflow can be immediately implemented by transportation agencies. It can be integrated into existing management programs, and used by current field engineers.

For the corridor analyzed in this study, the corridor is considered stable, with the worst potential for rockfalls located at the Slide 1 test site. 


\section{References}

1. Pierson, L. A., \& Van Vickle, R. (1992). Rockfall hazard rating system. Transportation Research Record, 6-6.

2. Hoek, E. (2000). Practical rock engineering.

3. Pantelidis, L. (2009). Rock slope stability assessment through rock mass classification systems. International Journal of Rock Mechanics and Mining Sciences, 46(2), 315-325.

4. Pierson, L. A., \& Van Vickle, R. (1993). Rockfall hazard rating system participant's manual. Federal Highway Administration, Publication No. FHWA SA-93-057.

5. Lato, M. (2010). Geotechnical applications of LiDAR pertaining to geomechanical evaluation and hazard identification.

6. Hervás, J., Barredo, J. I., Rosin, P. L., Pasuto, A., Mantovani, F., \& Silvano, S. (2003). Monitoring landslides from optical remotely sensed imagery: the case history of Tessina landslide, Italy. Geomorphology, 54(1), 63-75.

7. Heckmann, T., Bimböse, M., Krautblatter, M., Haas, F., Becht, M., \& Morche, D. (2012). From geotechnical analysis to quantification and modelling using LiDAR data: a study on rockfall in the Reintal catchment, Bavarian Alps, Germany. Earth Surface Processes and Landforms, 37(1), 119-133.

8. Hu, H., Fernandez-Steeger, T. M., Dong, M., Nguyen, H. T., \& Azzam, R. (2010, June). 3D modeling using LiDAR data and its geological and geotechnical applications. In Geoinformatics, 2010 18th International Conference on (pp. 1-6). IEEE.

9. Sustainable Geotechnical Asset Management. (2014, March 7). Retrieved March 30, 2015, from http://mtri.org/geoasset

10. Vessely, M. 2013, Geotechnical Asset Management Implementation Concepts and Strategies. Report FHWA-CFL/TD-13-003. US Department of Transportation, Federal Highway Administration, Western Federal Lands Highway Division. 73 pp.

11. Bernhardt, K., Loehr, J., \& Huaco, D. (2003). Asset Management for Geotechnical Infrastructure. Journal of Infrastructure Systems, 107-116.

12. Basu, D., Misra, A., \& Puppala, A. J. (2014). Sustainability and geotechnical engineering: perspectives and review. Canadian Geotechnical Journal, 52(1), 96-113.

13. Mian, J.F.; Whittlestone, A.P.; Patterson, D.; Rudrum, D.M.: 'A risk-based approach for the assessment and management of infrastructure assets', IET Conference Proceedings, 2011, p. 14-14

14. Dai, F. C., Lee, C. F., \& Ngai, Y. Y. (2002). Landslide risk assessment and management: an overview. Engineering geology, 64(1), 65-87. 
15. Santi, P. M., Russell, C. P., Higgins, J. D., \& Spriet, J. I. (2009).

Modification and statistical analysis of the Colorado rockfall hazard rating system. Engineering Geology, 104(1), 55-65.

16. Budetta, P., \& Nappi, M. (2013). Comparison between qualitative rockfall risk rating systems for a road affected by high traffic intensity. Natural Hazards and Earth System Science, 13(6), 1643-1653.

17. Guzzetti, F., Reichenbach, P., \& Ghigi, S. (2004). Rockfall hazard and risk assessment along a transportation corridor in the Nera Valley, Central Italy.Environmental Management, 34(2), 191-208.

18. Salvini, R \& Franciono, M. (2013). Geomatics for slope stability and rock fall runout analysis: A case study along the Alta Tambura road in the Apuan Alps (Tuscany, Italy). Italian Journal of Engineering Geology and Environment, 481-492.

19. Baillifard, F., Jaboyedoff, M., \& Sartori, M. (2003). Rockfall hazard mapping along a mountainous road in Switzerland using a GIS-based parameter rating approach. Natural Hazards and Earth System Science, 3(5), 435-442.

20. Aksoy, C. O. (2008). Review of rock mass rating classification: Historical developments, applications, and restrictions. Journal of Mining Science, 44(1), 51-63.

21. Sarkar, S., Kanungo, D. P., \& Kumar, S. (2012). Rock Mass Classification and Slope Stability Assessment of Road Cut Slopes in Garhwal Himalaya, India. Geotechnical and Geological Engineering, 30(4), 827-840.

22. Sonmez, H., \& Ulusay, R. (2002). A discussion on the Hoek-Brown failure criterion and suggested modifications to the criterion verified by slope stability case studies. Yerbilimleri, 26, 77-99.

23. Sonmez, H., \& Ulusay, R. (1999). Modifications to the geological strength index (GSI) and their applicability to stability of slopes. International Journal of Rock Mechanics and Mining Sciences, 36(6), 743-760.

24. Singh, B., \& Goel, R. (1999). Rock mass classification a practical approach in civil engineering (Vol. 46, p. 138). Amsterdam: Elsevier.

25. Fahimdanesh, S., \& Moghadas, N. (2014). Geomechanical Characteristics of the Rock Mass of Giladeh Mine. Research Journal of Environmental and Earth Sciences, 6(10), 475-481.

26. Francioni, M., Salvini, R., Stead, D., \& Litrico, S. (2014). A case study integrating remote sensing and distinct element analysis to quarry slope stability assessment in the Monte Altissimo area, Italy. Engineering Geology, 183, 290-302.

27. Ramamurthy, T. (2004). A geo-engineering classification for rocks and rock masses. International Journal of Rock Mechanics and Mining Sciences, 41(1), 89-101. 
28. Tzamos, S., \& Sofianos, A. I. (2007). A correlation of four rock mass classification systems through their fabric indices. International Journal of Rock Mechanics and Mining Sciences, 44(4), 477-495.

29. Romana, M. (1993). A geomechanical classification for slopes: slope mass rating. Comprehensive rock engineering, 3, 575-599.

30. Romana, M., Serón, J. B., \& Montalar, E. (2003, January). SMR geomechanics classification: application, experience and validation. In Proceedings of the 10th Congress of the International Society for Rock Mechanics, ISRM (pp. 1-4).

31. Irigaray, C., Fernández, T., \& Chacón, J. (2003). Preliminary rock-slopesusceptibility assessment using GIS and the SMR classification. Natural Hazards, 30(3), 309-324.

32. Yilmaz, I., Marschalko, M., Yildirim, M., Dereli, E., \& Bednarik, M. (2012). GIS-based kinematic slope instability and slope mass rating (SMR) maps: application to a railway route in Sivas (Turkey). Bulletin of Engineering Geology and the Environment, 71(2), 351-357.

33. Tomás, R., Delgado, J., \& Serón, J. B. (2007). Modification of slope mass rating (SMR) by continuous functions. International Journal of Rock Mechanics and Mining Sciences, 44(7), 1062-1069.

34. Tomas, R., Cuenca, A., Cano, M., \& García-Barba, J. (2012). A graphical approach for slope mass rating (SMR). Engineering Geology, 124, 67-76.

35. Lato, M., Kemeny, J., Harrap, R. M., \& Bevan, G. (2013). Rock bench: Establishing a common repository and standards for assessing rockmass characteristics using LiDAR and photogrammetry. Computers \& Geosciences, 50, 106-114.

36. Maerz, N. H., Otoo, J., Kassebaum, T., \& Boyko, K. (2012, May). Using LIDAR in highway rock cuts. In Proceedings of the 63rd annual highway geology symposium, Redding, CA (pp. 7-10).

37. McHugh, E., \& Girard, J. (2002, August). Evaluating techniques for monitoring rock falls and slope stability. In Proceedings 21st International Conference on Ground Control in Mining, Syd S. Peng, Christopher Mark, A. Wahab Khair, and Keith Heasley, eds, Morgantown, West Virginia (pp. 335-343).

38. Salvini, R., Francioni, M., Riccucci, S., Bonciani, F., \& Callegari, I. (2013). Photogrammetry and laser scanning for analyzing slope stability and rock fall runout along the Domodossola-Iselle railway, the Italian Alps. Geomorphology,185, 110-122.

39. Franklin, J. A., Maerz, N. H., \& Bennett, C. P. (1988). Rock mass characterization using photoanalysis. International Journal of Mining and Geological Engineering, 6(2), 97-112. 
40. Lato, M., Hutchinson, J., Diederichs, M., Ball, D., \& Harrap, R. (2009). Engineering monitoring of rockfall hazards along transportation corridors: using mobile terrestrial LiDAR. Nat. Hazards Earth Syst. Sci, 9(3), 935-946.

41. Haneberg, W. C. (2008). Using close range terrestrial digital photogrammetry

for 3-D rock slope modeling and discontinuity mapping in the United States. Bulletin of Engineering Geology and the Environment, 67(4), 457-469.

42. Burton, D., Dunlap, D. B., Wood, L. J., \& Flaig, P. P. (2011). Lidar intensity as a remote sensor of rock properties. Journal of Sedimentary Research, 81(5), 339-347.

43. Wu, L., Cui, C., Geng, N., \& Wang, J. (2000). Remote sensing rock mechanics (RSRM) and associated experimental studies. International Journal of Rock Mechanics and Mining Sciences, 37(6), 879-888.

44. Otoo, J. N., Maerz, N. H., Xiaoling, L., \& Duan, Y. (2011, June). 3-D discontinuity orientations using combined optical imaging and LiDAR techniques. In Proceedings of the 45th US rock mechanics symposium, Chicago.

45. Prudencio, M., \& Jan, M. V. S. (2007). Strength and failure modes of rock mass models with non-persistent joints. International Journal of Rock Mechanics and Mining Sciences, 44(6), 890-902.

46. Sturzenegger, M., \& Stead, D. (2009). Quantifying discontinuity orientation and persistence on high mountain rock slopes and large landslides using terrestrial remote sensing techniques. Natural Hazards and Earth System Science, 9(2), 267-287.

47. Kemeny, J. (2008). Ground-based lidar: rock slope mapping and assessment. Central Federal Lands Highway Division.

48. Otoo, J. N., Maerz, N. H., Duan, Y., \& Xiaoling, L. (2011). LiDAR and optical imaging for 3-D fracture orientations. In 2011 NSF Engineering Research and Innovation Conference, Atlanta, Georgia.

49. Nex, F. C., \& Rinaudo, F. (2011). LiDAR or Photogrammetry? Integration is the answer. Rivista Italiana Di Telerilevamento, 43(2), 107-121.

50. Haneberg, W. C., Norrish, N. I., \& Findley, D. P. (2006, September). Digital outcrop characterization for 3-D structural mapping and rock slope design along interstate 90 near Snoqualmie Pass, Washington. In Proceedings, 57th annual highway geology symposium, Breckenridge, Colorado (pp. 27-29).

51. Shannon \& Wilson, Inc. (2011). Draft Rock Slide Report MP 471.25, Caliente Subdivision Caliente, Nevada. Seattle, WA. Hultman, W.A.

52. Merkler, D. (2000). Soil Survey of Lincoln Country, Nevada, South (Vol. 1). Nevada: U.S. Department of Agriculture.

53. Sweetkind, D., Cederberg, J., Masbruch, M., \& Buto, S. (2011). Hydrogeologic Framework. In V. Heilweil \& L. Brooks (Eds.), Conceptual 
model of the great basin carbonate and alluvial aquifer system: USGS scientific... Reston, Virginia: U.S. Geological Survey.

54. Southern Nevada Water Authority. (2008). Conceptual Geologic Model. In Geology of White Pine and Lincoln Counties and Adjacent Areas (Vol. 1). Bureau of Land Management.

55. U.S. Geological Survey. Geologic Map of Lincoln County, Nevada [map]. 1:250,000. 2 degree quadrangle series. Nevada: USGS, 1963.

56. Bonnaffe, F., Jennette, D., \& Andrews, J. (2007). A method for acquiring and processing ground-based lidar data in difficult-to-access outcrops for use in three-dimensional, virtual-reality models. Geosphere, 3(6), 501-510.

57. Oppikofer, T., Jaboyedoff, M., Blikra, L., Derron, M. H., \& Metzger, R. (2009). Characterization and monitoring of the Åknes rockslide using terrestrial laser scanning. Natural Hazards and Earth System Science, 9(3), 1003-1019.

58. Lahren, M., Trexler Jr, J., \& Spinosa, C. (Eds.). (1993). Crustal Evolution of the Great Basin and the Sierra Nevada. Reno, Nevada: Department of Geological Sciences, Mackay School of Mines.

59. Giani, G. P. (1992). Rock slope stability analysis. CRC Press.

60. Hsü, K. J. (1975). Catastrophic debris streams (sturzstroms) generated by rockfalls. Geological Society of America Bulletin, 86(1), 129-140.

61. Hunter, G., \& Fell, R. (2003). Travel distance angle for" rapid" landslides in constructed and natural soil slopes. Canadian Geotechnical Journal, 40(6), 1123-1141.

62. Nicoletti, P. G., \& Sorriso-Valvo, M. (1991). Geomorphic controls of the shape and mobility of rock avalanches. Geological Society of America Bulletin, 103(10), 1365-1373.

63. Singh, R., \& Ahmad, M. (2011). Stability analysis of cut slopes using continuous slope mass rating and kinematic analysis in Rudraprayag district, Uttarakhand. Geomaterials, 2011.

64. Di Lucio, E., Fasani, G. B., \& Bretschneider, A. (2013). Potential rockfalls and analysis of slope dynamics in the Palatine archaeological area (Rome, Italy).Geologica Acta, 11(2), 245-264.

65. Tost, M., Cronin, S. J., \& Procter, J. N. (2014). Transport and emplacement mechanisms of channelised long-runout debris avalanches, Ruapehu volcano, New Zealand. Bulletin of Volcanology, 76(12), 1-14. 


\section{Appendix A: Permissions}

Below are copies of permissions to use figures from journals and a Ph.D. dissertation. These permissions apply to:

Table 2-2

Table 2-3

Table 2-4

Table 3-2

Figure 2-3

Figure 2-4

Figure 2-5

All other figures are fair-use government images, or original to the author of this report, so no permissions are required. 


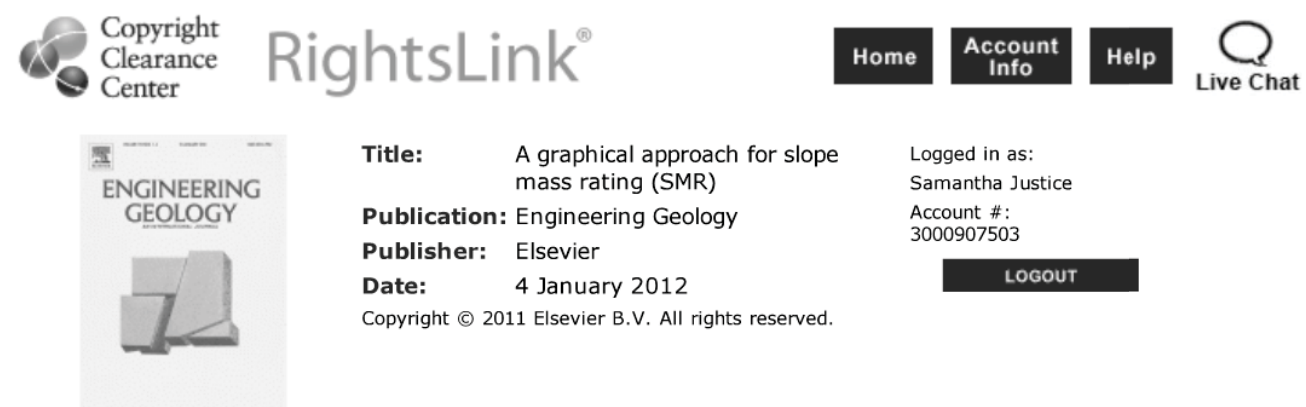

\section{Order Completed}

Thank you very much for your order.

This is a License Agreement between Samantha Justice ("You") and Elsevier ("Elsevier"). The license consists of your order details, the terms and conditions provided by Elsevier, and the payment terms and conditions.

Get the printable license.

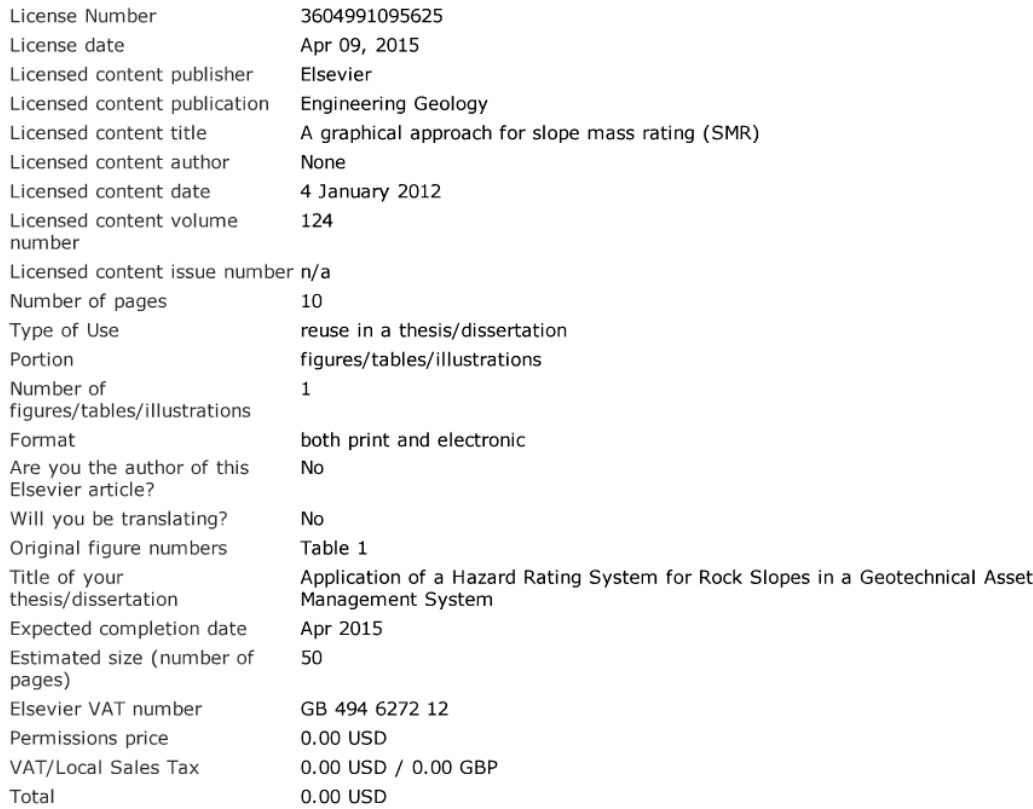

ORDER MORE... CLOSE WINDOW

Copyright (c) 2015 Copyright Clearance Center, Inc. All Rights Reserved. Privacy statement. Terms and Conditions. Comments? We would like to hear from you. E-mail us at customercare@copyright.com

Figure A-1: Permission to Reproduce table SeEn in TABLe 2-3. 
4/9/2015

Rightslink® by Copyright Clearance Center
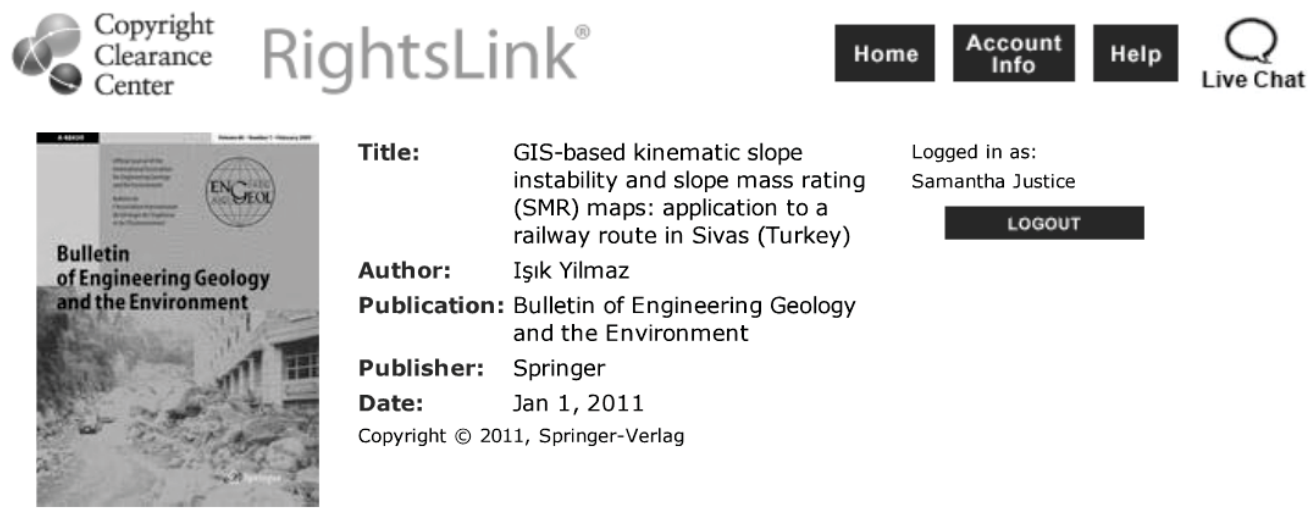

Title:

GIS-based kinematic slope

Logged in as:

instability and slope mass rating Samantha Justice

(SMR) maps: application to a

Samantha Justice

railway route in Sivas (Turkey)

LOGOUT

Author: Işık Yilmaz

Publication: Bulletin of Engineering Geology

and the Environment

Publisher: Springer

Date: Jan 1, 2011

Copyright (๑) 2011, Springer-Verlag

\section{Order Completed}

Thank you very much for your order.

This is a License Agreement between Samantha Justice ("You") and Springer ("Springer"). The license consists of your order details, the terms and conditions provided by Springer, and the payment terms and conditions.

\section{Get the printable license.}

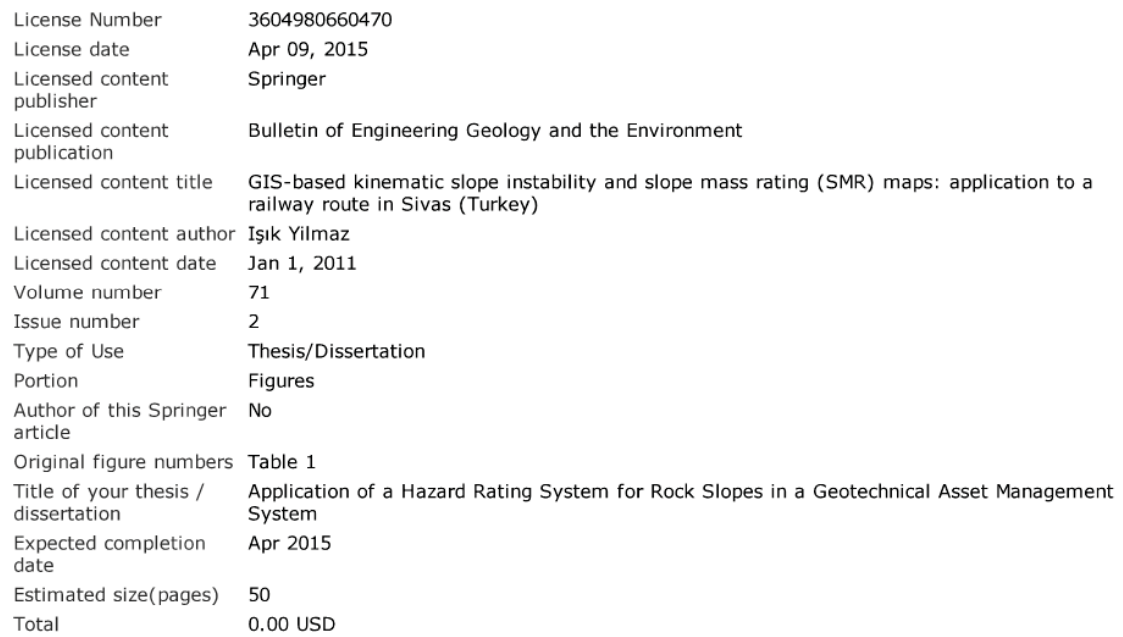

Copyright (c) 2015 Copyright Clearance Center, Inc. All Rights Reserved. Privacy statement. Terms and Conditions. Comments? We would like to hear from you. E-mail us at customercare@copyright.com

Figure A-2: Permission to ReProduce tABLE SEen IN TABLE 3-2. 


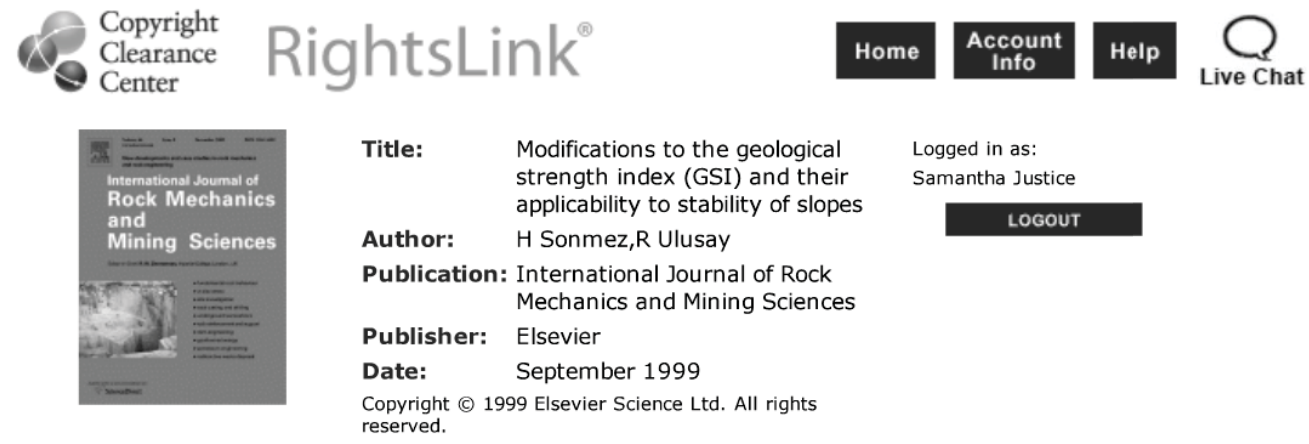

\section{Order Completed}

Thank you very much for your order.

This is a License Agreement between Samantha Justice ("You") and Elsevier ("Elsevier"). The license consists of your order details, the terms and conditions provided by Elsevier, and the payment terms and conditions.

\section{Get the printable license.}

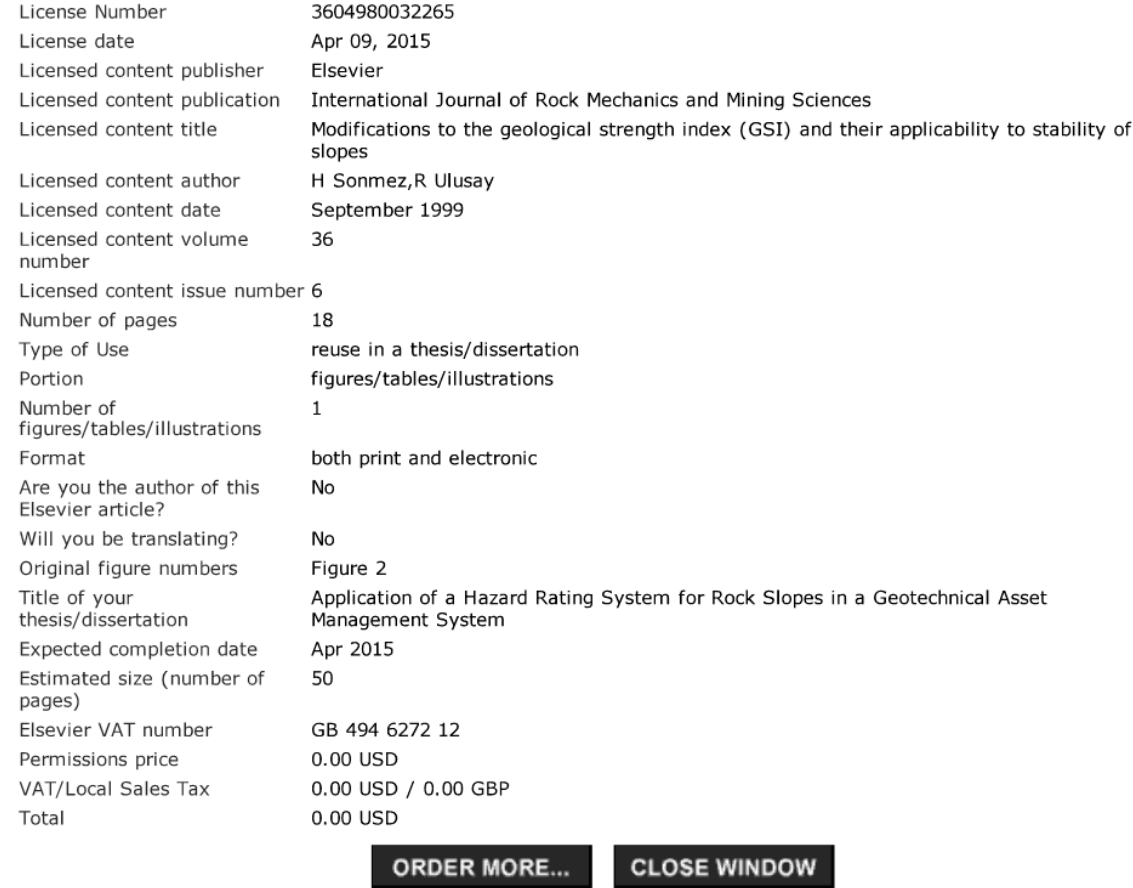

https://s100.copyright.com/AppDispatchServlet

Figure A-3: Permission to Reproduce table Seen in Figure 2-4. 
4/11/2015 Rightslink@ by Copyright Clearance Center

$4 / !$

86 Copyright

Center

RightsLink

Home

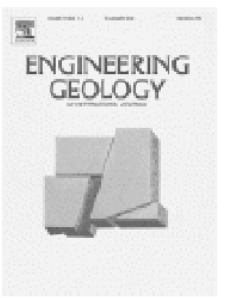

Title:

Lands lide risk assessment and

Logged in as:

Author: management: an overview

Samantha Justice

Aublican: Engineering Ceology

Account \#:

Publication: Engineering Geology

Publisher: Elsevier

3000907503

Date: April 2002

Copyright 62002 Elsevier Sclence B,V, All rights

reserved.

\section{Order Completed}

Thank you very much for your order.

This is a License Agreement between Samantha Justice ("You") and E|sevier ("E|sevier"), The license consists of your order details, the terms and conditions provided by Elsevier, and the pavment terms and conditions.

\section{Get the arintable license.}

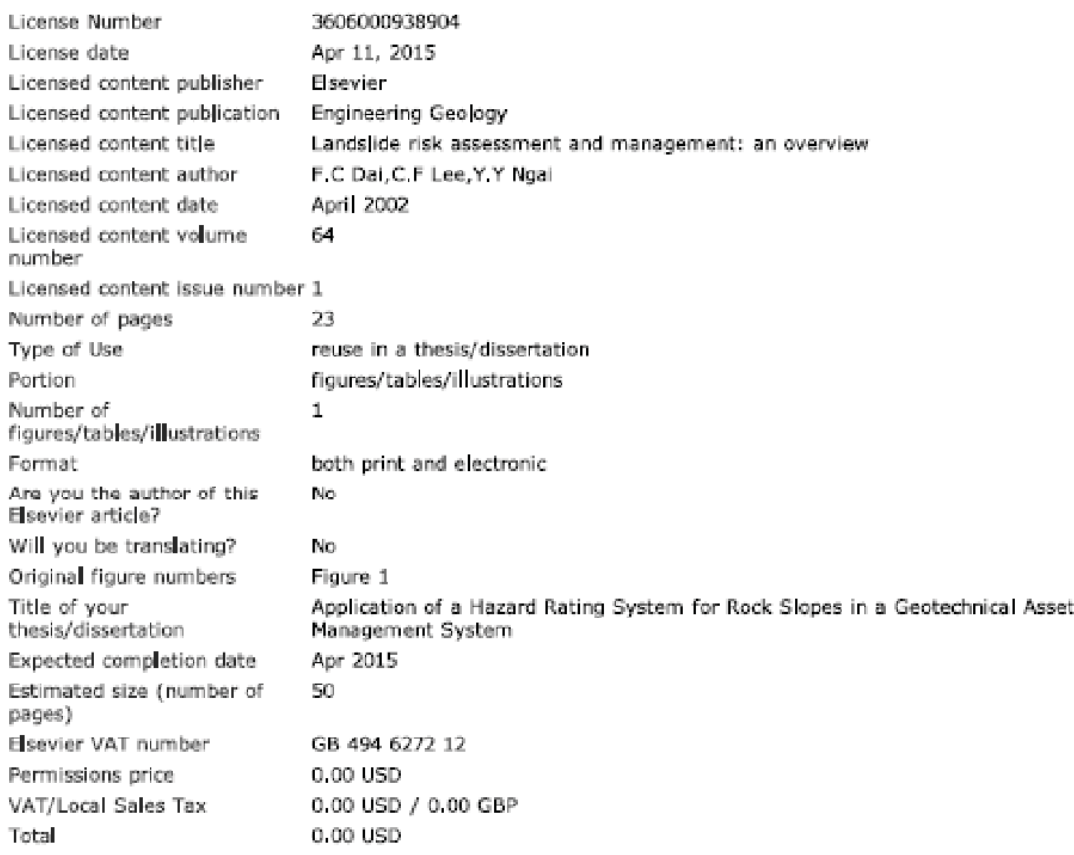

ORDER MORE.

CLOSE WINDOW

Copyright 02015 Convriaht Clearance Center. Inc. All Rights Reserved. Privacy statement. Terms and Conditions. Comments? We would like to hear from you, E-mail us at customercarecocoovirightcom

Figure A-4: Permission to Reproduce image SEen in Figure 2-2. 


\section{Permission to use figures \\ 4 messages}

Samantha Justice <smjustices@gmail.com>

To: mjlato@rocksense.ca

Thu, Apr 9, 2015 at 4:43 PM

Hello Mr. Lato,

I am a master's student at Michigan Technological University, in Houghton, Michigan. I am currently working on my thesis about incorporating LiDAR and Optical Photogrammetry technologies in the use of rock fall hazard assessment along transportation corridors. I came across your disseration "Geotechnical applications of LiDAR pertaining to geomechanical evaluation and hazard identification." during my literature review. I am hoping to use two of your figures in my thesis. The figures are:

Table 7-1

Figu re 11-1

If you could please give me permission to use these figures, it would be a great help. If you feel that you cannot, I understand and I will not use them. Please let me know. Thank you,

Samantha Justice

Master's Student

Michigan Technological University

Houghton, MI, USA

Matthew Lato<mjlato@rocksense.ca>

Thu, Apr 9, 2015 at 4:47 PM

To: Samantha Justice <smjustices@gmail.com>

Hi Samantha,

Please feel free to use Table 7-1, as for Figure 11-1, I only had 8 chapters in my thesis, can you send me a screen grab of the figure or tell me what page it is on

Thanks,

Matt

[Quoted text hidden]

Samantha Justice <smjustices@gmail.com>

Thu, Apr 9, 2015 at 5:27 PM

To: Matthew Lato<mjlato@rocksense.ca>

Matt,

Sure thing. It was my mistake, a transcribing error. The figures are:

Figu re 1-11

Table 7-1

https://mail.google.com $/ \mathrm{mail} / \mathrm{u} / 0 /$ ?ui $=2 \& \mathrm{ik}=6 \mathrm{cb}$ acc87f7\&view=pt\&search=inbox \&th=14c9fec1 $197960 \mathrm{f} 2 \& \operatorname{siml}=14 \mathrm{c} 9 \mathrm{fec} 1197960 \mathrm{f} 2 \& \operatorname{siml}=14 \mathrm{c} 9 \mathrm{feffb}$ aes $9091 \& \operatorname{siml}=$.

Figure A-5: EMAILS With AUTHOR OF THE PH. D DISSERTATION (2) GIVING PERMISSION TO REPRODUCES IMAGES SEEN IN FIGURE 2-3 AND TABLE 2-2. 
Geotechnical Applications of LiDAR Pertaining to Hazard Evaluation

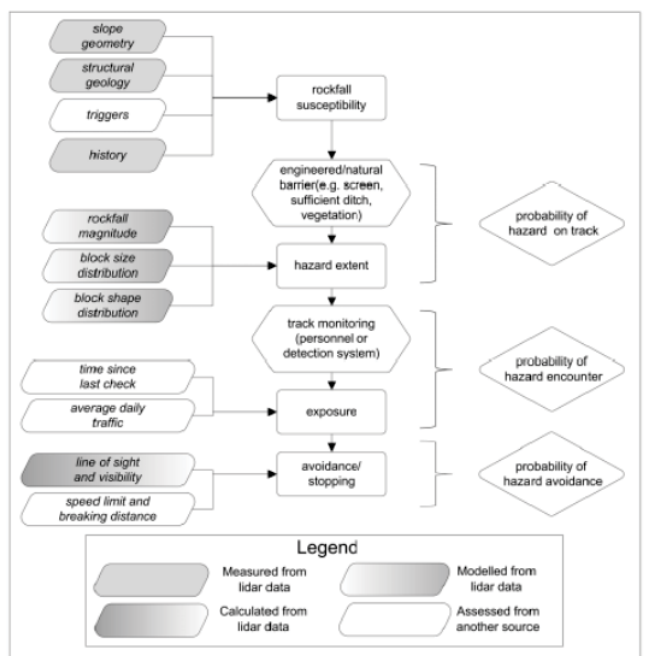

Figure 1-11: A rockfoll baind evaluntion franework with input values to be measured, evalunted, or modelled from optimally collected LiDAR data.

The use of LDAR data for hazard evaluation is strongly contingent on data management

protocols, processing workflows, and standardized feature extraction techniques. Unlike measurements

made in the field, all measurements taken from the LiDAR data remain part of the data structure and can

be reviewed at a later date. The volume of data collected, in concert with processing and storage

requirements of LDAR data, greatly increases the need for efficient and well-managed and organized

methodology and data protocols. This thesis demonstrates the application of LiDAR data - mobile and

Thanks again for letting me use them.

Samantha Justice

[Quoted text hidden]

Matthew Lato <mjlato@rocksense.ca>

Thu, Apr 9, 2015 at 5:32 PM

To: Samantha Justice <smjustices@gmail.com>

Sure -no problem at all!

Matt Lato, Ph.D, P.Eng (ON, BC)

Senior Engineer

BGC Engineering Inc.

M: +1.613.808.2145

E: mLato@bgcengineering.ca

Sent from a mobile device

FiguRe A-6: EMAILS WITH AUTHOR OF THE PH. D DISSERTATION (2) GIVING PERMISSION TO REPRODUCES IMAGES SEEN IN FIGURE 2-3 AND TABLE 2-2. 